Portland State University

PDXScholar

Winter 4-17-2017

\title{
The Force of Manhood: the Consequences of Masculinity Threat on Police Officer Use of Force
}

Aurelia Terese Alston

Portland State University

Follow this and additional works at: https://pdxscholar.library.pdx.edu/open_access_etds

Part of the Law and Race Commons, and the Psychology Commons

Let us know how access to this document benefits you.

\section{Recommended Citation}

Alston, Aurelia Terese, "The Force of Manhood: the Consequences of Masculinity Threat on Police Officer Use of Force" (2017). Dissertations and Theses. Paper 3532.

https://doi.org/10.15760/etd.5416

This Thesis is brought to you for free and open access. It has been accepted for inclusion in Dissertations and Theses by an authorized administrator of PDXScholar. Please contact us if we can make this document more accessible: pdxscholar@pdx.edu. 
The Force of Manhood:

The Consequences of Masculinity Threat on Police Officer Use of Force

by

Aurelia Terese Alston

A thesis submitted in partial fulfillment of the requirements for the degree of

\author{
Master of Science \\ in \\ Psychology
}

Thesis Committee:

Kimberly Barsamian Kahn, Chair

Eric Mankowski

Joel Steele

Portland State University

2017 


\begin{abstract}
Positive community-police relations, which are based on mutual trust, are key to equitable and just policing. Use of force that is perceived as unfair and biased can quickly undermine relations between the police and the public. In an attempt to understand what psychological factors contribute to police use of force decisions and potentially racially biased use of force application, this study proposed masculinity threat as an important psychological factor that influences police behavior. Masculinity threat occurs when a man's status as a man is threatened, and threats to masculinity are often associated with increased aggression and dominance as a way of restoring the threatened status. Policing is a male-dominated field, and because most victims of officer use of force are men, the current research examines how threats to male police officers' masculinity, including verbal and physical manifestations of threat, contribute to officer force against civilians. Past research has explored how high levels of trait masculinity threat (as measured by the Male Gender Role Stress scale; Goff, Martin, \& GamsonSmiedt, 2012) in police officers is associated with higher levels of force against racial minority suspects, however, no such research has examined state level masculinity threat (e.g., in the moment threats) as they occur in real world police-suspect interactions. Focusing on understanding the associations between use of force and state level masculinity threat, it was predicted that officers who have their masculinity explicitly and publicly threatened by male suspects will use more force against suspects compared to
\end{abstract}


interactions where no such masculinity threat has occurred. It was also predicted that minority suspects who threaten officers' masculinity will receive more force than White suspects. To test these hypotheses, reporting officers' (RO) narratives of use of force interactions (excluding lethal force) from a large police department on the West Coast were coded and analyzed. Contrary to the hypotheses, results suggest that masculinity threat within an officer-suspect interaction may relate to lower levels of average officer force and higher number of sequences (e.g., back and forth exchanges) between suspect and officer. While results are in the opposite direction of the hypotheses, they provide new information regarding the association between personal threats to officer manhood and their subsequent actions. Specifically, results suggest that masculinity threat has a more complicated relationship with force than previously predicted and future research would do well to investigate a potential interaction effect of trait level and state level masculinity on police use of force decisions. Several other areas of further research are outlined, such as the need to examine other suspect-level and officer-level variables such as age and tenure. Overall, the results of this study suggest the need for continued clarifying research. 


\section{Acknowledgements}

Thank you to my thesis committee for their support of this project and their ongoing efforts to teach me novel ways to approach research questions. I would also like to sincerely thank my family, friends and peers for their continued support. In particular, I would like to thank my husband, Sean, without whom my graduate studies at Portland State would not have been possible. 
Table of Contents

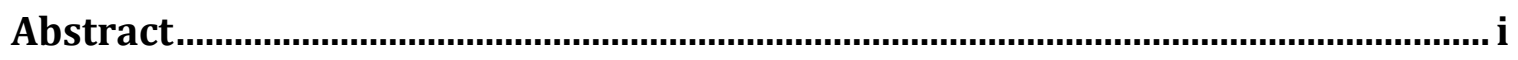

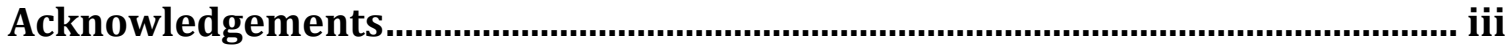

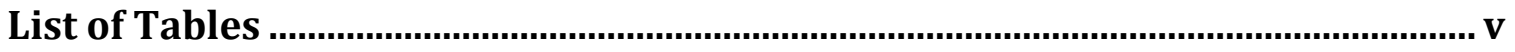

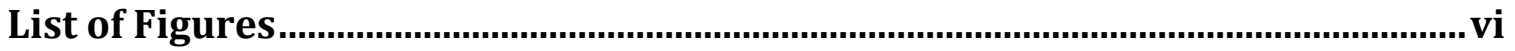

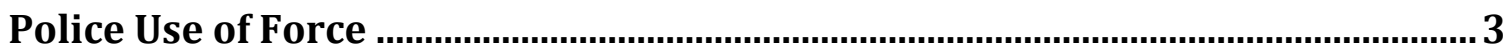

Disparities in Police Use of Force ................................................................................. 5

Race, Masculinity and Policing

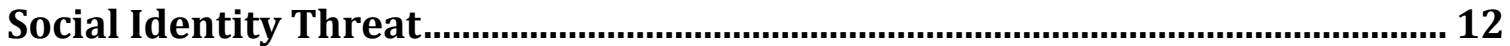

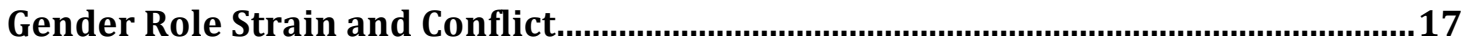

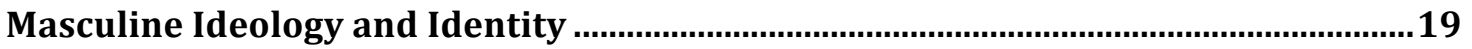

Masculinity Threat ....................................................................................................... 21

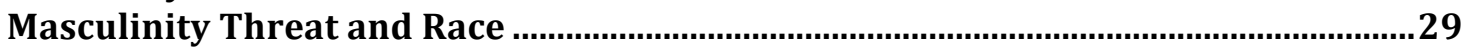

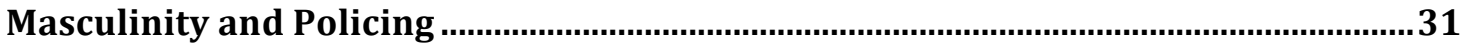

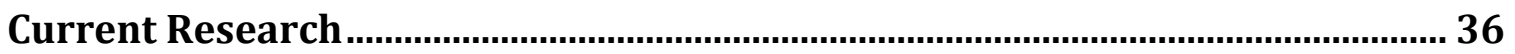

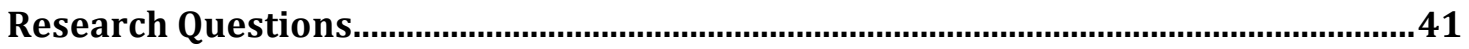

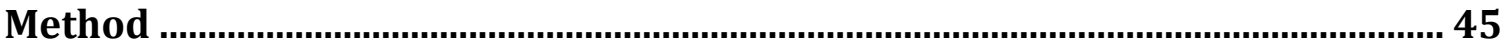

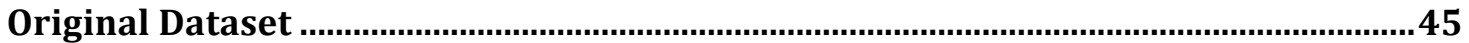

Measures from original use of force coding …......................................................................

Final measures for current project

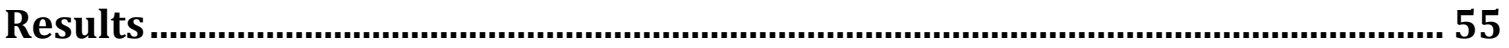

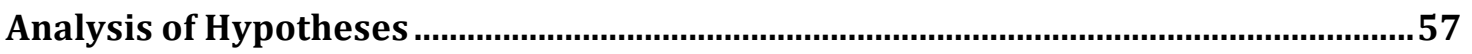

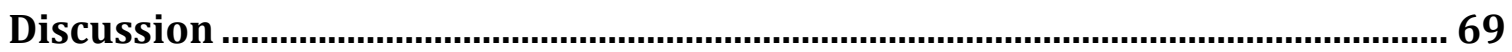

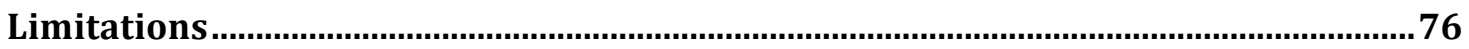

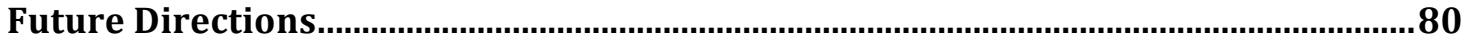

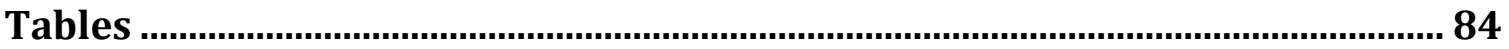

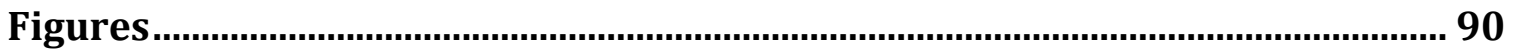

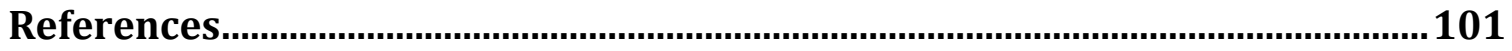

Appendix A: Use of force coding sheet - masculinity threat .............................122

Appendix B: Original use of force coding sheet .................................................. 123 


\section{List of Tables}

Table 1: Masculinity threat codebook........................................... 84

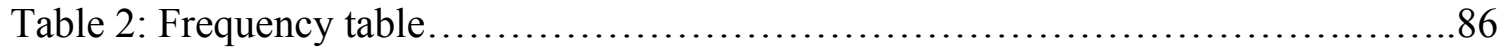

Table 3: Means, Standard Deviations, and Correlations among Variables of interest.....87

Table 4: Marginal means and standard errors for interaction outcome measures..........88 


\section{List of Figures}

Figure 1: Mean difference for First Officer Force $\ldots \ldots \ldots \ldots \ldots \ldots \ldots \ldots \ldots \ldots \ldots \ldots \ldots . .90$

Figure 2: Mean difference for Average Officer Force.............................91

Figure 3: Mean difference for Maximum Officer Force..............................92

Figure 4: Mean difference for Last Instance of Officer Force..........................93

Figure 5: Mean difference in Number of Sequences in narrative........................94

Figure 6: Mean difference in Officer Force prior to threat compared to.................95

Figure 7: Mean difference for First Officer Force by Suspect Race....................96

Figure 8: Mean difference for Average Officer Force by Suspect Race....................97

Figure 9: Mean difference for Maximum Officer Force by Suspect Race................98

Figure 10: Mean difference for Last Officer Force by Suspect Race...................99

Figure 11: Mean difference in Number of Sequences by Suspect Race..................100 


\section{Introduction}

"I said, 'get back or I'm going to shoot you.' He [Brown] immediately grabs my gun and says, 'you are too much of a pussy to shoot me."'

- Ferguson, MO Police Officer Darren Wilson describing the moment preceding his fatal shooting of unarmed 18year-old Black youth, Michael Brown on August 9, 2014.

On August 9, 2014 at approximately 12:03pm, 18-year-old African-American male Michael Brown was fatally shot in his suburban hometown of Ferguson, Missouri. Officer Darren Wilson, the White male police officer who fatally shot Brown, came upon Brown and his friend when they were jaywalking on a suburban street near Brown's home. The above quote represents part of Wilson's testimony to the grand jury hearing regarding the fatal shooting. Wilson recalls Brown calling him a "pussy" just moments before he shot Brown six times (Buchanan, 2014; Robles \& Bosman, 2014). This description about the moments prior to Michael Brown's death sets forth an important question about whether masculinity threat could play a role in police-suspect interactions.

Following the fatal shooting, many Ferguson citizens, and particularly the racial minority community, protested their outrage over the loss of Brown and the general state of policing and race relations in Ferguson and across America (BBC, 2015). These protests brought national attention to the case and continued as grand jury indictment proceedings took place for Officer Darren Wilson. On November 24, 2014, after three months of meetings, the grand jury decided not to indict Officer Darren Wilson on criminal charges for the death of Brown (Reilly, 2014). 
As suggested by the above example, as well as empirical research studies discussed later in this paper, police officers' psychological experiences can relate to police decision making during police-suspect interactions. While past research has examined psychological factors such as individual differences in attitudes (e.g., social dominance orientation) and past experiences with outgroup members impacting use of force outcomes (e.g., Correll et al., 2007; Sidanius, Liu, Shaw \& Pratto, 1994), I propose that threats to male officers' manhood also may contribute to increased use of force. Past literature has demonstrated that threats to male gender identity can trigger a compensatory behavioral response in men, but not women, which includes increased aggression (Bosson \& Vandello, 2011; Buss \& Schmitt, 1993). To examine the impact of threat to officer masculinity on police use of force, I examined first-person narrative reports of police officers following a police use of force interaction. An existing sample of use of force narratives have been broken down into discrete sequences (or steps in the interaction) to study what unfolds during an interaction that leads to force. These discrete sequences represent one suspect action and the subsequent officer reaction. Breaking down the narratives into discrete sequences involved following an established coding procedure, which is detailed in the Method section of this paper. By breaking policesuspect interactions down into sequences and coding for masculinity threat, important information regarding the psychological processes associated with such threats and their impact on use of force was gleaned. In the following sections, I review the literature on police use of force and disparate use of force against racial minorities, as well as the social psychological process of social identity threat, from which masculinity threat has 
its basis. Based on these literatures, I developed several research questions that explored how the phenomenon of police officer use of force can be further understood by examining the psychological experience of masculinity threat during these interactions over time.

\section{Police Use of Force}

Police use of force is defined as the "amount of effort required by police to compel compliance by an unwilling subject" (IACP, 2012). The authorization for officers to use force in an interaction with a suspect is defined broadly as being "dependent upon the need to safeguard the public, to accomplish some purpose for which the government has a legitimate interest in (for instance apprehending an individual with a warrant) or in self-protection" (Stewart, 2013. p. 3). Generally speaking, officers are encouraged to use the minimum level of force that is appropriate to resolve a particular situation (National Institute of Justice, 2009). While police use of force is, overall, a rare occurrence, it is still an important phenomenon to understand because, in addition to having the potential to cause significant bodily harm and injury, it has consequences on citizen trust and safety which are detailed later. Nationally, approximately $1.4 \%$ of people in the United States who had contact with the police experience some level of use of force from police officers, and of those who did have force used against them, $74 \%$ felt that the force was excessive (Bureau of Justice, 2008). Since citizens experience police use of force at varying levels, it is important to understand the varying degrees of police use of force.

Police use of force actions fall on a continuum of severity, and different police 
departments have different levels within their continuums (Bulman, 2011). An example of a police use of force continuum includes: officer presence (no force is used, "officers' attitudes are professional and nonthreatening"), verbalization (force is not physical, "officers issue calm, nonthreatening commands"), empty-hand control (officers use bodily force to gain control of a situation, "officers use grabs, holds and joint lock...punches and kicks to restrain an individual), less-lethal methods (officers use less-lethal technologies to gain control of a situation, "Officers may use a baton or projectile...chemical sprays...conducted energy devices to immobilize an individual"), and lethal force (officers use lethal weapons to gain control of a situation, "officers use deadly weapons such as firearms to stop an individual's actions") (NIJ, 2009).

Examining police use of force as a continuum instead of solely as lethal versus non-lethal has been an important line of inquiry (Garner, Schade, Hepburn \& Buchanan, 1995). Nonlethal police use of force is a particularly important phenomenon to understand because it has different precursors and consequences than lethal force and it occurs more frequently (Terrill \& Paoline, 2013). For example, researching police use of force as a continuum led to a better understanding of how officer force is used in general during interactions with citizens (Garner et al., 1995). Past research has shown that in cases involving nonlethal officer force, the majority of use of force cases fall fairly low on the continuum (e.g., have more verbal officer force actions) and level of suspect resistance tends to remain constant during nonlethal interactions (Terrill, 2003). In addition to understanding how force falls on a continuum, research has shown that certain racial groups face higher levels of police use of force and more frequently, than 
other racial groups.

\section{Disparities in Police Use of Force}

Application of police use of force is not spread proportionately across racial groups. In the local context, the Portland Police Bureau reported that in 2014, 2\% of interactions between police and suspects resulted in force and of that, $50 \%$ of suspects were White males and 24\% were Black males, yet Black males only represent $3 \%$ of the population in Portland (Jones, 2015; US Census Bureau, 2015). A DOJ 2012 investigation of the Portland Police Bureau also concluded that in addition to force, data on pedestrian and traffic stops has revealed that "... [the police bureau] disproportionately stops African Americans. The data indicate that $12-24 \%$ of [the police bureau's] traffic and pedestrian stops are of African Americans. However, only $6.4 \%$ of the City's overall percentage is African American" (2012). This type of racial disparity in police relations extends beyond Portland and is paralleled in other metropolitan areas in the Unites States. A report on police use of force in Cincinnati found that police officers are more likely to utilize force in order to gain control of an interaction when the suspect is a racial minority compared to when a suspect is White (Klahm, Frank, \& Brown, 2011). A 2015 report from Philadelphia found that Black suspects were more likely than any other racial group to be fatally shot in error (e.g., officer misidentifies that a suspect is armed based on a non-weapon like a cell phone; Fachner \& Carter, 2015). This disparate use of force against groups of people is not only morally wrong, but it is also a civil rights violation that has sparked increased attention over the last 10 years. The Department of Justice (DOJ) investigated more than 15 
police departments in the United States for civil rights violations between the years 2008-2013 alone (Stewart, 2013).

These civil rights investigations garnered a great deal of attention for that fact that police-suspect interactions that end in lethal force often involve racial minorities. The highest rates of justifiable homicide by police are of young Black males and are approximately 4 times more likely than Whites to experience arrest-related death (Bureau of Justice, 2001; Bureau of Justice, 2011). Examples of young Black males fatally shot by police in the last 5 years that received major media attention yet only represent a small fraction of the total cases included: Oscar Grant (California), who was killed by a Bay Area Rapid Transit police officer while he was laying on the ground handcuffed, Eric Garner (New York) who was strangled to death while he was being restrained by three officers, and Tamir Rice (Ohio), a 12-year-old boy playing with a toy gun, who was shot on sight before police spoke with him. Racially disparate use of force application by officers interacting with suspects incites racial tensions in communities and reflects America's history of racial inequality. As the United State continues to fight inequity, our interest in attempting to reduce racial bias in policing is amplified.

In an attempt to understand what is contributing to these disparate outcomes, research has examined several factors including police training, and police officer attitudes and biases at the explicit and implicit level. The role that suspect race plays in interactions between police and suspects has been well documented in psychological research: racism, stereotyping, and prejudice - at both implicit and explicit levels of cognition - can lead minority citizens to be more likely to be stopped and questioned by 
police, and these cognitions can actually distort how police interpret suspect actions, objects on their person, and the perceived level of danger they present (Correll, Urland, \& Ito, 2006; Eberhardt, Goff, Purdie, \& Davies, 2004; Kahn \& Davies, 2010; Trawalter, Todd, Baird, \& Richeson, 2008). Racial stereotypes are most influential under ambiguous circumstances, making the vagueness with which officers are guided in making use of force decisions particularly concerning (Greenwald \& Banaji, 1995; Rudman, 2004). Indeed, specific definitions and guidelines for use of force vary between police departments in the United States (Discover Policing, n.d.; NIJ, 2015). Compounding the vagueness with which police are trained to engage in use of force is a lack of a standard national curriculum for police training (Discover Policing, n.d.). Police departments across the country use different methods and techniques when training their officers, leading to a lack of consistency in policing curriculum both within departments and across departments. This lack of consistency and clarity leaves a great deal of room for subjectivity in the way police officers decide to use force, and against whom, within a given suspect interaction. This subjectivity, in turn, lends itself to human biases in perception and decision-making that contribute to the disparate application, and level, of use of force by police officers (Goff \& Kahn, 2012; Peruche \& Plant, 2006). Ambiguity in police training and policy can greatly impact the ways police officers' implicit racial biases play out in use of force decisions involving minority suspects.

At the explicit level, individuals understand of the content of societal stereotypes about Black Americans, even if they do not endorse or agree with these racial 
stereotypes (Devine, 1989; Devine \& Elliot, 1995). Explicit attitudes reflect the conscious, purposefully articulated attitudes that people have that can be self-reported. Implicit attitudes, on the other hand, reflect the unconscious, automatic attitudes we carry that are not consciously known to us (Greenwald \& Banaji, 1995). Even when people explicitly reject stereotypes, their implicit reactions may demonstrate biased associations (Dovidio, Kawakami, \& Gaertner, 2002). For example, in videogame simulations of police interactions with suspects, participants were more likely to "shoot" Black targets with weapons than their White counterparts, and were more likely to mistake that Black targets had weapons when they actually had non-threatening items. These biased shooting decisions were not predicted by explicit attitudes, but rather reflect more automatic or implicit attitudes, and police officers also showed this bias (Correll et al., 2007).

Additionally, concepts that are linked to stereotypes of certain groups can actually bias attention towards members of those groups without conscious thought. Priming abstract concepts (e.g., basketball) that are linked to stereotypes about Black Americans (e.g., Black Americans as naturally athletic) increased attentional bias towards Black faces (Eberhardt et al., 2004). Participants who were primed with faces of stereotyped group members (e.g., Black men's faces) were faster to identify degraded objects that are stereotypically linked to the individual's group membership (e.g., guns; Eberhardt et al., 2004). These results help explain how this type of biased attention contributes to findings from the aforementioned Philadelphia police report that Black suspects are more likely than any other racial group to be shot in error when an officer mistakenly 
identifies an object on their person (Fachner \& Carter, 2015).

These types of biases, found in the lab and the field, that contribute to excessive and disparate police use of force against particular groups heave meaningful consequences that extend beyond the officers and suspects involved. Regardless of race, the vast majority of people who experienced use of force at the hands of police felt that the force they experienced was unnecessary (Bureau of Justice, 2001; Bureau of Justice, 2008). Patterns of excessive force that are found across many police departments impact larger police-citizen relations and perceptions of police legitimacy that in turn impact how effective police can be at keeping peace within communities.

Consequences of Disparate Police-Suspect Relationships

The consequences of disparate police-suspect relations extend beyond injuries and fatalities and into community-police relations. In order for police officers to be most successful in their jobs as keepers of the peace, they need support and reciprocation from the community members they serve (Amadi, 2014; Schaffer, 1980). Due to racially disparate use of force, stops, and profiling, racial minorities are particularly distrustful of police, especially following a use of force incident that is perceived to be racially biased (Tyler, 2006). This lack of trust significantly impedes officer success because it threatens police legitimacy. When perceptions of police legitimacy are low in a particular community, people are less likely to cooperate with officers or provide information that officers can utilize to reduce crime (Tyler \& Huo, 2002). When citizens feel heard and respected via fair process in an interaction with a police officer, procedural justice levels are high (Tyler \& Huo, 2002). Procedural justice is a well- 
documented way to improve community-police relations and is defined as the perception of fairness in processes and procedures that resolve disagreements (Lind, Tyler \& Huo, 1997). Examples of high levels of procedural justice in an officer-suspect interaction would involve officers asking suspects to explain their side of a story, officers explaining why certain procedures are being followed, and using clear and transparent language. Research has shown that when procedural justice perceptions are high, suspects who end up in custody are more likely to be satisfied with the outcome (Huq, Tyler \& Schulhofer, 2011; Lind et al., 1997; Sunshine \& Tyler, 2003). Furthermore, when procedural justice is high, an officer-suspect interaction is more likely to be less physically dangerous for all involved parties (Tyler \& Huo, 2002).

In addition to harming community-police relations, disparate force can further alienate ethnic minority groups that have a long history of being systematically discriminated against in the United States (Kahn \& Martin, 2016). Minority group members who suffer disparate force at the hands of police officers may also suffer undue bias throughout the rest of the criminal justice system (Kahn \& Martin, 2016). As the first step in the criminal justice system, the consequences of interactions with the police have been shown to extend well beyond the interaction itself. Racial minorities that are arrested may also suffer negative impacts to their health, their experience on the job market, when searching for housing, and when seeking social services due to the arrest record (Kahn \& Martin, 2016).

In order to minimize risks to citizens and officers alike, more equitable policing is key. To achieve more equitable policing through less disparate applications of force 
during officer-suspect interactions, all of the contributing factors need to be understood. This thesis sets out to contribute to the understanding of what influences this uneven application of force by providing insight into another psychological aspect that can influence officer-suspect interactions: masculinity threat.

Race, Masculinity and Policing

Racially disparate police-suspect interactions impact perceptions of police legitimacy, which in turn affect the public's attitudes towards, and relations with, police. These relations affect police officers' ability to carry out their jobs and keep communities safe. In order to add to the existing literature on the factors contributing to racially disparate police use of force, I intend to examine a social psychological factor associated with gender identity — that of masculinity threat--that can influence police behavior in officer-suspect interactions.

Policing is a male dominated field with a culture of hyper-masculinity. According to the Federal Bureau of Investigation (2013), 88\% of full-time law enforcement employees are men. Additionally, men over the age of 16 (as opposed to women) are more likely to be the recipients of use of force at the hands of police officers, and Black males in particular are also more likely to be lethally shot than any other demographic group which highlights the disproportionality associated with this phenomenon (BJS, 2001; ProPublica, 2014). Research has also examined how masculine identity impacts police training and use of force (Prokos \& Padavic, 2002). Using participant observation, researchers have found that police academy trainings taught trainees that masculinity is essential to successful policing and encouraged 
developing a brand of masculinity that " 1 ) excluded women students and exaggerated differences between them and men; and 2) denigrated women in general" (Prokos \& Padavic, 2002, p. 339).

Additionally, research has shown that men who experience threats (or questioning) of their masculine identity sometimes respond with compensatory responses that are antisocial and aggressive in nature (Vandello \& Bosson, 2013). While these compensatory responses have been studied as trait level predictors of the outcomes of police-suspect interactions (e.g., Goff, Jackson, \& Kahn, 2016; Richardson \& Goff, 2015) specific in-the-moment (e.g., sequence-to-sequence; step-by-step) threats to officer masculinity have not been analyzed for their association with officer use of force during an interaction with a suspect, which this thesis will do by examining the temporal nature of masculinity threat in sequenced officer-suspect interactions.

The unofficial curriculum of masculinity in police trainings and the prevalence of contentious male officer and suspect interactions guide the focus of this thesis. I propose examining the relation between social identity threat, specifically masculinity threat, and police officers' use of force decisions in police suspect interactions with minority suspects. In the following sections, I review the literature on social identity threat, gender role strain/conflict, masculine ideology, masculinity threat and the role that race and masculinity play in policing. These literatures are discussed in order to provide a full background of why, and how, specific psychological threats to officer masculinity can relate to use of force decisions during interactions with suspects. 
Social identity theory states that the social identities (e.g., woman, Christian, etc.) that people consider important and integral aspects of themselves help individuals maintain positive levels of self esteem for both themselves and their group (Tajfel \& Turner, 1986). Social identity threat occurs when people experience situations during which their group identity is at risk of being devalued (Major \& O'Brien, 2005; Steele, Spencer \& Aronson, 2002). Social identity threat, ironically, increases the likelihood of enacting behavior that ends up reaffirming the negative perceptions that are ascribed to the in-group (Steele, Spencer \& Aronson, 2002; Walton \& Cohen, 2007). For example, stereotype threat, a form of social identity threat, refers to situations wherein an individual worries they will be judged based on a specific, situationally relevant stereotype about their in-group (Spencer, Steele, \& Quinn, 1999; Steele et al., 2002). Research on stereotype threat has shown that when a White man is 1) aware of the negative stereotype that White men are not naturally athletic and 2) made aware of the salience of their race, White men are more likely to feel at risk of being devalued in a test of natural athletic ability (e.g., a golf task) and are therefore more likely to confirm the negative stereotype by performing poorly while playing golf (Stone, Lynch, Sjomeling, \& Darley, 1999). People who identify with an in-group are aware of negative perceptions about that group, and are therefore sensitive to these situationally based threats. In turn, in-group members can experience defensive reactions to these perceptions (de Hoog, 2012).

Furthermore, the effects of social identity threat are greater when an individual has higher levels of identification with that group. For example, women who have higher 
levels of gender identification (e.g., identify strongly with womanhood) perform worse on tests of math ability under stereotype threat than their equally threatened, loweridentifying counterparts (Schmader, 2002). Likewise, Black students who experience stereotype threat underperform in academic settings and underperformance increases as racial group identification increases (Purdie-Vaughns, Steele, Davies, \& Ditlmann, 2008; Steele et al., 2002).

Social identity threat can also impact Black Americans' behavior in policesuspect interactions. Since there is a negative stereotype about Black Americans as criminals (Devine, 1989; Devine \& Elliot, 1995), Black American suspects who are interacting with police may fear confirming the negative stereotype about their group. Knowledge of the cultural stereotype in combination with feeling targeted based on this stereotype may contribute to behaviors that police may consider "suspicious" like nervousness and evasion. In turn, police officers are looking for these very signs (e.g., nervousness and evasion) as demonstrations of guilt and may misunderstand that Black American suspects are experiencing social identity threat as opposed to demonstrating some level of criminal guilt (Kahn, McMahon, \& Stewart, 2016; Najdowski, 2011). More specifically, Black men report fearing that police officers will rely on stereotypes of Blacks as criminals when interacting with them (Najdowski, Bottoms, \& Goff, 2015). This fear in turn lead Black men to feel stereotype threat and anticipate that they would exhibit odd or nervous behaviors like avoiding eye contact and freezing up (Najdowski et al., 2015). Further, racial minorities who report higher levels of stereotype threat during police interactions are more likely to distrust police and avoid interacting with them in 
the future (Kahn, Lee, Renauer, Henning \& Stewart, 2016) which contributes to tense police-citizen relations.

In addition to the way Black Americans may experience stereotype threat and its implication for police-suspect interactions, men in general are particularly susceptible to a similar type of social identity threat termed masculinity threat. Masculinity threat is an important consideration for police-suspect interactions since the majority of police are male, male suspects are more likely to experience force than female suspects, and because policing is categorized as a masculine domain (BJS, 2008; Prokos \& Padavic, 2002). Self-identified men are susceptible to this type of identity threat because manhood is considered to be tenuous, ever in question, and never fully proven (Kimmel, 2012; Vandello \& Bosson, 2013). When a man's masculinity is called into question, men may enact compensatory responses in order to defend their identities. To provide context for the importance of examining masculinity threat in police-suspect interactions, a review of gender and role theory literature is necessary before providing an in-depth summary of social psychology's empirical examination of masculinity threat.

Gender as a Social Construct

Gender is a social role identity that is salient in our social interactions (Luhtanen \& Crocker, 1992). According to the American Psychological Association, gender is considered to reflect "attitudes, feelings, and behaviors that a given culture associates with a person's biological sex" (2011). This definition reflects a standard approach to gender and its connection to biological sex, one based on the two sex categories that are most normalized in western society -- female (woman) and male (man). 
Gender must also be considered through the lens of the situation and social arrangement because gender "is the activity of managing situated conduct in light of normative conceptions of attitudes and activities appropriate for one's sex category. Gender activities emerge from and bolster claims to membership in a sex category" (West \& Zimmerman, 1987). Gender itself cannot be summed up as a mere set of traits masculine versus feminine- rather, gender is the product of social interaction, and the social desirability of demonstrating idealized versions of feminine and masculine (Goffman, 1976). This idea of gender being the result of social interaction encompasses the idea of gender performativity, or "doing" gender. Gender performance (e.g., the way we dress, talk, engage in social interactions) is the way we demonstrate to the outside world our identity as a sexed being (Butler, 1988). The ways we perform gender and interact with others who also perform gender impact our attitudes about who we are, who other people are, and our behavior (Butler, 1999). Theorists posit that different constructions we have for each gender performance and expression (i.e., females as emotional and passionate and males as rational and stoic) are directly linked to various inequities that take place in the social world (Hare-Mustin \& Marecek, 1988; Keller, 1995). For example, stereotypes that men are higher in assertiveness, self-esteem, visualspatial ability, and mathematical abilities, and women are higher in verbal ability, extroversion, nurturance, and trust may contribute to the roles that each respective group takes on (Deaux \& Major, 1987; Feingold, 1994, Maccoby \& Jacklin, 1974).

However, research indicates that these large, widespread trait differences are actually small in effect size (Hyde \& Plant, 1995; Shibley \& Denison, 1981). And while 
sexism, both benevolent and hostile, still exists within society and across nations, there has been dialogue around what it means for women to hold such gender norm restrictions (Glick et al., 2000; Sibley \& Wilson, 2004). Such conversations, however, about restrictions of the male role were far less frequent for many decades. In the 1970's, an interest in studying the psychology - the correlates and consequences - of the male gender role emerged. At that point in time, clinicians and researchers alike took up the pursuit, realizing that a key aspect of righting social inequity hinged on unpacking how men are also restricted and impacted by their gender role (O’Neil, Helm, Gable, David, \& Wrightsman, 1986). While there is a great deal of important research on the way gender is taught, learned, and developed through childhood and adolescence (see Steensma, Kreukels, de Vries \& Cohen-Kettenis, 2013; Thorne, 2013), the present study and the research literature referenced in this paper focuses on adult men, who self-identify as such, and their gender identity in our social world.

Gender Role Strain and Conflict

In order to understand how threat to masculine identity impacts police-suspect interactions, it is important to consider how theories of gender role strain and conflict contributed to the psychological understanding of the male gender role and associated norms. Theories of gender role strain and gender role conflict reflect psychology's effort to understand how men are restricted and held back from self-actualization due to socialized gender roles. Gender role strain reflects the experience of stress that occurs as men move through the social world as gendered beings who must adhere to norms (Pleck, 1995). This paradigm consists of three types of gender role strain: discrepancy strain 
(stereotypes of proper gendered roles exist and people differentially conform to them), trauma strain (traumatic experiences occur when boys are being socialized as gendered beings), and dysfunction strain (which occurs when conforming to gender role stereotypes and norms that have negative consequences on the actor). These three subtypes of strain are impacted to varying degrees by the endorsement of masculinity ideology, or "beliefs about the importance of men adhering to culturally defined standards for male behavior... operationalized by measures of attitudes toward the male gender role" (Pleck, 1993).

Building off of this idea of gender role strain, particularly dysfunction strain, is the theory of gender role conflict. Gender role conflict is a psychological experience that occurs when adherence to gender role norms cause "restriction, devaluation, or violation of others or self' (O’Neil, 2008). Gender role conflict has been assessed using the Gender Role Conflict Scale (GRCS) over the past 30 years, which factor analyses indicate has four factors: 1) success, power, competition issues, 2) restrictive and affectionate behavior between men, 3) restrictive emotionality, and 4) conflicts between work and family relations (Good et al., 1995; O’Neil et al., 1986). Of the 37 items and four factors, the GRCS assesses a man's intrapersonal and interpersonal gender role conflict and "an equal mix of items relating to men's thoughts, feelings and behaviors that result in negative psychological outcomes" (O’Neil, 2008, p.369).

Taken together, the theories of gender role strain and gender role conflict reflect an important transition in men and masculinity studies over the past 50 years. Some theories have focused on masculine identity as a correlate and precursor to dysfunctional 
behaviors, while others have focused on what it means for men to compensate for a threat to their masculinity. The following sections intend to outline and describe the role that both identity and situation have in explaining men's restriction, devaluation, and violation of others or self.

Masculine Ideology and Identity

Masculine identity reflects a spectrum of the socially constructed roles and regulations for manhood that men internalize throughout their upbringing (Pleck, Sonenstein \& Ku, 1994). Research has shown that men who hold traditional attitudes about masculinity are more likely to engage in various psychologically and physically destructive behaviors, including not using condoms, rape myth endorsement, not engaging in intimacy with sexual partners, little concern with a sexual partner's desire for condom use, and impregnating a sexual partner as proof of masculinity (Bunting \& Reeves, 1983; Pleck et al., 1994). Men who endorse these traditional gender roles also believe that relationships between men and women, in general, are characterized as “adversarial" (Pleck et al., 1994). This endorsement of traditional gender roles by men also contributes to using violence to enforce gender role adherence against men. Studies have found that gender role enforcement contributes to physical aggression towards gay men (Vincent, Parrott \& Peterson, 2011; Parrott, 2009). Indeed, violence (and threats of violence) contributes to the ways gender is policed, especially by men since physical aggression is a part of the traditional identity of manhood (Cohn \& Ziechner, 2006). These findings indicate that endorsement of traditional masculinity is therefore not only 
destructive to the men who hold the views, but to the women and non-role-conforming men with whom they engage.

Researchers have theorized that this endorsement of traditional masculinity is also what contributes to American men dying almost ten years earlier, on average, than American women. Courtenay (2000) contends that due to gender role associated activities and the way people enact gender, men demonstrate their masculine roles by the "denial of...vulnerability, emotional and physical control, the appearance of being strong and robust, dismissal of any need for help, a ceaseless interest in sex, the display of aggressive behaviors and physical dominance." Traditional masculine actions reinforce the idea that taking care of health related issues is a feminine action, and men would rather risk their longevity, their bodies, and a healthy mind than do gender in a way that is feminine (Jackson, 2014; Sabo \& Gordon, 1995). This denial of the feminine contributes to substance abuse, improper care of existing illnesses/diseases, refusal to seek treatment, and under-utilization of resources (Courtenay, 2000). For example, traditional male role attitudes predict alcohol consumption in men, such that the more men subscribe to traditional attitudes the more alcohol they consume (McCreary, Newcomb \& Sadava, 1999). The experience of gender role stress is also a risk factor for men's alcohol problems (McCreary et al., 1999). The aforementioned Success, Power and Competition factors of the GRCS are also positively related to alcohol use, while the Restricted Emotionality factor is positively related to negative attitudes towards help seeking (Blazina \& Watkins, 1996). 
In addition to the negative impact that risky sexual behaviors and beliefs have on women, there is also a link between adherence to masculine gender norms and intimate partner violence (Moore \& Stuart, 2005; Vandello \& Cohen, 2008). Hypermasculinity, gender role norm adherence, and gender role conflict have all been shown to partially predict (or explain) intimate partner violence when men are the perpetrators and women are the victims (Parrott \& Zeichner, 2003; Reidy, Berke, Gentile \& Zeichner, 2014; Reidy, Shirk, Sloan \& Zeichner, 2009). At an implicit level, men who feel insecure in their manhood are more likely to remember gender-atypical faces compared to men who feel secure in their manhood (Lick, Johnson, \& Riskind, 2014). Researchers posit that gender insecure men are more likely to remember atypical male faces because they want to distance themselves from men who do not live up to masculine presentation (Lick et al., 2014). These results imply that a man's feeling about his own gender role can impact the lens through which he views the world by moderating the association between his gender (in)security and memory for atypical male faces. Therefore, any man who experiences feelings of insecurity around his role as a man may have biased attention. This biased attention may contribute to subsequent aggressive behaviors.

\section{Masculinity Threat}

The previous section discussed the various ways masculinity and manhood have been conceptualized and studied in different subfields of psychology. Building off of these findings, social psychology has focused on the nature of manhood and the compensatory responses associated with contextual threats to masculinity - the social identity threat known as masculinity threat. 
As previously discussed, masculinity is not just an ideological belief or a stable set of traits. Masculinity can also be threatened in a very specific moment. That is, it has both state (e.g., Vandello \& Bosson, 2013) and trait (e.g., Goff et al., 2016; Richardson \& Goff, 2015) components. Across the short history of America, what remains constant about manhood is the anxiety surrounding its potential for failure, not specific personality characteristics (Kimmel, 1998). When America was founded, there was little to no question of a White man's assumed high status, but as more groups gained civil rights, that unquestioned power grew more tenuous, causing traditional manhood to be more anxiety prone (Kimmel, 1996). At any point, a man's power can be overthrown by a group previously considered to be subordinate and non-threatening, contributing to the ethos (and psychological findings) of threats to manhood (e.g., challenges to manhood) as anxiety provoking.

Gender socialization is constantly shifting, and while certain traits are more often linked with femininity versus masculinity, researchers have attempted to build a reliable, culturally relevant definition of manhood with little success (Eagly \& Wood, 1995; Hyde \& Plant, 1995). Definitions of masculinity and manhood are relative to historical time and geography. An example of this cultural relativity can be seen in the phenomenon of male honor. Brazilians, coming from a culture that places high value on male honor, are more likely to rate a husband who has been cheated on by his wife as less manly than are Americans, who do not come from an honor culture (Vandello \& Cohen, 2003). Rather, what remains consistent across time and place is that manhood as a state is one that must be constantly proven and displayed in a public domain. This state produces a constant 
worry in the socialized man, for at any moment he could be required to "prove" himself, even if it is unclear what form that "proof" should take (Kimmel \& Mahler, 2003; Kimmel \& Messner, 2004).

Since what has remained consistent about manhood has been its fragile nature, social psychological research has focused on the effects and outcomes of the anxiety associated with manhood's tenuous states. Over the last fifteen years, the psychological precursors, consequences, and foundations for this type of masculine anxiety have been examined (Vandello \& Bosson, 2013). In social psychological research, manhood is characterized as a) existing as an ambiguous status that must be accomplished (i.e. cannot be born into, which is quite different than the way womanhood is conceptualized); b) incredibly difficult to achieve and retain as a status (that is, one can have their masculine identity questioned at any moment, regardless of their past demonstrations); c) being reliant on the approval and recognition of others - it must be earned and defended publicly, in sight of others (Vandello \& Bosson, 2013).

In addition to these three tenets of precarious manhood, manhood is consistently conceived of as being the opposite of three things: womanhood, homosexuality, and impotence (Vandello \& Bosson, 2013). While there is little stability over time and across place in what masculinity is, there is stability in how masculinity is proven and what masculinity is not. Any experience that likens a man to a woman, to a homosexual, or to physical weakness can act as a threat to manhood insofar as these comparisons actively remind men of potential identity misclassification. Identity misclassifications, which are inaccurate categorizations into socially subordinate groups, act as threats to identity for 
men because role violations threaten men's high social status (Bosson, Prewitt-Freilino, \& Taylor, 2005). Gender identity misclassification is a fearful state for heterosexual men which contributes significantly to gender norm adherence (Bosson, Taylor \& PrewittFreilino, 2006).

Masculinity threat is a social identity threat that occurs when a man feels that his status as a man is being questioned (Vandello \& Bosson, 2013). The experience of masculinity threat can trigger behaviors that attempt to prove or reassert masculine identity through, what has been coined, a masculine compensatory response (Vandello \& Bosson, 2013). Unlike masculine ideology and gender adherence which examine an enduring and developing sense of masculine self, state level experiences of masculinity threat refer to specific moments in time wherein a man's masculinity has been questioned and his subsequent response to that specific threat, which makes up a compensatory response (Vandello \& Bosson, 2013). Masculine compensatory behaviors are actions that men can, but don't always, enact following a threat to masculinity in order to restore their threatened status. These masculine compensatory behaviors overlap with many of the outcomes that are predicated by masculine identity scales (e.g., the previously discussed Gender Role Conflict Scale), like substance abuse, risk-taking, physical aggression, and discriminatory practices because these behaviors are considered culturally masculine. While these tenants and types of responses provide important insight into the phenomenon of masculinity threat, it is important to note that not every threat to masculine identity results in a response that is a masculinity compensatory response, although they are often associated with each other. Likewise, men are not always 
engaging in one specific compensatory response; rather, research suggests that men who do engage in compensatory responses are likely to do so in accordance with what is relevant in a given situation and the types of compensatory responses can vary (Vandello $\&$ Bosson, 2013). That is, aggression is not always the sole compensatory response that men engage in following a threat to masculinity, although it is a common response. Other responses might include increased anxiety and stress (Goff et al., 2016). Examples of the different types of masculinity compensatory responses are detailed below in the following empirical studies.

Achieving masculinity as a status symbol is reliant on recognition from others. Research has shown that following a masculinity threat, masculinity is ideally reinforced publicly because recognition from others is a valuable tool to restoring ones status of manhood (Weaver, Vandello \& Bosson, 2013). In one such study, college men were randomly assigned to either sample a "feminine" scented hand lotion (experimental masculinity threat condition), or a "masculine" power drill (control no-threat condition) in the presence of the experimenter. Participants in the experimental masculinity threat condition were more likely to place larger monetary bets than their control group counterparts, as well as choose a smaller immediate financial payoff as opposed to greater financial payoff later in time. However, men in the masculinity threat condition only placed the larger bets if they thought that the decision was being viewed publicly by others (Weaver et al., 2013). Risky decision-making is associated with masculinity because it implies fearlessness and little inhibition, which are masculine ideals. Interestingly, the threats to masculinity did not have to occur publicly for the 
compensation to occur - it is only the compensation that, when it occurs publicly, has the strongest impact. These results imply that in order for risk-taking to act as a masculine compensatory response, it is most effective when it happens publicly and in view of others, supporting the third tenet of the precarious manhood thesis that underlines the importance of external approval.

In another set of studies examining masculine compensatory behaviors, men who were given feedback that suggested that they were feminine (masculinity threat) were more likely to demonstrate support for war and dominance hierarchies (Willer, Rogalin, Conlon, \& Wojnowicz, 2013). Likewise, men who received feedback that they had a more feminine personality demonstrated significantly higher levels of negative affect toward effeminate gay men (Glick, Candice, Gangl, Gibb, Klumpner, \& Weinberg, 2007). Interestingly, this negative affect was only directed at effeminate gay men and not masculine gay men. These results suggest that the public nature with which a man demonstrates his prowess is essential to gain respect from other men, further supporting the claims of the third tenet of the precarious manhood thesis. Similarly, when heterosexual men experience masculinity threat and are then forced to interact with a partner whom they believe to be gay, they behave more aggressively towards said partner than those who received no such threat. This pattern of behavior remained regardless of the participant's level of homophobia (Talley \& Bettencourt, 2008). Negative affect, antisocial intentions, and poor financial decision making can be detrimental for men who feel their masculinity has been threatened, as well as those around them. 
Physical aggression is another important documented masculine compensatory response that men might enact after experiencing masculinity threat, and it is the focus of this thesis . Following a threat to masculinity, one way that a man can attempt to reclaim his manhood is by acting physically aggressive or violent in order to distance himself from the social groups (i.e., women, homosexuals) that are thought of as physically inferior. Funk and Werhun (2011) have shown that a threat to masculinity not only leads men to overcompensate physically, but it also compromises cognitive ability and selfcontrol. Said another way, some men feel stress and internal conflict when their masculine identity is challenged. In order to cope with this increased internal conflict, some men utilize physical aggression and other prototypically masculine behaviors to compensate (Eisler \& Skidmore, 1988). In another example, male participants were randomly assigned to either a hairstyling task (experimental, masculinity threat condition) or a rope-reinforcing task (control, no-threat condition) (Bosson, Vandello, Burnaford, Weaver, \& Wasti, 2009). Participants in the masculinity threat condition subsequently punched a punching bag harder than their control group counterparts. Additionally, following the same procedure, men whose masculinity had been threatened were more likely to choose to engage in punching a punching bag versus solving a puzzle. According to the researchers theoretical assumptions, punching a punching bag provided threatened men with a physical outlet to demonstrate their strength and prowess, while solving a puzzle provided no such outlet for demonstration. When masculinity threatened men were not given the choice to engage in the physically aggressive activity, but instead were only given the opportunity to solve a puzzle, their anxiety-related 
cognitions were higher than the threatened men who were able to punch the punching bag (Bosson, et al. 2009). Not only do men respond with more physical aggression (i.e., punching harder following a threat to masculinity), but they will also actively seek out a way to express physical aggression in order to restore their manhood. If men cannot reassert their masculinity by enacting a compensatory response, their anxiety-related thoughts significantly increase (Bosson et al., 2009). These results imply that compensation through action is key to proving masculinity.

In addition to acting physically aggressive as a personal compensatory response to threat, men are also more likely to justify other men's physical aggression (Bosson \& Vandello, 2011). Since men view manhood as a tenuous role, they are more likely to be understanding towards other men who have used physical aggression to re-assert masculinity. In one research example, participants read a (mock) police report about a person that punched a same-sex stranger after that stranger publicly humiliated them in front of a potential opposite-sex dating partner. Participants were randomly assigned to either read about a man who punched another man (the stranger that humiliated them), or about a woman who punched another woman (the stranger that humiliated them). Results showed that when male and female participants read about the woman punching the stranger, they provided negative internal attributions for her behavior. However, when men read about the man who punched the stranger, they attributed his behavior to situational attributions, while the women did not (Weaver, Vandello, Bosson, \& Burnaford, 2009). These results suggest that men understand that masculinity is tenuous and must be constantly proven, which is why the male participants did not attribute the 
male puncher's physical aggression to individual stable characteristics. While the research on masculine compensatory behaviors and attributions following threats to masculinity have been helpful to understanding masculine behavior in social interactions, little research has examined how race influences masculinity threat. I now turn to reviewing the existing literature on masculinity threat and race to better understand police use of force within these contexts.

\section{Masculinity Threat and Race}

Psychologists have long theorized about the ways in which socialized gender roles intersect with class, race, sexuality and other key identities and how these intersections impact intergroup relations, intragroup relations, and self-schemas (Bem, 1981; Goff \& Kahn, 2013; Hernandez, 2001; Purdie-Vaughns \& Eibach, 2008; Shields, 2008). Stereotypes about Black men as virile, manly, physically imposing, and ape-like have been well documented (Goff, Eberhardt, Williams, \& Jackson, 2008). Stereotypes about White men - that they are not athletically inclined and that they are worse at math than Asian men - hold far less stigma in the social world (Aronson, Lustina, Good, Keough, Steele, \& Brown, 1999). Since stereotypes about White men and Black men are different, identity theory would suggest that these groups would also experience threats to their manhood differently (Aronson et al., 1999; Biernat \& Manis, 1994).

In one such study that examined how Black men and White men might differentially experience threats to their masculinity, Black male and White male participants were randomly assigned to either receive racially discriminatory feedback or non-race related feedback (Goff, Di Leone \& Kahn, 2012). Through a series of 
procedures, participants were asked to perform pushups both at the beginning of the study (pre-condition effects), and after experiencing racial discrimination, as well as fill out a word search task. Results demonstrated that Black participants who experienced discrimination found more masculinity-threat related words (e.g., pansy) on a word task than both masculinity threatened White participants and non-masculinity-threatened Black participants. This indicates that racial discrimination can make Black men more aware of implicit masculinity threat cues. That is, the experience of racial discrimination for Black men carried with it a subsequent masculinity threat.

Additionally, Black participants who were in the discrimination condition performed more pushups than the Black men who did not undergo discrimination, indicating a corresponding physical compensatory response to the masculinity threat, which involved completing more pushups to restore their manhood. On the other hand, White men who faced discrimination actually performed fewer pushups than White men who were not discriminated against. Since White men can rely on the current and past social status they have within society to compensate for a personal threat like racial discrimination, they do not need to prove their racial status through their own physicality to the same extent that Black men do. For Black men in this study, racial discrimination acted as a form of masculinity threat, and these participants in turn enacted compensatory responses when under such threat. White male participants did not experience masculinity threat when faced with racial discrimination in this study. Taken together, these findings suggest the importance of examining the role of race in officer-suspect interactions that include masculinity threat, especially considering that the most volatile 
and disparate police-suspect interactions in our nation's history have involved male officers and minority men (Goff et al., 2012).

Masculinity and Policing

One domain in which masculinity threat might be particularly powerful is policing. As mentioned, policing remains a male dominated profession. This gender imbalance contributes to a "hidden" curriculum within policing academies that encourages a hegemonic masculinity which excludes women, degrades the feminine in general, and subsequently upholds the notion that traditional masculine behaviors and traits are the epitome of what a good officer should be (Prokos \& Padavic, 2002). The consequence of upholding a masculinity that requires physical dominance and superiority within policing has been linked to aggressive patrol styles, risky vehicle and foot chases, and felony arrests (Herbert, 2001). Encouraging displays, formally or informally, of masculinity in policing can lead to increased levels of use of force by officers who feel their manhood has been questioned because aggression is a way to demonstrate male honor (Salter, 2013).

Before delving deeper into the literature on masculinity threat and policing, it is important to note that masculinity threat (e.g., an overcompensation based on a man's gender role conflict following a threat to his male identity) is not always triggered. Rather, there are certain men who are more prone to experience masculinity threat based on their role adherence and ideology (Goff et al., 2016; Richardson, 2015). However, there are also men that feel less compelled to react to these types of threats. Keeping this in mind, most of the literature on the culture of hyper-masculinity within police 
departments suggests that police officers, especially police officers who are at the bottom of the hierarchy and who often interact with citizens, will likely fall into the former category of more masculinity threat prone men (Richardson \& Goff, 2015).

Bearing in mind that officers may be more likely to fall into the more threat prone category due to their profession's emphasis on masculinity and maleness, it is of note that physical aggression is a common compensatory response through which men can prove (or affirm) their manhood after experiencing a perceived threat. Given its close relationship to their job roles, police officers haven been shown to engage in aggression as a compensatory response following a masculinity threat. In a series of studies, researchers demonstrate that police officers higher in trait level masculinity threat measures (measured via the Male Role Gender Stress scale) are more likely to compensate when threatened by using higher levels of ultimate force against minority suspects (Goff et al., 2016; Richardson, 2015; Richardson \& Goff, 2015). First, a laboratory study involving undergraduate participants demonstrated that under masculinity threat, men lowered the pitch in their voices significantly to sound more masculine compared to men who did not experience masculinity threat (Goff et al., 2016.). Results also suggested that when male participants believed that an interaction partner would not comply with their request, their male gender role stress increased, indicating that being disobeyed can trigger a threat to masculine identity. In a second study, researchers assigned participants to hypothetical scenarios. Participants were assigned to either a designated driver scenario (pretesting revealed the perception of the scenario to be moderately masculine) or a police officer scenario (pretesting revealed the 
perception of the scenario to be extremely masculine). For the participants who were assigned to imagine themselves as police officers, they were more attuned to masculinity threat words when they expected to interact with a Black, rather than a White, suspect (Goff et al., 2016). These results suggest that the masculinity of the policing domain itself is enough to prime participants' attention to words that are associated with challenges to masculinity. In an additional exploration of the connection between masculinity threat and race in the context of violent altercations, White and Asian male participants were randomly assigned to either have their masculinity threatened or affirmed, and to read about a White man shooting a black teenager or a Black man shooting a White boy. Results indicated that the men who had their masculinity threatened found the White adult shooter to be more masculine and justified in his action than those who had their masculinity affirmed. These results suggest that when White and Asian male men have their masculinity threatened they are more likely to justify and support violence against Black boys, but not against White boys.

In order to test whether these results translated to police officers themselves, the paradigm was tested with police officers from a large city police department in the United States. The results of this analysis found that police officers high in trait level masculinity threat are more likely to shoot Black suspects, but not White suspects (Goff et al., 2016). The implications of these findings are that police officers, who are in a domain that primes masculinity, are also susceptible to biased behavior when they feel their status might be threatened by a minority suspect. These findings also suggest that men distinguish which domains are most masculine and in turn experience minority men 
as a threat to their manhood, especially when they anticipate non-compliance. These masculinity threatened men react to these perceived threats to the extent that 1) they feel threatened and 2) they feel the context of the interaction is masculine, i.e., the environment is one that elicits aggression or authority, both of which confer gender role stress and conflict for men (Moore \& Stuart, 2005).

These results shed light on how masculinity within the policing domain can relate to officer compensatory behaviors when interacting with suspects. Interactions with noncompliant suspects can trigger masculinity threat for the officer, who is vulnerable both in terms of physical safety and in terms of psychological stability as a figure of masculine authority. If a suspect does not respect an officer's authority by either verbally insulting the officer's manhood or by physically challenging his dominance, the officer's gender role stress may increase and in turn, he may be more likely to engage in more forceful behavior.

In addition to the effects that policing as a masculine domain have on officer behaviors, police work also attracts people who tend to be higher in an individual characteristic known as Social Dominance Orientation (SDO) (Sidanius et al., 1994). SDO is the belief that some groups of people should be hierarchically advantaged, with dominant groups having more power over subordinate groups. This belief contributes to an informal cultural norm in policing that informs the type of respect officers demand from citizens, especially suspects (Ho et al., 2012; Sidanius et al., 1994). This cultural norm of police officers as enforcers of social dominance may theoretically serve to enhance the compensatory masculine responses officers are susceptible to as a function of 
their gender role. Between the masculine nature of the domain and the self-selection into a group that can perpetuate dominant behaviors, it is important to understand how these effects can be lessened.

Shedding light on how the negative effects of masculinity threat can be mitigated in the policing domain, research has shown that officers who hold a broader conception of the way men should behave, think and feel (e.g., non-traditional) are less likely to experience masculinity threat and the associated compensatory, overly aggressive response during interactions (Kahn, Goff, \& Glaser, 2016). Here, non-traditional conceptions of masculinity would include de-emphasizing male power and competition, dominance and restrictive affection with other men (O'Neil et al., 1986). In one such intervention focused on changing officer conceptions as a way to mitigate negative outcomes associated with masculinity threat, police officers were taught about the phenomenon of masculinity threat and its risks and warning signs within the self and within others. Next, participants engaged in interaction scenarios. During these scenarios participants watched videos of other authority figures who were either high or low in masculinity threat interacting with noncompliant interaction partners. They watched and discussed techniques around diffusing the conflict and being aware of cues that demonstrate susceptibility to masculinity threat. After watching these scenarios, police officers discussed the content and strategies they could use to diffuse masculinity threat interactions. The intervention included discussion of broad definitions of masculinity, and how broader definitions of masculinity could help to alleviate associated threats to masculine identity. Results have demonstrated that intervening with police officers by 
teaching about masculinity threat and broadening conceptions of masculinity can decrease insecure masculinity at the trait level and its associated overly aggressive compensatory response (Kahn \& Davies, 2010).

Taken together, these studies suggest that police officers are indeed susceptible to threats to their masculinity. Officers who experience heightened masculinity threat (as defined by male role gender stress) are more likely to view minority suspects as threatening and are more likely to shoot Black suspects than white suspects (Goff et al., 2016; Richardson, 2015; Richardson \& Goff, 2015). However, these effects are not immune to mitigation as interventions have been successful in decreasing masculinity threat in officers (Goff et al., 2016; Richardson, 2015; Richardson \& Goff, 2015. While these initial studies demonstrate that masculinity threat can affect police behavior, more research is needed to fully understand the breadth of its effects. In order to gain a deeper understanding of how state masculinity threat's directed at an officer can impact use of force, this study will evaluate police use of force narrative files to isolate how masculinity threat affects police use of force in an interaction.

\section{Current Research}

As previously discussed, empirical investigations of officer use of force commonly rely on understanding force as a continuum (as opposed to a dichotomy of lethal versus nonlethal). Most of these studies have examined the relation between officer trait level masculinity threat and the final outcome of force (i.e., the force that the officer uses at the end of an interaction) as the dependent variable (Goff et al., 2016; Richardson \& Goff, 2015). This study focused on state level masculinity threats as it 
occurs within an officer-suspect interaction and utilized various use of force levels at different time points in the interaction in an attempt to uncover a deeper understanding of how state masculinity threat relates to officer force across an interaction. In order to provide context for how these variables were defined and how my hypotheses were developed, I will briefly outline the process for collecting these data which is later detailed in the method section.

When an officer uses force against a suspect, many departments, including the department from which the data for this thesis originated, require a detailed report to be written from the officer's perspective narrating what they believed happened, step by step, during the interaction. These files become an official record of what occurred in the incident. Use of force narratives have also been used by police departments and research partners in order to deconstruct and study police use of force interactions. By developing a detailed coding process of these narrative files that breaks down each step of the interactions into a "sequence", researchers have been able to identify important precipitating factors to police use of force as it unfolds in an interaction, and this approach has garnered increased support and validity over the past decade (Hickman \& Atherly, 2012; Hickman, Atherly, Lowery, \& Alpert, 2015). For example, departments who have used this type of analysis have found that the momentary information available to the officer, such as whether the suspect(s) was a threat to third parties, and the suspect's level of resistance at the sequence level affects the application of police force (Hickman et al., 2015; Stewart, 2013). To conduct this type of analysis, independent coders go through the relevant use of force narratives and code officer and suspect 
actions sequence by sequence. This coding process allows for a more fine-tuned analysis of use of force and it has proven useful in understanding how use of force unfolds over time during a officer-suspect interaction (Hickman et al, 2015; Kahn, Steele, McMahon \& Stewart, 2016; Stewart, 2013).

Analyses utilizing this type of sequenced data have not only proven fruitful in uncovering how use of force is applied as an interaction unfolds, but also in how force is applied differently for different racial groups. For example, research has shown that early on in an interaction between an officer and suspect, differences in force are apparent for Black Americans and Latinos compared to White suspects. Black and Latino suspects experience higher levels of force at the beginning of an interaction compared to White suspects (Kahn et al., 2016). Since this type of coding and sequencing has proven to provide rich information about psychological biases that associated with officer-suspect interaction, the current project utilized this method to study the role of masculinity threat on police use of force during an interaction with a suspect.

The current research project utilized a dataset that had already undergone a sequenced coding process following the validated process described above (see Kahn et al., 2016; Stewart, 2013). The data have been deconstructed into discrete sequences in order to see what happens step by step in an interaction that leads to the ultimate force outcome. Each sequence (of which there are multiple within one police-suspect interaction) is defined as one suspect action and one subsequent action taken by the police officer and directed towards the suspect. In order to examine the relation between 
masculinity threat and officer use of force at different points within an officer-suspect interaction, and with suspects of different races, I performed an additional coding of the police use of force narratives. This coding was specific to masculinity threat instances that officers report experiencing while interacting with a suspect. For example, when a suspect responds to an officer by likening them to an inferior group or status (e.g., women, homosexual, or physically weak), a momentary masculinity threat may be invoked for the police officer. That is, when a suspect tells the officer that they are too weak to challenge them, or when a suspect calls an officer a homophobic slur, this can act as a threat to the officer's masculinity via gender role stress. More specifically, a masculinity threat was coded as having taken place if an officer reports that the suspect "called [the officer] a weak bitch" or "pounded his chest and would not stop staring into [the officer's] eyes" (See method section for full coding information). Since the increased stress associated with masculinity threat can trigger compensatory behaviors, like physical aggression, I examined the relation between use of force following these masculinity threats at different points within the officer-suspect interaction. Since much of the past research on masculinity threat and policing has focused on highest officer force as the dependent variable, I tested the association between officer-reported masculinity threat and first instance of officer use of force, average officer use of force, maximum officer use of force and final officer use of force in order to gain insight in to the larger context of state level masculinity threat and police use of force.

In addition to testing an association between masculinity threat and a broad range of use of force outcomes, I examined how multiple masculinity threats might impact use 
of force over time within an officer-suspect interaction. I investigated this association because if a masculinity threat occurs more than once within a sequenced interaction, it is possible that there may be a greater change in officer use of force associated with a particular time point which could guide researchers to focus on mitigating that particular interaction point. I also examined how suspect race and masculinity threat in combination relate to police use of force in the interaction. A police officer's perception that a minority man is not cooperating with their authority in conjunction with direct questioning of their manhood may feel like an exaggerated threat to the officer's masculinity because of stereotypes of Black men as hyper-masculine (Goff, Thomas, \& Jackson, 2008). Past research has suggested that Black suspects received more force than White suspects when police officers experience increased masculinity threat (defined as male gender role stress; Richardson \& Goff, 2015). However, the relation between officer use of force and the interaction of masculinity threat and suspect race has not been examined across various outcomes and as a state, momentary variable (as opposed to a personality trait of the officer). This study examined a broad range of officer force outcomes and their relation to state masculinity threat experience by the officer in order to provide new information to our understanding of force and masculinity threat.

In order to understand how masculinity threat and suspect race might associate with officer use of force, three research questions were addressed. First, Research Question 1 explored the relation between use of force and masculinity threat at the global level (e.g., did an officer report masculinity threat occurring at any point within the interaction?). Second, Research Question 2 focused on how multiple masculinity threats 
can impact changes of officer force across time in the interaction. Third, Research Question 3 examined the relation between officer use of force and masculinity threat in combination with suspect race. Each research question provided unique insight into how masculinity threat may relate to officer use of force. The research questions and the respective hypotheses are detailed below.

Research Questions

Research Question 1: How does masculinity threat relate to use of force at the overall interaction level?

Hypotheses 1a - 1e. These hypotheses focused on masculinity threat at the global level in order to elucidate how officers' experience of masculinity threat at any point within an interaction with a suspect relates to their use of force directed towards the suspect and the length of the interaction. I predicted that masculinity threat relates to an increase in police officers' use of force in an officer-suspect interaction. To examine this hypothesis, I evaluated the following force levels within a sequence as the dependent variables: first officer force, average officer force, maximum officer force, last officer force, and number of sequences. I predicted that these outcomes would be impacted in particular because officers may enact forceful compensatory behaviors to restore their threatened status that non-masculinity threatened officer will not. I also included average suspect resistance as a covariate for Hypothesis 1a-1d because suspect resistance impacts officer actions since officers are trained to respond to a suspect's action with the means necessary to control the situation (Stewart, 2013). Therefore, in order to account for the actual variance in use of force associated with masculinity threat, the effect of average 
suspect resistance was controlled so that analyses could clarify the relationship between masculinity threat and the various outcomes in question.

I predicted that the first force used in a sequence that included masculinity threat would be higher for interactions during which officers' masculinity had been threatened versus first force in an interaction where no masculinity threat had occurred (Hypothesis 1a). I predicted that the average force used in an officer-suspect interaction that involved masculinity threat would be higher compared to cases where no such threat had occurred (Hypothesis 1b). I also predicted that the maximum amount of force used by police officers would be higher, on average, for interactions during which an officer's masculinity had been threatened by the suspect versus not threatened (Hypothesis 1c). Similarly, I predicted that the last amount of force used by an officer in an officer-suspect interaction wherein a suspect threatened officer masculinity would include higher levels of officer force than in interactions where the suspect had not threatened officer masculinity (Hypothesis 1d). I also predicted that sequences involving masculinity threat would be shorter than sequences with no such threat (Hypothesis 1e) because officers would defend their threatened masculinity by acting more forcefully (as hypothesized above), which would in turn relate to the interaction ending more quickly (e.g., having fewer back and forth sequences).

Research Question 2: How do masculinity threats that occur during an officer-suspect interaction relate to force across time in the interaction?

Hypothesis $2 \mathrm{a} \& 2 \mathrm{~b}$. Hypothesis 2 focused only on cases that involved masculinity threat (as opposed to comparing all cases that involved threat versus no threat 
as Hypothesis 1a-1e did) in order to gain an understanding of how masculinity threat might impact officer force at specific time points in the interaction. Hypothesis $2 \mathrm{a}$ predicted that the level of force used immediately following a masculinity threat would be significantly higher than the level of force used directly prior to the masculinity threat. Testing Hypothesis 2a provided more detailed information regarding change in officer force directly following a threat since Hypothesis 1a examined the relation between officer force and masculinity threat only at the global interaction level -not the specific sequence level.

To test Hypothesis $2 b$, only cases with at least two officer-directed masculinity threats were included in the analysis. Hypothesis $2 \mathrm{~b}$ predicted that the first masculinity threat in a multiple masculinity threat interaction would be associated with the largest increase in police use of force, in that it would illicit the highest change in officer force compared to subsequent threats in the same interaction. That is, masculinity threat would have its strongest association with use of force the first time it occurs, with a lower magnitude increase in use of force in subsequent experiences in the interaction. Covariates included in the analysis of Hypothesis $2 \mathrm{~b}$ included prior suspect level of resistance (as this would impact the level of force an officer would find necessary), and the control the officer achieved in the prior sequence (as this would impact how much a suspect could pose a continued risk). This hypothesis intended to hold these variables constant because Hypothesis $2 \mathrm{~b}$ explored change in force over and above the control the officer established in the previous sequence, as well as the suspect's resistance in the prior sequence. Without holding control achieved and suspect resistance constant the 
analyses would not clarify the relationship between masculinity threat and change in use of force between the sequence prior to the masculinity threat and the sequence following the masculinity threat.

Research Question 3: Do suspect race and masculinity threat interact to influence officer use of force?

Hypothesis $3 \mathrm{a}-3 \mathrm{e}$. Hypothesis 3 examined if there were racial disparities in police use of force following a threat to masculinity. As described earlier, Black men are stereotyped as prototypically masculine - Black men are considered to be the epitome of strength and aggression (Goff et al., 2012). Based on this greater association of masculinity with racial minorities, I predicted that racial minority suspects would receive higher officer use of force than White suspects during an interaction that involved masculinity threat versus not because the stereotypes of minority men as hyper masculine may have trigger a greater experience of threat in the officers. Specifically, I predicted that officers would use higher levels of force in the first instance of force against minority suspects who threatened their masculinity compared to White suspects who threatened their masculinity (Hypothesis 3a). I also predicted that officers would use higher levels of average force against racial minorities in interactions that involved a threat to masculinity compared to White suspects (Hypothesis 3b). I predicted that officers would use higher levels of maximum force against minority suspects who threatened masculinity compared to black suspects who threatened masculinity (Hypothesis 3c). I also predicted that officers would use more force in the last sequence (of an officer- 
suspect interaction) against racial minority suspects who threatened masculinity compared to White suspects who threatened masculinity (Hypothesis $3 \mathrm{~d}$ ).

Like Hypotheses 1a-1d, Hypotheses 3a-3d included average suspect resistance as a covariate in order to control for the suspects actions towards the officer during the interaction. Lastly, I predicted that the average number of sequences (within the interaction) for minority suspects who threatened officer masculinity would be fewer than White suspects who threatened masculinity. I predicted this because minority suspects may present a greater threat to officer masculinity (based on stereotypes of minority men as hyper masculine) which might motivate officers to use more force faster, which would be associated with the interaction lasting fewer sequences (Hypothesis 3e; Goff et al., 2012; Kahn et al., 2016).

\section{Method}

To examine these hypotheses, I analyzed 61 use of force narrative files that came from a larger dataset of narrative files that had already undergone a sequencing coding (see Kahn et al., 2016; Stewart, 2013). I will first describe the elements of the larger data set before specifying the additional coding performed for this project specifically.

\section{Original Dataset}

The original data consisted of 212 first-person narratives from officers who interacted with a suspect and used force during the interaction (see Kahn et al., 2016; Stewart, 2013). Police officers are required to write these accounts following an interaction with a suspect that involved use of force. The use of force narratives being examined come from a large police department in an urban city in the Western United 
States and represent police-suspect interactions in which an officer has used non-lethal force (e.g., hand on back, pepper spray use). Narratives provide step-by-step detail of the officers' memory of the interaction from the time they arrive on scene to the suspect's arrest. These first-person officer accounts become court record, and because of this they are supposed to be written in an objective manner, documenting the events from the time they arrive at the scene to the time the suspect is in custody. The officers in the narratives are de-identified as to avoid any breach of confidentiality. Ninety-two of these cases involved White suspects, 72 involved Latino suspects and 47 involved Black suspects and 177 were men. All of the use of force incidents included in this research took place during 2012.

These data files have been previously coded for use of force sequencing following a validated process described hereafter (Hickman et al., 2015; Kahn et al., 2016; Stewart, 2013; Terrill 2003). This coding process centered on deconstructing the officer-suspect interactions into discrete sequences. Each sequence represents one suspect action and one subsequent officer reaction towards a suspect. Therefore, within one officer narrative of the interaction with a suspect, there are multiple discrete sequences. In order to code these sequences, each sequence was rated according to the initial suspect action (e.g., the level of suspect resistance), the officer's response (officer level of force), and the level of control achieved by the reporting officer.

Coders were trained extensively over the course of 10-weeks, and averaged approximately 40 hours of training. Coders learned about "police tactics, terminology and training" and engaged in "touring police facilities, reviewing training materials on 
police use of force... reviewing police reports... additional independent sessions" with a police expert and academic researcher (Stewart, 2013). The coding of officer narratives took place in a police facility and all information was kept onsite under the supervision of a police Sergeant in the police department. Coders met jointly in order to sequence the narratives and come to a decision regarding the number of back-and-forth, discrete officer-suspect sequences within an interaction. Then coders coded the narratives independently for variables such as suspect resistance and officer actions. Reliability analysis between coders revealed high levels of reliability for this coding process (Stewart, 2013). See Appendix B for a sample of the original coding sheet.

Measures from original use of force coding

Number of sequences. The total number of sequences that took place over the course of the entire officer-suspect interaction (sequence number does not exceed 15 officer-suspect sequences). A sequence is defined as a single suspect action and the corresponding officer's reaction (Kahn et al., 2016; Stewart, 2013).

Suspect resistance. This measure represents the suspect's level of resistance towards the officer. Every discrete sequence began with a measure of suspect resistance that was coded on a scale from 0 (no resistance) to 6 (use of lethal force). If the suspect refused instructions from the officer, either verbally or non-verbally, it was coded as a 1 (verbal/passive resistance). Verbal threats or assuming a posture considered threatening was coded as a 2 (use of posture and verbal threats). Attempts to avoid custody by running, or abruptly moving away from the officer were coded as a 3 (physical noncompliance). Wrestling with or hitting the officer was coded as a 4 (active physical 
resistance). Throwing of a small or large item was coded as a 5 (use of a non-lethal weapon; Kahn et al., 2016; Stewart, 2013).

Officer Actions. This measure represents the level of force used by the officer from a scale of 0 (verbal exchange) to 5 (intermediate weapon use) during the coded sequence. Examples for the range from 0-5 are as such: Lawful orders, coded as a 1, indicates that the officer verbally instructed the suspect to listen to their commands, e.g., "put your hands in the air"; Light contact, coded as a 2, indicates that the officer made physical contact with the suspect, but not in a manner intended to be painful, e.g., placed handcuffs on suspect; Physical control tactic, coded as a 3, indicates force used to cause compliance and could hurt the suspect, e.g., wrestling the suspect to the ground; Advanced physical/chemical, coded as a 4, indicates use of physical strikes to the suspect and/or use of pepper spray; Intermediate weapon use, coded as a 5, indicates the use of less-lethal weapons, e.g., a Taser or beanbag gun (Kahn et al., 2016; Stewart, 2013).

Control Achieved. This measure indicates the control an officer was able to achieve over the suspect during the specific sequence and ranges from a scale of 0 (none-suspect had free movement) to 6 (in vehicle; hobbled). Examples for the range form 0-6 include: Isolated, blocked, cornered, coded as a 1, refers to a suspect's inability to interact with others, Physical hold; single limb controlled, coded as a 2, refers to officer holding at least one limb. Pin; multiple limbs controlled, coded as a 3, refers to a suspect being unable to move or being pinned to ground. Tased effectively, coded as a 4, refers to a suspect being disabled by a Taser. Handcuffed, coded as a 5, indicates that the officer has handcuffed both of the suspect's hands. In police vehicle; hobbled, coded as a 
6 , refers to a suspect being placed into the officer's vehicle compartment (Kahn et al., 2016; Stewart, 2013).

In order to investigate the hypotheses and research questions of the current project the already sequenced use of force case files underwent an additional round of coding for masculinity threat. Given the focus on masculinity, only narratives that involved male officers and male suspects were included for analysis. The following sections will outline the specific procedure and measures associated with this project specifically. Additional coding procedure

Masculinity threat codes were developed based on experimental and theoretical literature - no such codes have been used or developed in published documents to this researcher's knowledge. Coders identified examples of masculinity threat and nonmasculinity threat codes based on various statements or actions in the officers' narrative that were attributed to the suspect, i.e., coders focused on evaluating the language used in the narrative files that officers wrote. Verbal threats to masculinity included any remarks made by the suspect that likened the officer to a woman, a homosexual man, or to being physical weak or impotent (Bosson \& Michniewicz, 2012; Funk \& Werhun, 2011; Glick et al., 2007; Pleck et al., 1994; Vandello \& Bosson, 2013). For example, verbal threats to officer masculinity included as few as one or two words (e.g., "you're a pussy") or direct challenges requesting the officer to prove their manhood (e.g., "try and catch me, you bitch"). In these examples the officer is reporting that the suspect has not only questioned his physical prowess, but has likened him to a woman using profane language. 
In addition to verbal threats to officer masculinity, physical threats were coded as well. Physical masculinity threats included suspect behavior that is linked to evolutionary male dominance, e.g., chest thumping, puffing chest out, and muscle tensing with prolonged eye contact (Greenwood, 2010; Hall 1995). An example of a physical threat to masculinity is an officer reporting that "he [the suspect] would not stop staring at me and flexing his muscles and pounding his fists against his chest". The officer is reporting that they felt threatened due to the highly dominant masculine nature of the suspect's behavior. While these physical masculinity threats were coded, they were far fewer in number (compared to verbal masculinity threats) due to their very specific nature - an officer must report a specific challenge to their masculinity via these physical threats for it to have been coded as such. Since this is the first time a codebook like this has been used, only cases that had very clear, prototypical statements or actions that challenged the officers manhood directly were coded as masculinity threats.

As aforementioned, in order to maintain as much fidelity as possible, this project focused on coding masculinity threats in a straightforward and prototypic manner. To do this, the codes had to be specific to masculinity threat and not general non-compliance. A narrative that reported a suspect saying "I'm not going with you - you can't catch me" was not coded as a masculinity threat because there is no direct mention of the officer's manhood, and instead represents general non-compliance. Likewise, physical masculinity threats were distinguished from general suspect aggression, e.g., forming a fist or trying to kick the officer, as these are more indicative of general resistance and not specific to masculine identity. For example, an officer reporting that a suspect was 
"clenching his fists and blading his stance, readying to fight" was not coded as a masculinity threat because there is no officer reflection on male dominance in those behaviors.

In addition to the clear distinction between masculinity threat and non-compliance made during the coding of the data, cases that were unclear or vague were excluded from analyses per the recommendation of the researcher's thesis committee. While there are several other metrics that could have been applied to the coding of the masculinity threat variable (e.g., severity of threat, patterns of specific words/actions used during threat) because no other codebook has been developed to apply to threats experienced outside the lab environment, no information exists that could guide development of scales of these sorts. See Table 1 for codebook and Appendix A for example of coding sheet.

Following a training period of approximately 10 hours, two trained coders, including one coder from the sequencing coding of the original dataset, coded the narratives to assess masculinity threat (masculinity coding defined and discussed in detail below). Coders' training began with a review of the literature on masculinity threat written by Jennifer Bosson and Joseph Vandello in 2013. After reading this review, coders discussed their understanding of the literature. Next, coders practiced their understanding of what constitutes a masculinity threat by reading fabricated files and discussing their impressions. The primary researcher clarified any confusion associated with the coding.

Research assistants then went to the secure office within the police department from which the files came and coded the 212 narratives. Since this coding was specific 
to masculinity threat, the coders utilized a coding sheet throughout the process (see Appendix A) both for the sake of matching the procedure to the original coding process and to serve as a guideline. Once each assistant completed the coding, the coders tallied how many masculinity threat cases were found and randomly selected approximately the same number of comparison group cases (e.g., narratives without masculinity threat). The original procedural plan was to place cases that the coders disagreed upon in a pile to be coded by a third party later. However, based on the coders' strict adherence to prototypical masculinity threats, no disagreement was found and therefore the third coder did not have to examine any narratives.

Once the additional coding process was complete, the primary researcher added 1) the identifying file information (e.g., case number), 2) masculinity threat present (1) or not (0), and 3 ) the sequence in which the threat(s) occurred, to the previously discussed existing dataset.

Final measures for current project

With the additional data coded, the following variables were used in the current project:

First Officer Force. This measure represents the amount of force used by the officer the first time an officer uses force in a suspect-officer interaction. Said another way, this measure represents the level of force an officer uses the first time they use force that is greater than " 0 " on the Officer Actions continuum variable outlined in the measures from the original data set. 
Average Officer Force. This measure represents the average amount of force used by the officer the across the suspect-officer interaction. Average officer force was calculated by summing the force levels across all sequences in the interaction and dividing by the number of sequences in the interaction.

Average suspect resistance. This measure represents the average resistance a suspect uses throughout the interaction with an officer. Average suspect resistance was calculated by summing the suspect resistance levels across all sequences and dividing by the number of sequences in the interaction.

Maximum Officer Force. This measure represents the highest amount of force used by the officer at any point within the interaction.

Last Officer Force. This measure represents the last or ultimate amount of force used by officer during the interaction.

Masculinity threat code. The measure indicates whether a threat to the officer's masculinity has occurred via the suspect's verbal or physical behaviors. This measure is dichotomous (dummy coded), with 0 representing no masculinity threat present in the sequence, and 1 representing masculinity threat present in the sequence. Each sequence (within an interaction) has a measure of 1) whether masculinity threat occurred or not and 2) the type of masculinity threat present and also is denoted as either physical (e.g., pounding chest) or verbal (e.g., officer having his strength questioned) or involving both types.

Preliminary Power Analyses. A preliminary coding of the use of force files before the official analyses began estimated between 29-35 use of force incidents in 
which a masculinity threat by the suspect towards the officer was present. This estimate was used to test apriori power analyses. In regards to Hypothesis 1a-d (which explored how global masculinity threats are related to force at different points during an officersuspect interaction), and Hypothesis 1e (which explored how global masculinity threat relates to sequence length within an interaction) $G^{*}$ Power sensitivity analyses (e.g., minimal detectable effect size) were run since the sample size was constrained. Sensitivity analyses indicated that a minimal effect size of .48 would be necessary in order to have sufficient power at $80 \%$ for Hypothesis 1a-e with $\mathrm{N}=70$ (35 masculinity threat cases, 35 control cases). Since past research has shown a large effect size $(d=.81)$ for physical aggression as a compensatory response to masculinity threat (Bosson et al., 2009), Hypothesis 1 should have had sufficient power to reject the null hypothesis.

Hypothesis 2 explored how masculinity threat relates to officer use of force at the sequence level in the interaction. Several forms of power analyses were run for Hypothesis 2a-b. For Hypothesis 2a, a sensitivity power analysis was conducted which revealed that for a paired sample T-Test with total sample size of 70, an effect size of .40 would be necessary. Drawing again from Bosson et al. (2009) that found a large effect size of masculinity threat $(d=.81)$, Hypothesis 2 a should have had sufficient power to correctly reject the null hypothesis. For Hypothesis $2 b$, a sensitivity power analysis revealed that with a sample size of 20 (approximately 10 following first threat versus 10 following second threat), an effect size of .93 would be necessary. In order to contextualize this sensitivity test, I ran a post-hoc power analysis which revealed that 
with 10 data points in each group $(\mathrm{N}=20)$ and a large estimated effect size $(d=.81)$, again drawn from Bosson et al., (2009), power was estimated at 68\%.

Hypothesis 3 predicted that racial minority suspects will bear the brunt of officer masculinity threat more than their White counterparts at the interaction level. A sensitivity power analysis revealed that with the preliminary sample size (12 White, 16 minority suspects), an effect size of .78 is necessary to reach statistical power of $80 \%$. Additionally, post-hoc analyses revealed that with the preliminary sample size and estimated effect (again drawn from Bosson et al., 2009; $d=.81$ ), power of $80 \%$ would be reached.

\section{Results}

Overall, 61 officer use of force narratives were coded for the analyses. Due to the very strict prototypical definition used to train coders on masculinity threat, $100 \%$ agreement was reached on the masculinity threat codes. Table 2 reports frequencies of suspect race and condition (masculinity threat versus no masculinity threat). Thirty-four cases were coded as having no reported masculinity threat present (Global Masculinity Threat $=0 ; n=34$ ), while 27 cases were coded as having masculinity threat present (Global Masculinity Threat $=1 ; n=27)$. All reporting officers and suspects were men. Of the 61 suspects, 18 are Black men, 18 are Hispanic men, 1 is an Asian man, and 24 are White men. The reporting officer demographic information was not available due to confidentiality, but possible implications of officer demographics can be found in the discussion section of this thesis. For Hypothesis 3, Black and Latino men were included as the racial minority group, and the one narrative involving an Asian male suspect was 
excluded from the analyses, since stereotypes of hyper-masculinity apply primarily to Black and Latino men (Rios, 2009). Based on these parameters, 60 of the 61 coded narratives were used for analysis of Hypothesis 3.

Table 3 reports means, standard deviations, and correlations for the variables of interest. On average, suspect resistance was generally low on the continuum of force across the dataset $(M=2.10, S D=.72)$, as was first officer force $(M=1.38, S D=.78)$ and average officer force $(M=2.12, S D=.59)$. As expected, maximum officer force $(M$ $=3.84, S D=.90)$ was higher across the dataset, as was last officer force $(M=3.38, S D=$ 1.13). These preliminary analyses suggest a general trend towards increasing force as an interaction progresses. Average suspect resistance correlated significantly with average officer force and maximum officer force. Of note, as the number of sequences in an interaction went up, the level of average officer force went down.

Tests of the assumptions of multiple regressions were conducted. The primary concern that arose from these tests was of the normality of the variables. The distribution of errors was more normal for some variables than others but upon counsel from the methods expert on this thesis committee, it was suggested that the normality was not so off as to negate the normality assumption nor is it within the scope of the current project to perform a log-transformation. The residual plot was examined and the distribution of residuals indicated that there was homogeneity of variances. Multicollinearity was tested by examining the variance inflation factors (VIF) and all variables had VIF levels below the suggested level (5) indicating no multicollinearity. 
All cases that were analyzed had at least two sequences documented between the suspect and the officer. Upon coding of the data, no cases had only physical masculinity threat present and therefore no analysis could be performed to examine differences between types of threat (verbal versus physical).

Analysis of Hypotheses

Research Question 1: How does masculinity threat relate to use of force at the overall interaction level?

Results of the following hypothesis tests are associated with the regression equations specified below. For Hypotheses $1 \mathrm{a}-\mathrm{d}, \mathrm{X}_{1}$ represents masculinity threat (present versus not), and $\mathrm{X}_{2}$ was specified as a covariate, which represents the average suspect resistance (calculated as the sum of suspect resistance levels across sequences divided by the number of sequences in the interaction) to control for the amount of force the suspect used against the officer.

Hypothesis 1a (First Officer Force). It was predicted that police-suspect interactions that involve masculinity threat to the officer would relate to greater initial use of force in the interaction compared to non-masculinity threat interactions. The following regression equation was used to evaluate this hypothesis,

$\mathrm{Y}_{\mathrm{FOF}}=b_{0}+b_{1} \mathrm{X}_{1, \mathrm{MT}}+b_{2} \mathrm{X}_{2, \mathrm{ASR}}+\varepsilon$

FOF $=$ First Officer Force; MT= Masculinity Threat; ASR = Average Suspect

Resistance 
Results from a multiple regression analysis suggests that masculinity threat directed at the officer and average level of suspect resistance during the officer-suspect interaction did not explain a significant amount of the variance in first instance of officer force $\left[R^{2}=.01, F(2,58)=.37, p=.69\right]$. Global masculinity threat did not significantly predict level of force used by the officer in their first instance of using force, $(b=-.10$, se $=.20, \mathrm{CI}:-.50$ to $.31, p=.64)$, see Figure 1 . These results suggest that masculinity threat directed at a police officer at the global level does not significantly relate to first instance of officer use of force. Specifically, the observed beta coefficient for the MT variable $\left(b_{1}\right)$ is neither significant nor positive when controlling for average levels of suspect resistance. Therefore, Hypothesis 1a is not supported.

Hypothesis $1 \mathrm{~b}$ (Average Officer Force). It was hypothesized that police-suspect interactions that involve masculinity threat directed toward the officer would predict greater average force used throughout the interaction, controlling for average suspect resistance throughout the interaction. The following regression equation was used to examine this hypothesis,

$\mathrm{Y}_{\mathrm{AOF}}=b_{0}+b_{1} \mathrm{X}_{1, \mathrm{MT}}+b_{2} \mathrm{X}_{2, \mathrm{ASR}}+\varepsilon$

$\mathrm{AOF}=$ Average level of Officer Force; MT= Masculinity Threat; ASR = Average Suspect Resistance

Results from a multiple regression analysis suggest that masculinity threat directed at the officer at the global level in combination with average suspect resistance accounted for a significant amount of variance in average level of officer force $\left[R^{2}=.37, F(2,58)=\right.$ 
17.21, $p<.001]$. Controlling for average level of suspect resistance, global masculinity threat had a significant negative relation to average officer force $(b=-.28, s e=.12$, CI: .53 to $-.04, p=.03$ ), see Figure 2 . Officer-suspect interactions that involve masculinity threat are associated with lower levels of officer force. After controlling for average suspect resistance, officers who experience masculinity threat use less force than officers who did not experience masculinity threat. It was hypothesized that the coefficient $b_{1}$ would be significant and positive, indicating higher levels of average force exerted by officers when masculinity threat is present than when it is not, controlling for average levels of suspect resistance throughout the interaction. Since $b_{1}$ is significant but negative, Hypothesis $1 b$ is not supported.

Hypotheses 1c (Maximum Officer Force). It was hypothesized that policesuspect interactions that involve masculinity threat will include greater maximum force used in the interaction than officer-suspect interactions that do not include masculinity threat. The following regression equation was used to examine this hypothesis,

$\mathrm{Y}_{\mathrm{MAX}}=b_{0}+b_{1} \mathrm{X}_{1, \mathrm{MT}}+b_{2} \mathrm{X}_{2, \mathrm{ASR}}+\varepsilon$

MAX $=$ Maximum Officer Force; MT= Masculinity Threat; ASR = Average

Suspect Resistance

A multiple regression analysis revealed that masculinity threat and average suspect resistance did not account for a significant amount of the variance in maximum officer force $\left[R^{2}=.07, F(2,58)=2.28, p=.11\right]$. Controlling for average level of suspect resistance, masculinity threat at the global interaction level is not significantly associated 
with maximum officer force, $(b=-.09$, se $=.23$, CI: -.55 to $.37, p=.69)$, see Figure 3 . Since the observed beta coefficient, $b_{1}$, is neither significant nor positive, results do not support Hypothesis 1c.

Hypotheses 1d (Last Officer Force). It was predicted that police-suspect interactions that involve masculinity threat will involve higher levels of force used in the last sequence of officer force within the interaction. The following regression equation was used to examine this hypothesis,

$$
\mathrm{Y}_{\mathrm{LOF}}=b_{0}+b_{1} \mathrm{X}_{1, \mathrm{MT}}+b_{2} \mathrm{X}_{2, \mathrm{ASR}}+\varepsilon
$$

LOF $=$ Last Instance of Officer Force; MT= Masculinity Threat; ASR = Average Suspect Resistance

Results from a multiple regression analysis revealed that masculinity threat and average suspect resistance did not account for a significant amount of the variance in last officer force $\left[R^{2}=.07, F(2,58)=2.15, p=.13\right]$. Controlling for average level of suspect resistance, masculinity threat does not significantly relate to level of last officer force ( $b$ $=.20, s e=.29, \mathrm{CI}:-.38$ to $.77, p=.50$ ), see Figure 4 . Officer-suspect interactions that involve masculinity threat are not significantly associated with higher levels of last officer force compared to officer-suspect interactions that do not involve masculinity threat. Since the beta coefficient, $b_{1}$, is not significant, results do not support Hypothesis $1 d$. 
Hypotheses 1e (Number of Sequences). It was predicated that officer-suspect interactions that involve masculinity threat would end more quickly and therefore have less sequences in the interaction than officer-suspect interactions that do not involve masculinity threat.

In order to test whether officer-suspect interaction length (defined by number of sequences within an interaction) differed significantly between officer-suspect interactions that involved masculinity threat and officer-suspect interactions that did not involve masculinity threat, an independent-samples $t$-test was used. Results indicate that officer-suspect interactions that involve masculinity threat have a significantly higher number of sequences $(M=7.07, S D=2.85)$ than officer-suspect interactions that do not involve masculinity threat $(M=4.35, S D=1.92), t(59)=-4.44, p<.001$, see Figure 5 . While there is a significant difference in sequence number between interactions that involve masculinity threat and interactions that do not, the results are in the opposite direction as predicted, therefore Hypothesis 1e is not supported.

Research Question 2: How do masculinity threats that occur during an officer-suspect interaction relate to force at specific points of time in the interaction?

Hypothesis 2a. It was predicted that the level of force used immediately following a masculinity threat would be significantly higher than the level of force used immediately prior to the masculinity threat. To test this hypothesis, a paired sample $t$-test was conducted with one group representing the level of force immediately before a masculinity threat (defined as the level of force used in the sequence prior to the masculinity threat) and the other group representing the force subsequent to the threat 
(defined as the level of force used in the sequence immediately following the masculinity threat). A paired-samples $t$-test was conducted because use of force prior to threat and use of force following threat come from the same cases.

Results revealed a marginally significant difference between use of force prior to masculinity threat $(M=1.39, S D=1.09)$ and use of force following masculinity threat $[(M=1.74, S D=1.24), t(31)=-1.88, p=.07]$, see Figure 6 . While it seems that use of force prior to masculinity threat is lower than use of force following a masculinity threat, the result of the $t$-test was not significant at the .05 level. Therefore, Hypothesis $2 \mathrm{a}$ is marginally supported.

Hypothesis $2 \mathrm{~b}$. Hypothesis $2 \mathrm{~b}$ focused on interactions that have multiple instances of masculinity threat, and how they differentially relate to use of force. It was predicted that the first masculinity threat in a multiple masculinity threat interaction would relate to the largest increase in police use of force, in that it would elicit the highest change in officer force compared to subsequent later masculinity threats in the same interaction. The intraclass correlation coefficient of these data $(\rho=.41)$ indicated that approximately $41 \%$ of the variance in use of force is between interactions.

Therefore, a multilevel model (below) was estimated to show whether use of force varied significantly across time points within an interaction involving masculinity threat.

$$
\begin{aligned}
& \mathrm{Y}_{\mathrm{MAX}}=\beta_{0}+\beta_{1(\text { control achieved prior) }}+\beta_{2 \text { (suspect resistance prior) }}+\varepsilon . \\
& \beta_{0}=\pi_{00}+\pi_{01(\mathrm{MTC})} \\
& \mathrm{MTC}=\text { Masculinity Threat Count }\left(1^{\text {st }} \text { instance, } 2^{\text {nd }} \text { instance }\right)
\end{aligned}
$$


The original model, as shown above, predicted that important control variables would be level of suspect resistance prior to masculinity threat, and control achieved by officer prior to masculinity threat. However, due to very low sample size, this model could not converge, and so they were not included in the final analysis. Results indicated that the average use of force was .46 at time point 1 during an interaction involving masculinity threat. Masculinity threat count (e.g., $1^{\text {st }}$ threat, $2^{\text {nd }}$ threat and so on) did not significantly relate to use of force, $\left(\gamma_{10}=-.05, S E_{\tau 0}=.26, p=.83\right)$. Hypothesis $2 \mathrm{~b}$ cannot be tested fully and is therefore not supported in its current form.

Research Question 3: Does the interaction of suspect race and masculinity threat relate to officer use of force?

Results of the following hypothesis are associated with the outlined regression equations. For hypothesis testing of Research Question 3, suspect race is a binary predictor, with White suspects in one group and Black and Latino suspects in the comparison group (White suspects $=0$, Black and Latino suspects $=1$ ). As in Hypothesis 1a-d, use for force was examined in multiple ways in the interaction (i.e., first officer force, average officer force, maximum officer force, and last officer force) and average suspect resistance is specified as a control variable.

Hypothesis 3a (First Officer Force). It was predicted that a suspect race $\mathrm{x}$ masculinity threat interaction would be found, indicating that higher levels of first instance of officer force would be used against racial minority suspects who threaten officer masculinity compared to White suspects who threaten officer masculinity. The following regression equation was used to test this hypothesis, 


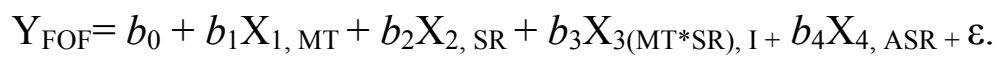

FOF $=$ First Instance of Officer Force; MT = Masculinity Threat; SR $=$ Suspect

Race; I = Interaction of MT \& SR; ASR = Average Suspect Resistance

Results of this multiple regression model showed that masculinity threat, suspect race, the interaction of masculinity threat and suspect race, and average suspect resistance as a covariate, did not explain a significant amount of the variance in the level of first instance of officer force $\left[R^{2}=.02, F(4,55)=.31, p=.87\right]$. No significant main effects were found for masculinity threat $(b=.10, s e=.35, \mathrm{CI}:-.59$ to $.77, p=.77)$ nor suspect race $(b=.08, s e=.29, \mathrm{CI}:-.50$ to $.67, p=.78)$, and no interaction effects were found $(b$ $=-.33, s e=.45, \mathrm{CI}:-1.22$ to $.57, p=.47$ ), see Figure 7 . Since no significant interaction beta was found, results did not support Hypothesis $3 a$.

Hypothesis $3 b$ (Average Officer Force). It was predicted that a suspect race by masculinity threat interaction would be found, such that higher levels of average officer force would be used against racial minority suspects who threaten officer masculinity compared to White suspects who threaten officer masculinity. The following regression equation was used to test this hypothesis,

$$
\mathrm{Y}_{\mathrm{AOF}}=b_{0}+b_{1} \mathrm{X}_{1, \mathrm{MT}}+b_{2} \mathrm{X}_{2, \mathrm{SR}}+b_{3} \mathrm{X}(\mathrm{MT} * \mathrm{SR}), \mathrm{I}+b_{4} \mathrm{X}_{4, \mathrm{ASR}+} \varepsilon
$$

$\mathrm{AOF}=$ Average Officer Force; MT = Masculinity Threat; SR = Suspect Race; I

$=$ Interaction of MT \& SR; ASR = Average Suspect Resistance 
A significant amount of variance in the amount of average force used by an officer in an interaction $\left[R^{2}=.41, F(4,55)=9.89, p<.001\right]$ was explained by masculinity threat, suspect race, the interaction between masculinity threat and suspect race, and average suspect resistance. No significant main effects for masculinity threat ( $b$ $=-.20, s e=.20, \mathrm{CI}:-.61$ to $.21, p=.34)$ nor suspect race $(b=-.18, s e=.17, \mathrm{CI}:-.52$ to $.17, p=.31)$ were found. The interaction of masculinity threat and suspect race $(b=$ $.10, s e=.26$, CI: -.63 to $.43, p=.7$ ) was also not significant, see Figure 8 . Since there was no significant interaction beta, Hypothesis $3 \mathrm{~b}$ is not supported.

Hypothesis 3c (Maximum Officer Force). It was predicted that a suspect race by masculinity threat interaction occurs in which higher levels of maximum force will be used against racial minority suspects who threaten officer masculinity compared to White suspects who threaten officer masculinity. The following regression model was used to guide this hypothesis test,

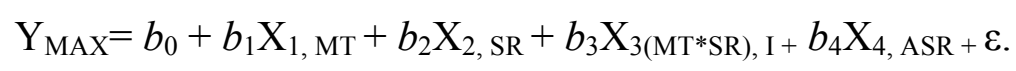

MAX = Maximum Officer Force; MT = Masculinity Threat; SR = Suspect

Race; I = Interaction of MT \& SR;ASR = Average Suspect Resistance

Results of the model indicated that masculinity threat, suspect race, the interaction there-of and average suspect resistance did not explain a significant amount of variance in the maximum amount of force used by an officer $\left[R^{2}=.12, F(4,55)=1.85, p=.13\right]$. 
There were no significant main effects of masculinity threat $(b=.37$, $s e=.38$, CI: -.39 to $1.13, p=.33)$ or suspect race $(b=.21, s e=.32$, CI: -.43 to $.86, p=.52)$ and no significant interaction between subject race and masculinity threat $(b=-.71, s e=.49$, CI: -1.70 to $.27, p=.15$ ), see Figure 9. Since no significant interaction beta was obtained, Hypothesis $3 \mathrm{c}$ is not supported.

Hypothesis 3d (Last Officer Force). Hypothesis 3d focuses on last amount of officer force (that is above " 0 ") as related to suspect race and masculinity threat. It was predicated that a suspect race by masculinity threat interaction occurs in which last instance of officer force will be higher against racial minority suspects who threaten officer masculinity compared to White suspects who threaten officer masculinity. The following regression equation was used to guide this hypothesis test,

$$
\mathrm{Y}_{\mathrm{LOF}}=b_{0}+b_{1} \mathrm{X}_{1, \mathrm{MT}}+b_{2} \mathrm{X}_{2, \mathrm{SR}}+b_{3} \mathrm{X}_{(\mathrm{MT} * \mathrm{SR}), \mathrm{I}}+b_{4} \mathrm{X}_{4, \mathrm{ASR}}+\varepsilon
$$

LOF $=$ Last Instance of Officer Force; MT = Masculinity Threat; SR = Suspect Race; I = Interaction of MT \& SR; ASR = Average Suspect Resistance

Masculinity threat, suspect race, the interaction there-of, with average suspect resistance as a covariate, did not explain a significant amount of variance in the amount of force used by an officer the last time he used force in an interaction $\left[R^{2}=.12, F(4,55)=1.91\right.$, $p=.12]$. No significant main effects were found for masculinity threat $(b=.26, s e=.48$, CI: -.70 to $1.21, p=.59)$ or suspect race $(b=-.42, s e=.40, \mathrm{CI}:-1.23$ to $.38, p=.3)$ and no significant interaction between subject race and masculinity threat was found $(b=$ - 
$.02, s e=.61, \mathrm{CI}:-1.25$ to $1.21, p=.98)$, see Figure 10 . Since no significant interaction beta was found, Hypothesis $3 \mathrm{~d}$ is not supported.

Hypothesis 3e (Number of Sequences). It was predicted that a suspect race by masculinity threat interaction occurs in which minority suspects who threaten officer masculinity will have shorter interactions (e.g., fewer sequences) with officers than White suspects who threaten masculinity. The following regression equation was used to guide this hypothesis test,

$\mathrm{Y}_{\mathrm{NS}}=b_{0}+b_{1} \mathrm{X}_{1, \mathrm{MT}}+b_{2} \mathrm{X}_{2, \mathrm{SR}}+b_{3} \mathrm{X}_{(\mathrm{MT} * \mathrm{SR}), \mathrm{I}+} \varepsilon$

NS = Number of Sequences; MT = Masculinity Threat; SR = Suspect Race; I = Interaction of MT \& SR

Results indicated that masculinity threat, suspect race, the interaction there-of and average suspect resistance explained a significant amount of variance in the number of sequences in the interaction $\left[R^{2}=.29, F(4,55)=5.65, p=.001\right]$. A significant main effect was found for masculinity threat ( $b=3.00, s e=1.03$, CI: .95 to 5.06, $p=.005)$, suggesting that when a masculinity threat occurs, the number of sequences in an interaction increase by 3 sequences. No main effect was found for suspect race $(b=-.15$, $s e=.87, \mathrm{CI}:-1.89$ to $1.59, p=.87$ ) and no significant interaction between subject race and masculinity threat was found $(b=-.36, s e=1.33, \mathrm{CI}:-3.01$ to $2.30, p=.79)$, see Figure 11. Consistent with the results from Hypothesis 1e, the main effect of masculinity threat on number of sequences is again supported, although in the opposite direction than originally predicted. However, there is no significant interaction beta, and therefore Hypothesis $3 \mathrm{e}$ is not supported. 
Observed Power Analyses. As described earlier, apriori power analyses were run based on the preliminary sample size and the estimated effect size of masculinity threat based on previous masculinity threat research (Bosson et al., 2009). These preliminary power analyses suggested that hypotheses may be slightly underpowered, but not greatly so (see Methods for initial power analyses). However, G*Power post hoc analyses revealed that several hypotheses were well under the suggested .80 cutoff (Faul \& Erdfelder, 1992; Howell, 2013).

Hypotheses above $80 \%$ power. For both Hypothesis $1 \mathrm{~b}$ and $1 \mathrm{e}$, power was well above the $80 \%$ threshold at $99 \%$ and $98 \%$, respectively. Like Hypothesis $1 \mathrm{~b}$ and $1 \mathrm{e}$, Hypothesis $3 \mathrm{~b}$ and $3 \mathrm{e}$ were sufficiently powered to correctly reject a false null hypothesis with $99 \%$ and $98 \%$ power respectively.

Hypotheses below $80 \%$ power. Post hoc observed power analyses indicated that for Hypothesis 1a, 1b, 1c, and 1d, power to correctly reject a false null hypothesis was well below the suggested $80 \%$ (respectively, observed power was $11 \%$ for $\mathrm{H} 1 \mathrm{a}$, and $44 \%$ for H1c and H1d). As for Hypothesis $2 \mathrm{a}$, there was a $73 \%$ chance of correctly rejecting a false null. While power at $73 \%$ isn't particularly low, it also does not meet the common standard. Hypothesis $2 \mathrm{~b}$ was well underpowered. Hox (2010) estimates that if a multilevel model has less than 5 cases per group (in this case, less than 5 cases per $1^{\text {st }}, 2^{\text {nd }}$ or $3^{\text {rd }}$ masculinity threat) and less than 50 groups (there are only 3 groups max) the model will be well under power and unlikely to converge, as our analysis confirmed. Post hoc power analyses for Hypothesis 3a, 3c, and 3d also indicated a lower power to correctly reject a false null hypothesis (observed power was $11 \%$ for $\mathrm{H} 3 \mathrm{a}$, and $57 \%$ for $\mathrm{H} 1 \mathrm{c}$ and 
H1d). These results suggest that had a larger sample size or larger effect sizes been obtained, our power to correctly reject the null hypothesis might have been greater. The consequences of this lack of statistical power are discussed in the discussion section of this paper.

Suppression. Suppression occurs when the relationship between two predictor variables conceals the relationship that each variable has with the outcome variable (Cohen, Cohen, West \& Aiken, 2003). The results of suppression in regression analyses can be that one of the beta coefficients flips signs (becoming negative or positive when alone it is the opposite direction). Since the beta coefficients in the analyses were consistently negative, opposite of the prediction made in the hypotheses, I tested the models for suppression. By running each analysis as a simple regression with no control, e.g., without average suspect resistance, the beta coefficients did not flip signs. Said another way, when masculinity threat was the only predictor of force, the beta coefficients remained negative - they were not positive when excluding average suspect resistance from the model. This indicates that suppression is not taking place within these models and indeed the negative beta coefficients associated with masculinity threat are valid.

\section{Discussion}

The present study investigated whether a masculinity threat directed towards a police officer during an interaction with a suspect related to the amount of force the officer used during the interaction. Research Question 1 explored how masculinity threat relates to use of force at the overall interaction level. I predicted that the first instance, 
average, maximum and last instance of officer force would be higher in interactions that included masculinity threat at any point within the interaction and that sequence length would be shorter. Research Question 2 explored whether multiple masculinity threats that occur during an officer-suspect interaction relate to force at specific time points in the interaction. I predicted that the level of force used following a masculinity threat would be higher than the level of force used prior to the masculinity threat and that the first masculinity threat in a multiple masculinity threat interaction would be associated with the greatest increase in use of force compared to second and third masculinity threats. Research Question 3 explored whether a suspect race and masculinity threat interaction relates to officer use of force. I predicted that the first instance, average, maximum, and last instance of officer force would relate to the interaction between suspect race and masculinity threat, in that Black and Latino suspects who threatened officer masculinity would experience greater officer force than White suspects who threatened officer masculinity.

Results of this study suggest some unexpected, if not complex, relations between masculinity threat and officer use of force. Results of Research Question 1 suggest that masculinity threat is associated with significantly lower levels of average officer force, when controlling for average suspect resistance (Hypothesis 1b). Officer-suspect interactions that do not involve masculinity threat are significantly shorter in number of sequences than officer-suspect interactions that do involve masculinity threat (Hypothesis 1e). These results suggest that masculinity threat is associated with less force and longer interactions (in terms of sequences). Perhaps officer-suspect interactions that involve 
masculinity threat are associated with more de-escalating behaviors (e.g., speaking slowly and at a normal volume and not closing in too close physically) from the officer which would increase the number of sequences in an interaction and mean less force being used on average. Alternatively, since most of the documented masculinity threats were verbal, these results could indicate that the masculinity threats themselves inspire more dialogue, as opposed to physical action, from the officer which would be consistent with less average force and higher number of sequences (because verbal exchanges count as sequences within the interaction). However, analyses of Hypothesis 1a (first instance of officer force), Hypothesis 1c (maximum officer force) and Hypothesis 1d (last instance of officer force) were not significant. Taken together, no definitive conclusions can be drawn about global masculinity threat's association with use of force across a broad range of outcomes since only two of the hypotheses showed significant relations in the direction opposite of predictions.

While no definitive conclusions can be drawn, theory might provide a possible explanation for these results. Police officers who are higher in trait masculinity threat may be less likely to report state masculinity threat due to their heightened awareness of the consequences of admitting such an experience (Goff et al., 2016; Richardson \& Goff, 2015). For example, an officer who is naturally higher in trait masculinity threat might underreport a suspect calling him a term associated with femininity in order to maintain the perception of his authority and to allow him to justify force as a compensatory response without breaching his duty to diffuse a conflict. If this occurred, this narrative would have been coded as a no-masculinity threat case, confounding the analyses. On the 
other hand, an officer low in trait-masculinity threat may not see any harm to his masculine identity in reporting exactly what the suspect did or said. This officer, being less likely to experience a masculinity threat than his high-trait masculinity counterpart, would be less likely to enact a compensatory response, in this case, increased use of force.

Interpretation of Research Question 2 is less consistent in light of findings from Research Question 1. When examining the specific time point within the interaction where masculinity threat occurred, use of force prior to masculinity threat was marginally lower than officer force following masculinity threat (Hypothesis 2a). While not significant at the .05 level, this does suggest that for each individual instance of masculinity threat in the sample, officer force tended to be higher immediately following masculinity threat compared to force prior to the threat. The direction of the results in Hypothesis $2 \mathrm{a}$ (which did not include the covariate average suspect resistance) best match experimental findings on masculinity threat, since published results show an increase in physical aggression following a threat to a man's masculinity and an increase in male gender roles stress following a threat to a male police officer's masculinity (Goff et al., 2012; Weaver et al., 2009). Perhaps, in the moment, masculinity threats lead to greater use of force because the officers use physical control tactics to keep the situation with the suspect from escalating further. Verbal masculinity threats are represented as suspect verbal resistance (which is categorized as level 2 in the suspect resistance continuum), and an increase above verbal commands from the officer (e.g., the officer using physical control tactics) in response to the suspect could explain this marginal increase between 
force prior to force following threat. If this is the case, perhaps officers consider verbal masculinity threats to be warning signs of impending physical non-compliance and attempt to get ahead of it by increasing their immediate force, without it impacting their average level of force during the interaction (Hypothesis 1b). However, since there isn't a significant association between masculinity threat and other officer force outcomes, these postulations lack consistent support. Additionally, the temporal sequencing of multiple masculinity threats within an interaction did not significantly impact the change between force prior to threat and force following threat (Hypothesis 2b). Due to very small sample size, Hypothesis $2 \mathrm{~b}$ was not able to converge with the hypothesized covariates of suspect force prior and officer control achieved prior, so no conclusive statements can be made regarding how multiple masculinity threats during an interaction might differentially impact officer force depending on which threat it was (e.g., first threat, second threat and so on).

Analysis of Research Question 3 did not reveal any significant statistical interactions between suspect race and masculinity threat. In this sample, racial minority men who threaten officer masculinity do not experience heightened officer force compared to their White counterparts. Of note is that results from Hypothesis $3 b$ (that examined how the suspect race $\mathrm{x}$ masculinity threat interaction related to average use of force) were not significant, even though Hypothesis $1 \mathrm{~b}$ (which examined how masculinity threat related to average officer force) was significant. Both models included the covariate average suspect resistance, but when suspect race was added into the model, enough of the variance was accounted for by suspect race that masculinity threat was no 
longer significantly associated with average suspect resistance even though it was significantly related in Hypothesis $1 \mathrm{~b}$. Therefore, suspect race and masculinity threat may be sharing some variance.

While Research Question 3 did not suggest significant differences in use of force for minority versus White suspects, these findings need to be contextualized to not draw focus from the injustice of disparate use of force against racial minorities in the United States. As discussed in the literature review in this thesis, racial minorities experience disparate use of force across the United States (Fachner \& Carter, 2015; Jones, 2015; Klahm et al., 2011) and there are several contributing factors that could explain why no significant results were found in this particular study. Research has shown that phenotypically prototypical minorities suffer more consequences of racial bias than their less prototypical counterparts (Eberhardt et al., 2004) and White men who are low in phenotypic protoypicality are more likely to receive force than their more prototypical counterparts (Kahn, Goff, Lee, \& Motamed, 2016). Therefore, differences may exist at the within race level that demonstrate racial disparities that are masked at the group level. It is also important to note that explicit and implicit biases contribute to disparities in police stops and police calls, not just police force, which means that minority men are more likely to have interactions with the police than their white counterparts, regardless of whether force was used or not (Goff \& Kahn, 2012). Research examining racial disparities within use of force has also demonstrated that while minority suspects may not always receive more maximum or final force than White suspects, they receive force earlier in the interaction compared to Whites, again demonstrating the disparate outcomes 
in policing for minority group members (Kahn et al., 2016). Taken together, these research findings point to the weighty issue of racial bias facing our policing system, and should not be discounted due to the non-significant results of this study.

There are some additional factors that could have contributed to these findings that I discuss below, however there is no way of empirically investigating whether these factors impacted the current findings. A great deal of past research has demonstrated a statistical relation between suspect race and officer force (Fachner \& Carter, 2015; Kahn et al., 2016; Klahm et al., 2011), but results of this study suggest that state level masculinity threat that occurs during an interaction between an officer and a suspect does not interact with suspect race to contribute unique predictive validity above and beyond suspect race. One possible explanation could be that when officers who are in positions of power and authority have an aspect of their identity threatened, like their manhood, they do not feel the need to compensate with greater force overall. Indeed, some previous research has shown that when White men are faced with bias based on their race, no masculinity threat is experienced because they rely on feelings of superiority and power in that social identity and do not compensate with aggression (Goff et al., 2012). Even though the results are based on lab studies of racial discrimination and this project relied on coding masculinity threat in archival data, considering the findings together, one possible explanation is that perhaps in-the-moment use of force by police officers after receiving a masculinity threat from a minority suspect is mitigated by an officer's already authoritative status. 
Aside from the differences in the global interaction level and sequential examination of use of force as they relate to masculinity threat, it is possible that recent nationwide focus on officer awareness of biases have contributed to these results. In general, police trainings that have addressed masculinity threat within certain police departments could be contributing to less force being used at the global level when a masculinity threat occurs, although there is no evidence that such a training has occurred at the police department from which the files originated. These trainings, which focus on educating and mitigating the effects of the culture of masculinity within policing, can impact officer's decisions to use force and pursue suspects (Kahn, Goff \& Glaser, 2016). Perhaps these types of initiatives are providing resources for officers that help mitigate potentially negative impacts of masculinity threats, which could be one explanation for why masculinity threat is associated with less average force at the global interaction level.

\section{Limitations}

While results from this study provided information regarding the way average officer force and sequence length relate to state masculinity threat at the global level within an un-simulated officer-suspect interaction, there are limitations. First, the perspective of the suspect was not available and therefore couldn't be matched to the officer(s) first-person narrative account of the use of force incidents. Therefore, an important point of view is left out of this analysis. The masculinity threat that each party (suspect and officer, respectively) experiences potentially contributes to the respective force used during the interaction. Ideally researchers would have access to this other 
perspective (that of the suspect) in order to utilize an Actor-Partner Interdependence Model (Cook \& Kenny, 2005). Since no suspect perspective is available, the suspect point of view is left out of this project and no objective perspective of masculinity threat's occurrence is available (i.e., only the officers' subjective experience is taken into account).

Second, there is no comparison between suspect-police interactions when force is not present. It is possible that there is an association between masculinity threat and the presence versus absence of police use of force. However, because the primary concern of this research is predicting how disparities in levels of use of force relate to threats to masculinity, it was necessary to examine files that include some level of force.

Interactions between police officers and suspects that do not result in use of force do not have a first person narrative requirement. This means that no conclusive statements can be made regarding whether masculinity threat impacts interactions that do not involve force.

Third, some of this study's hypotheses were statistically underpowered. Use of force data is confidentially located within each police department across the United States, and each department has their own ways of recording and operationalizing policesuspect use of force data. Due to this limited access, the current project was greatly underpowered and is therefore susceptible to type II error, which is a failure to reject a false null hypothesis. It is possible that the non-significant results obtained are not indicative of the true relationship between masculinity threat and force, particularly for Hypothesis 1c, 1d, 3c and 3d. Hypothesis 2b, which utilized multilevel regression to 
understand how multiple masculinity threats relate to changes in officer force, could not converge with the appropriate control variables due to a very small sample size ( 7 cases total). This leaves a gap in our understanding of how multiple masculinity threats (in one officer-suspect interaction) may relate to officer use of force based on their temporal sequencing. It is possible that if this test were not underpowered, I could have achieved clarity around which, if any, of multiple masculinity threats are associated with the highest increases in officer force.

Fourth, since these data have only come from one police department in the U.S., it is possible that the current findings do not generalize to other departments. The specific geography, the political atmosphere as well as the history of intergroup conflict present in the city from which the files originated creates issues for generalizability. Each police department in the U.S. is faced with its own level of rural versus urban climate, bureau politics, and city politics that can impact the way officers are trained to use force and the support officers have from community members. These types of differences present a challenge to generalizability.

Fifth, causal conclusions about the relationships among the measured variables cannot be drawn, as the three conditions that allow for causality via internal validity (temporal precedence, covariation of cause and effect, and ruling out alternative associations between variables) are not all present within these secondary data. Specifically, since there was no systematic manipulation of masculinity threat alternative explanations cannot be ruled out. It is also important to keep in mind that these reports are written by officers who are under certain mandates and restrictions and could very 
well be concealing the true circumstances of the situation that preceded the use of force. Officers may be motivated to do this in order to bolster the rationale behind their decisions, as a use of force decision that is not in line with a suspect's non-compliance can lead to disciplinary action. Not unlike social desirability effects, officers are motivated to narrate the interaction with a suspect through a lens that makes their actions as officers appear justified and necessary. For example, it is possible that masculinity threat did occur in narratives that were coded as containing no masculinity threat, but the officers didn't write that into their narrative because they didn't want to draw attention to that aspect of the interaction, especially if it involved a minority suspect. It is important to note that while this motivation to avoid seeming biased might mask differences in general, research that does not rely on first-person narratives has found that racial bias impacts use of force decisions, and these narratives have already shown some racial differences in use of force application (Kahn al., 2016).

Another important consideration for these findings is the correlational nature of these data. Much of the masculinity threat literature in social psychology has utilized experimental methods, which likely have lower mundane realism, and have resulted in higher effect sizes, since a very specific manipulation is being conducted in a controlled setting. When comparing the effect sizes of the results of the current study to the effect sizes of the previously cited experimental works on masculinity threat, there is a discrepancy. Experiments on masculinity threat show large effect sizes for aggression following a masculinity threat, while the effect sizes found in the present study were 
small. This helps to explain the underpowered results of this thesis as discussed in the power analysis located in the Results.

Keeping in mind these limitations, the current project does provide initial insights into the psychological phenomenon of state level masculinity threat as it plays out in a non-experimental setting between police officers and suspects.

\section{Future Directions}

For the majority of highly publicized and disputed use of force cases, a male officer and a male suspect are the primary actors. Past analyses have not empirically examined how these interactions might be impacted by in-the-moment threats to masculine identity. This research shed initial light on the association between masculine compensation and officer use of force during officer-suspect interactions, but more research is needed to fully investigate this topic.

Despite the conflicting findings and underpowered hypothesis tests of this study, future research should continue developing and implementing interventions on masculinity threat within the policing context (e.g., see Kahn et al., 2016). Based on the literature of male gender role stress, hyper-masculine culture within policing, and the racial disparities within the United States justice system, more research is needed to understand how the psychological experiences of officer and suspects are connected to these outcomes. Since the current study's analyses were greatly underpowered, having a larger sample size could provide some clarity of the findings that would be more generalizable to other departments. 
In addition to larger sample sizes for future research, other variables should be considered that might help explain how masculinity threat relates to officer use of force. For example, certain geographic locations in the United States, like the Southern part of the country, are more likely to have cultures that value male honor and associated violence to protect it (Vandello \& Cohen, 2003). If officers (and suspects alike) hail from these areas, they may be more susceptible to compensate following a threat to their masculinity than those from other parts of the US that do not have such a history, which includes the current context for this study. Another variable worth examining in the future would be suspect age and it's interaction with race. Since young minority men are perceived as prototypically masculine in their strength and prowess (Ferber, 2007), it is possible that suspect race alone isn't enough to act as a threat to an officer's masculinity. For example, a racial minority man who is considered to be a senior citizen would likely not elicit the same type of compensatory response a 25 year old minority man would due the senior's perceived weakness. Likewise, officer level variables like tenure could also contribute to masculinity threat reactions. For example, an officer who has more experience may be less likely to enact a compensatory response than his young, more easily agitated counterpart whose social identity holds significant psychological meaning.

Another important future direction that would lend insight into these results would be an exploration of hormonal and physical factors that may moderate the relationship between masculinity threat and engaging in compensatory responses that involve physical aggression. Recent research has suggested that high testosterone levels reduce susceptibility to masculinity threats, while other research has found the opposite, 
indicating the need for further research that expands these findings and their implications in real world settings (Caswell, Bosson, Vandello, \& Guinn Sellers, 2014; Willer et al., 2013). Further research exploring physiological markers and their changes during officer-suspect interactions that include masculinity threat could lead to important insights into the ways officers can reduce stress and anxiety on the job. For example, if a certain time point within an officer-suspect interaction is related to the greatest spike in cortisol, psychological interventions like mindfulness meditation could be implemented to address those physiological responses. Understanding how officers experience psychological and physiological stress as a chronic work experience is important because it is linked to many negative outcomes such as anxiety, depression, and illness (see Ganster \& Rosen, 2013) that might also contribute to officers' ability to accurately apply use of force against suspects.

Like physiological measures, another more objective account of officer-suspect interactions that could contribute to understanding disparate force would be body camera video coding (see Kahn \& Martin, 2016 for a review). While controversial in its own right, body camera footage taken during officer-suspect interactions could provide the additional perspective of the suspect and provide insight into how masculinity threatened men experience an audience. First, it is possible that suspects are also experiencing masculinity threat when interacting with officers and their behavior toward the officer could be a compensatory response to said threat. Second, it is unclear whether an officer would utilize the opportunity to defend his manhood through physical force (since there would be recorded footage of the incident) or whether he would be dissuaded against 
using undue force because of the record of the interaction. This type of analysis could aid in clarifying these possible scenarios.

Overall, the current project has added to the existing literature on masculinity threat and police use of force by coding first-person narratives for masculinity threat, which has not been done before, and by examining a broad range of force outcomes. Since this data reflected officer perceptions as they occurred during suspect interactions, the psychological perspective of the officer was taken into account instead of simulated in an experimental study, as has been done in the past. Additionally, masculinity threat was operationalized as a state, in the moment, variable, which provided a fuller perspective on how masculinity threat operates in officer-suspect interactions outside of an officer's personal level of male gender role stress. This study also examined how length of officer-suspect interactions may vary in relation to masculinity threat (e.g., are interactions shortened or lengthened if masculinity threat is involved?). Results suggest that masculinity threat at the global level is associated with lower levels of average officer force and more discrete sequences within an officer-suspect interaction. When suspect resistance and prior officer control is not taken into consideration there is a marginal increase from force prior to a discrete masculinity threat and force following said masculinity threat. Overall, further research needs to be conducted in order to draw more clear conclusions about how state masculinity threat relates to officer force within an officer-suspect interaction. 
Tables

Table 1.

Masculinity Threat Codebook

\begin{tabular}{llll}
\hline $\begin{array}{l}\text { Type of } \\
\text { threat }\end{array}$ & $\begin{array}{l}\text { Definition of type of } \\
\text { threat }\end{array}$ & $\begin{array}{l}\text { Examples of } \\
\text { Threat }\end{array}$ & $\begin{array}{l}\text { Examples of Supporting Research } \\
\text { non- } \\
\text { masculinity } \\
\text { threat }\end{array}$ \\
\hline
\end{tabular}

\begin{tabular}{|c|c|c|c|c|}
\hline Verbal & $\begin{array}{l}\text { Verbal threats to } \\
\text { masculinity include } \\
\text { any remarks and/or } \\
\text { name-calling that } \\
\text { liken the RO } \\
\text { (reporting officer) to } \\
\text { a woman, a } \\
\text { homosexual man, or } \\
\text { to being physically } \\
\text { weak or impotent. } \\
\text { Threats can be one- } \\
\text { word (name-calling), } \\
\text { or a direct challenge } \\
\text { to prove manhood. }\end{array}$ & $\begin{array}{l}\text { "Try and } \\
\text { catch me, you } \\
\text { bitch", "I'm } \\
\text { going to kick } \\
\text { your ass", } \\
\text { "homo", } \\
\text { "pussy", } \\
\text { "hoe", } \\
\text { "weak", "you } \\
\text { can't hurt } \\
\text { me", "I'm } \\
\text { going to kick } \\
\text { your ass" }\end{array}$ & $\begin{array}{l}\text { "I'm not } \\
\text { going with } \\
\text { you", "fuck } \\
\text { you", "leave } \\
\text { me alone" }\end{array}$ & $\begin{array}{ll}- & \text { Pleck et al. } \\
& (1994) \\
- & \text { Bosson \& } \\
& \text { Michniewicz } \\
& (2013) \\
- & \text { Vandello \& } \\
& \text { Bosson (2013) } \\
- & \text { Glick et al. } \\
& (2007) \\
- & \text { Funk \& } \\
& \text { Werhun (2011) }\end{array}$ \\
\hline Physical & $\begin{array}{l}\text { Physical threats to } \\
\text { masculinity include } \\
\text { any mention by the } \\
\text { RO of the suspect } \\
\text { using their body in } \\
\text { such a way that they } \\
\text { feel challenged by a } \\
\text { male suspect's } \\
\text { dominance action. }\end{array}$ & $\begin{array}{l}\text { "puffing their } \\
\text { chest up", } \\
\text { "thumping his } \\
\text { chest and } \\
\text { smashing } \\
\text { windows" }\end{array}$ & $\begin{array}{l}\text { "bladed } \\
\text { stance", } \\
\text { "forming a } \\
\text { fist", } \\
\text { "clenching } \\
\text { hands" } \\
\text { Different } \\
\text { from physical } \\
\text { masculinity } \\
\text { threats } \\
\text { because they } \\
\text { are } \\
\text { demonstrative } \\
\text { of general } \\
\text { non- } \\
\text { compliance }\end{array}$ & $\begin{array}{ll}\text { - } & \text { Greenwood } \\
& (2010 \\
- & \text { Hall }(1995)\end{array}$ \\
\hline
\end{tabular}


and are not associated

with male

dominance 
Table 2.

Frequencies

\begin{tabular}{llrr}
\hline & & Frequency & Percent \\
\hline Global Masculinity Threat & & 27 & 44.3 \\
& Yes & 34 & 55.7 \\
& No & 61 & 100 \\
& Total & & \\
Suspect Race & & 24 & 39.3 \\
& White & 18 & 29.5 \\
& Black & 18 & 29.5 \\
& Latino & 1 & 1.7 \\
& Asian & 61 & 100 \\
\hline & Total & & \\
\hline
\end{tabular}


Table 3.

Means, Standard Deviations, and Correlations among Variables of interest

\begin{tabular}{|c|c|c|c|c|c|c|c|c|}
\hline Variable & $M$ & $S D$ & 1 & 2 & 3 & 4 & 5 & 6 \\
\hline $\begin{array}{l}\text { 1. Average Suspect } \\
\text { Resistance }\end{array}$ & 2.10 & .72 & - & & & & & \\
\hline 2. First Officer Force & 1.38 & .78 & .095 & - & & & & \\
\hline 3. Average Officer Force & 2.12 & .59 & $.56 * *$ & .35 & - & & & \\
\hline $\begin{array}{l}\text { 4. Maximum Officer } \\
\text { Force }\end{array}$ & 3.84 & .90 & $.27 *$ & .14 & $.49 * *$ & - & & \\
\hline 5. Last Officer Force & 3.38 & 1.13 & .25 & -.07 & $.35 * *$ & $.46 * *$ & - & \\
\hline 6. Number of Sequences & 5.56 & 2.72 & -.13 & -.18 & $-.32 *$ & .07 & .08 & - \\
\hline
\end{tabular}

Note: $N=60, * p<05, * * p<.01$. 
Table 4.

Marginal means and standard errors for interaction outcome measures

\begin{tabular}{|c|c|c|c|c|}
\hline & Race & MT (Yes or No) & $M$ & $S E$ \\
\hline \multirow[t]{4}{*}{ First Officer Force } & White & MT Yes & 1.50 & .25 \\
\hline & & MT No & 1.36 & .21 \\
\hline & Black or Latino & MT Yes & 1.24 & .19 \\
\hline & & MT No & 1.47 & .18 \\
\hline \multirow[t]{4}{*}{ Average Officer Force } & White & MT Yes & 2.29 & .18 \\
\hline & & MT No & 2.17 & .16 \\
\hline & Black or Latino & MT Yes & 1.83 & .14 \\
\hline & & MT No & 2.25 & .13 \\
\hline \multirow[t]{4}{*}{ Maximum Officer Force } & White & MT Yes & 4.20 & .28 \\
\hline & & MT No & 3.64 & .24 \\
\hline & Black or Latino & MT Yes & 3.59 & .22 \\
\hline & & MT No & 4.00 & .21 \\
\hline \multirow[t]{4}{*}{ Last Officer Force } & White & MT Yes & 3.90 & .36 \\
\hline & & MT No & 3.36 & .30 \\
\hline & Black or Latino & MT Yes & 3.29 & .28 \\
\hline & & MT No & 3.16 & .26 \\
\hline \multirow[t]{2}{*}{ Number of Sequences } & White & MT Yes & 7.20 & .77 \\
\hline & & MT No & 4.71 & .65 \\
\hline
\end{tabular}




\begin{tabular}{llll}
\hline Black or Latino & MT Yes & 7.00 & .59 \\
& MT No & 4.16 & .56 \\
\hline
\end{tabular}




\section{Figures}

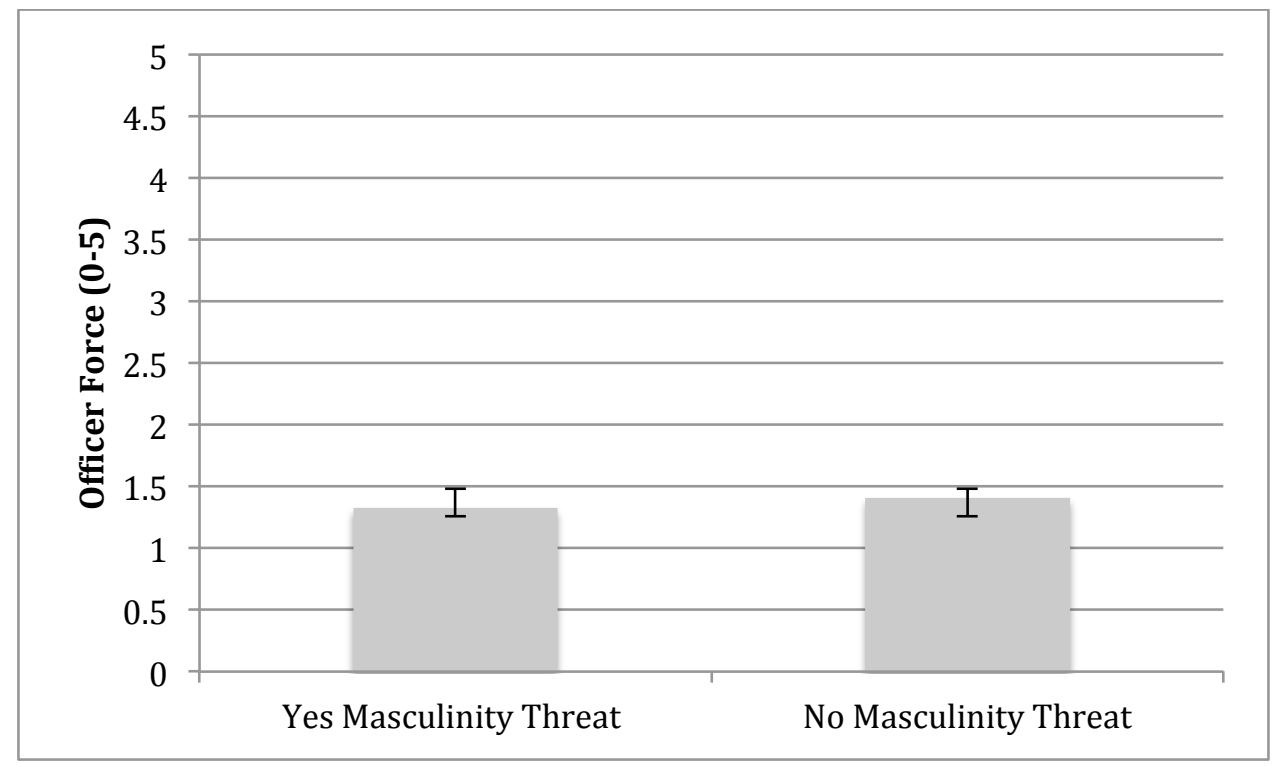

Figure 1. Mean difference in the first instance of officer force used between officersuspect interactions that involve masculinity threat compared to ones that do not involve masculinity threat (Hypothesis 1a). 


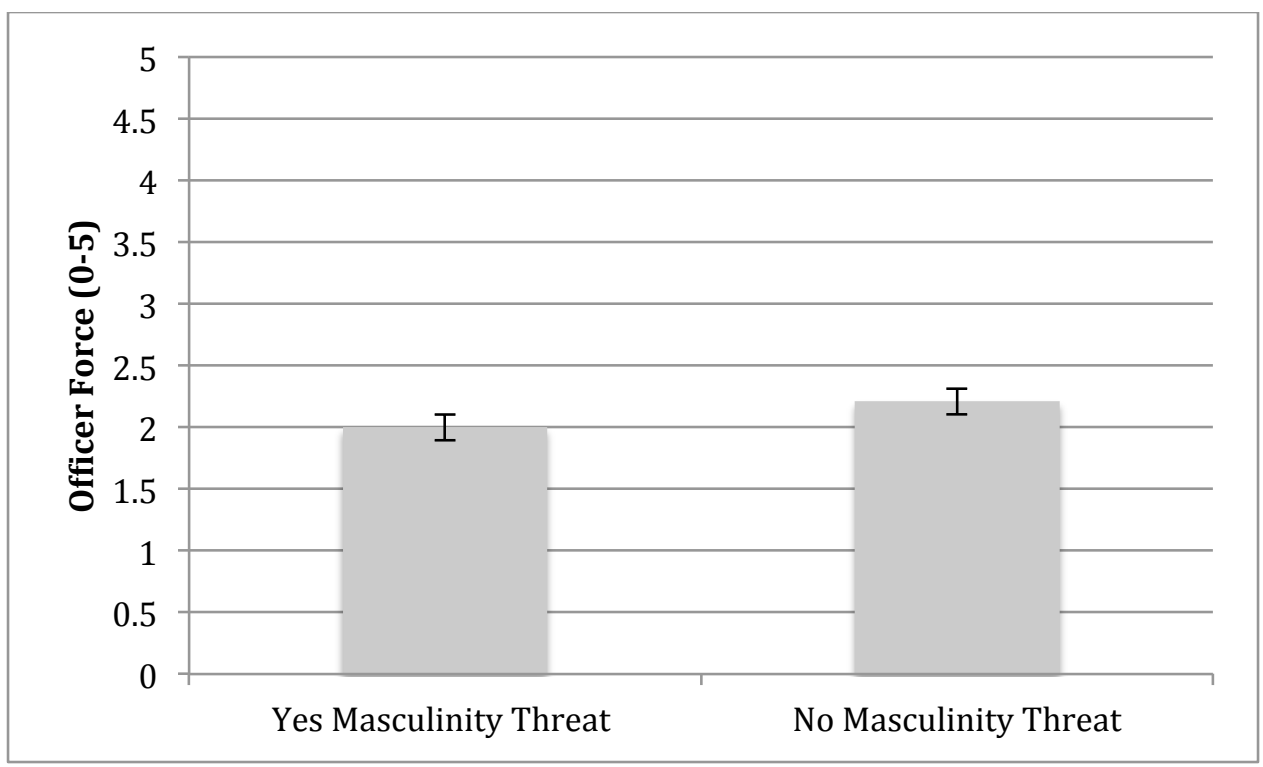

Figure 2. Mean difference in the average level of officer force used between officersuspect interactions that involve masculinity threat compared to ones that do not involve masculinity threat (Hypothesis 1b). 


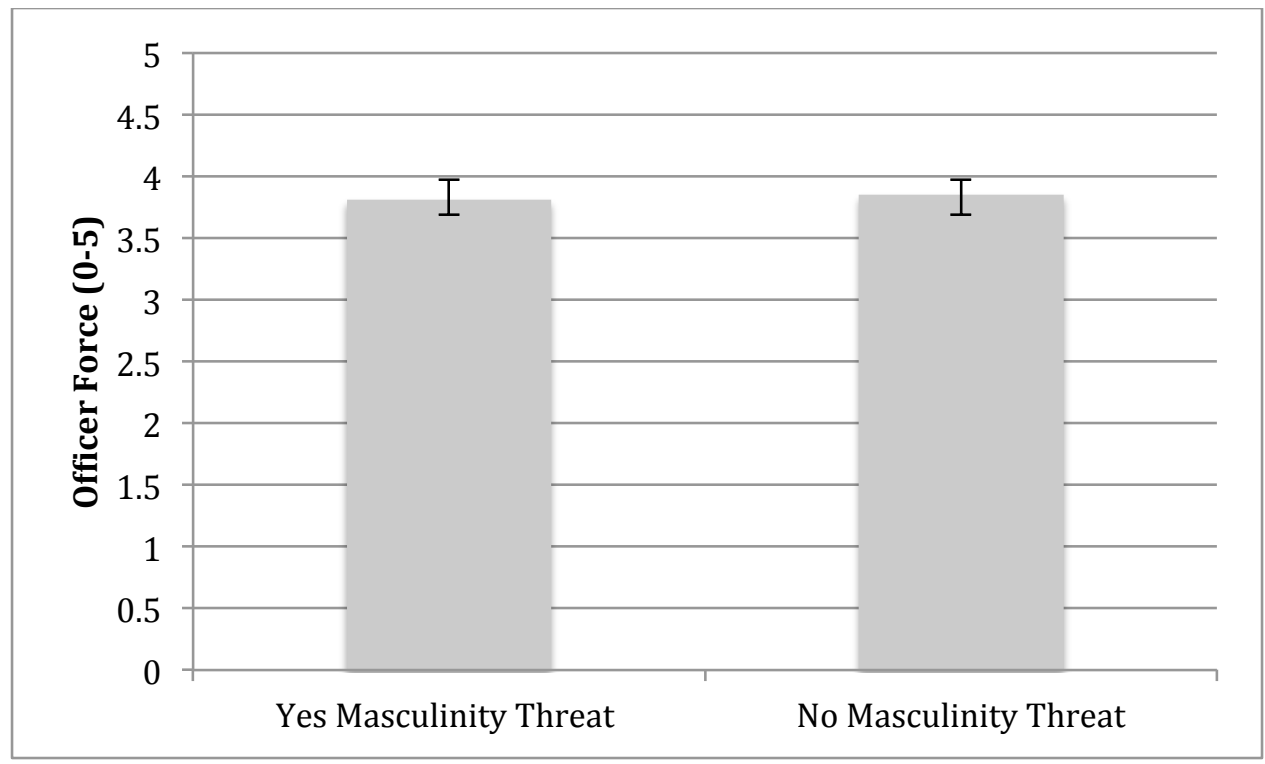

Figure 3. Mean difference in the maximum level of officer force used between officersuspect interactions that involve masculinity threat compared to ones that do not involve masculinity threat (Hypothesis 1c). 


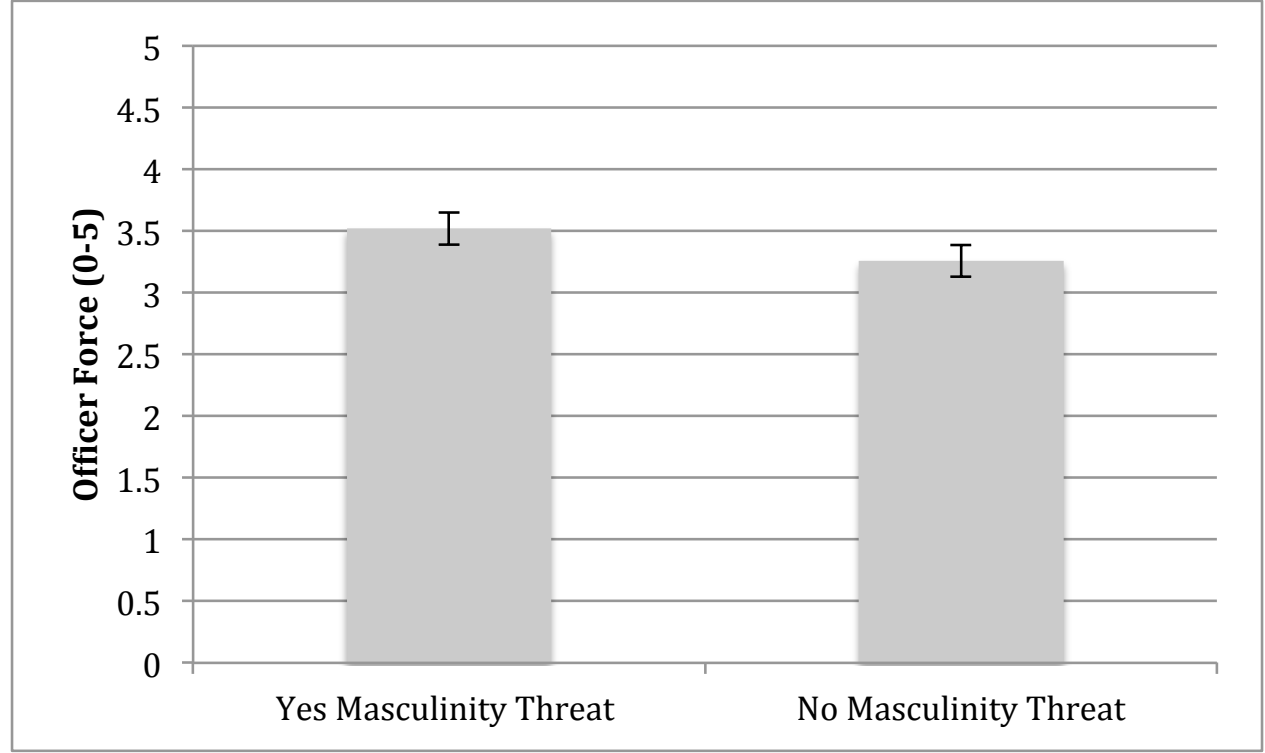

Figure 4. Mean difference in the last instance of officer force used between officersuspect interactions that involve masculinity threat compared to ones that do not involve masculinity threat (Hypothesis 1d). 


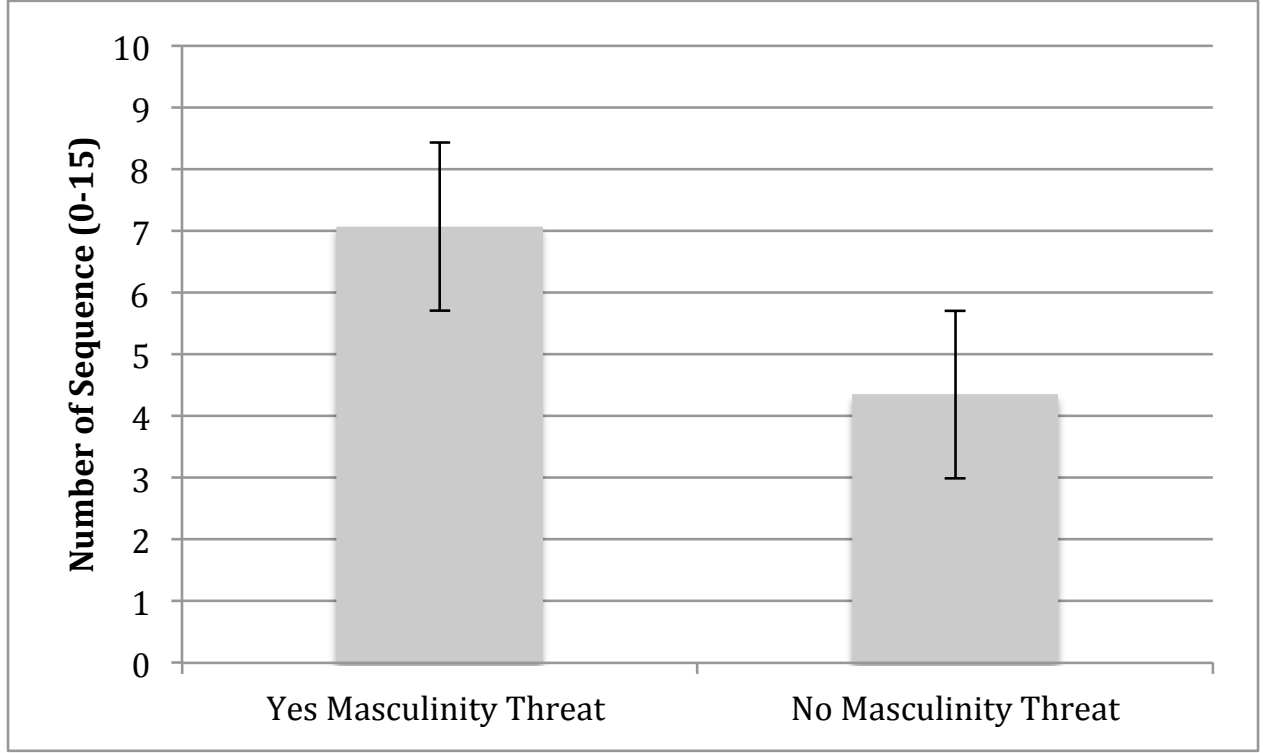

Figure 5. Mean difference in the number of sequences within a suspect-officer interaction between cases that involve masculinity threat compared to ones that do not involve masculinity threat (Hypothesis 1e). 


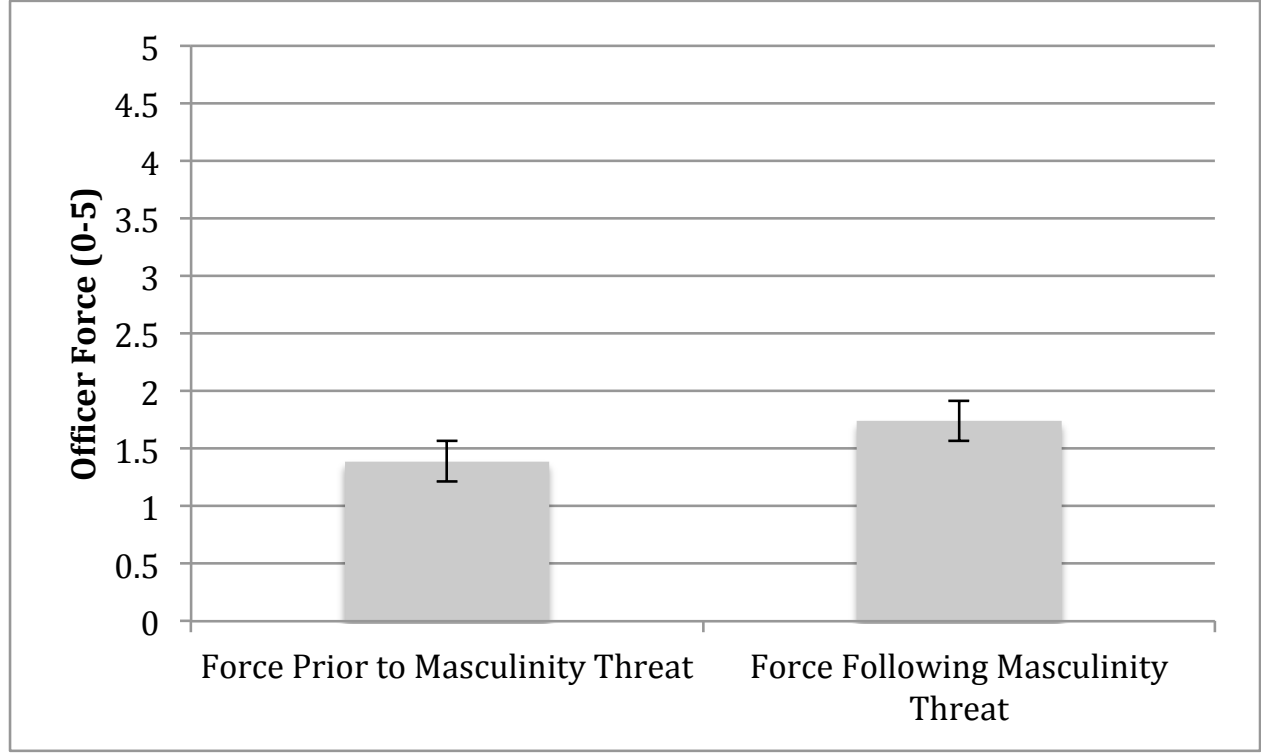

Figure 6. Mean difference in amount of officer force prior to a masculinity threat compared to level of officer force following a masculinity threat (Hypothesis 2a). 


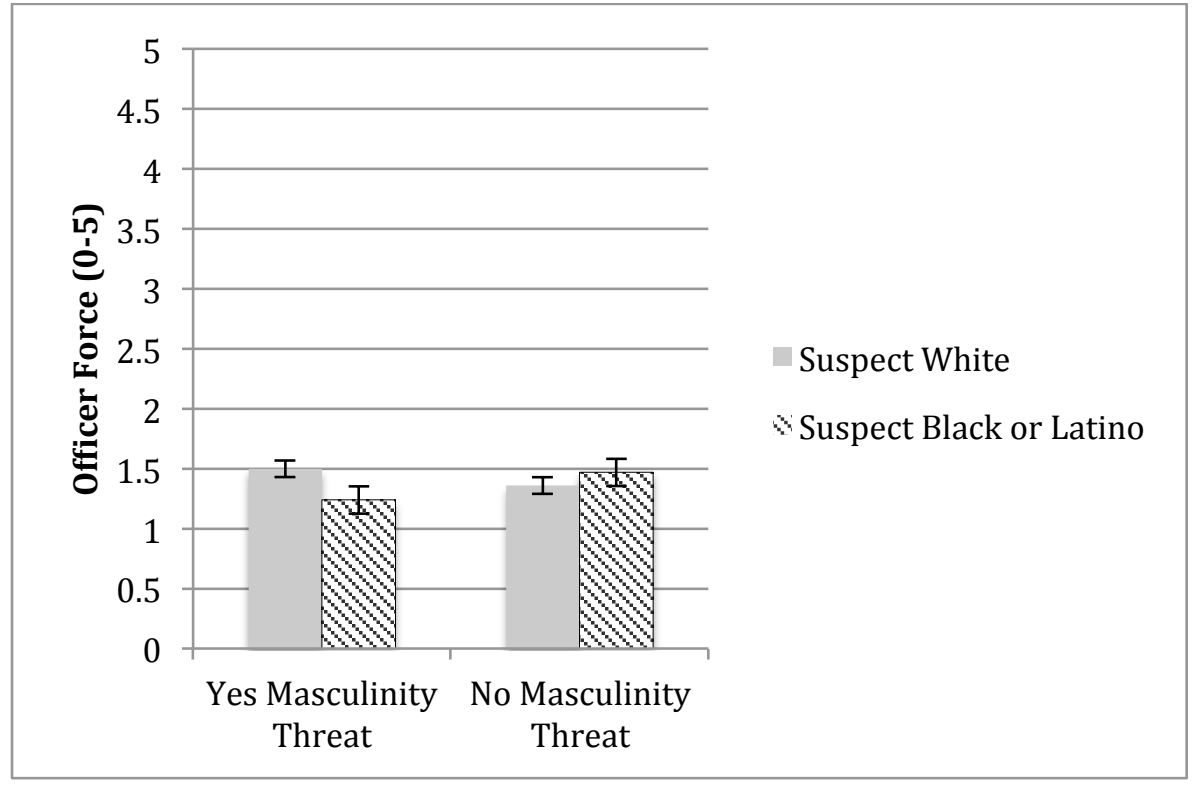

Figure 7. Mean differences in first instance of officer force between officer-suspect interactions that involve White suspects that do or do not threaten officer masculinity and minority suspects that either do or do not threaten officer masculinity (Hypothesis 3a). 


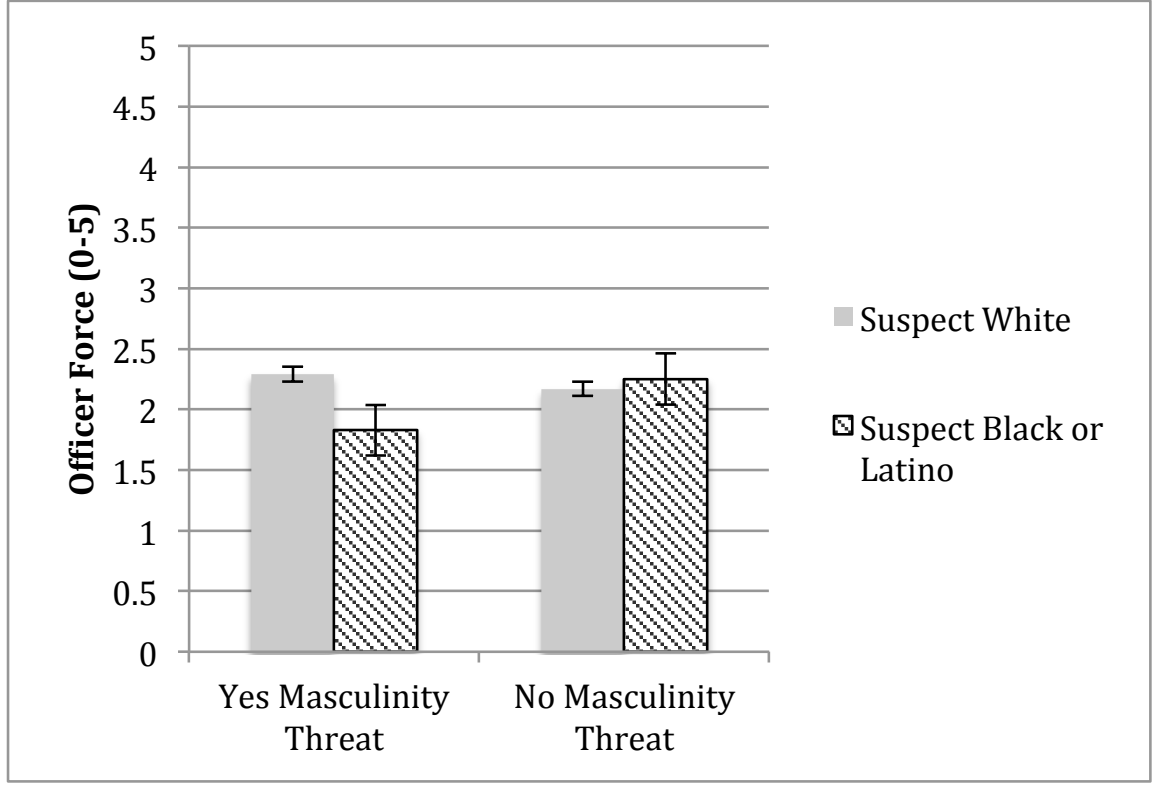

Figure 8. Mean differences in average level of officer force between officer-suspect interactions that involve White suspects that do or do not threaten officer masculinity and minority suspects that either do or do not threaten officer masculinity (Hypothesis $3 b$ ). 


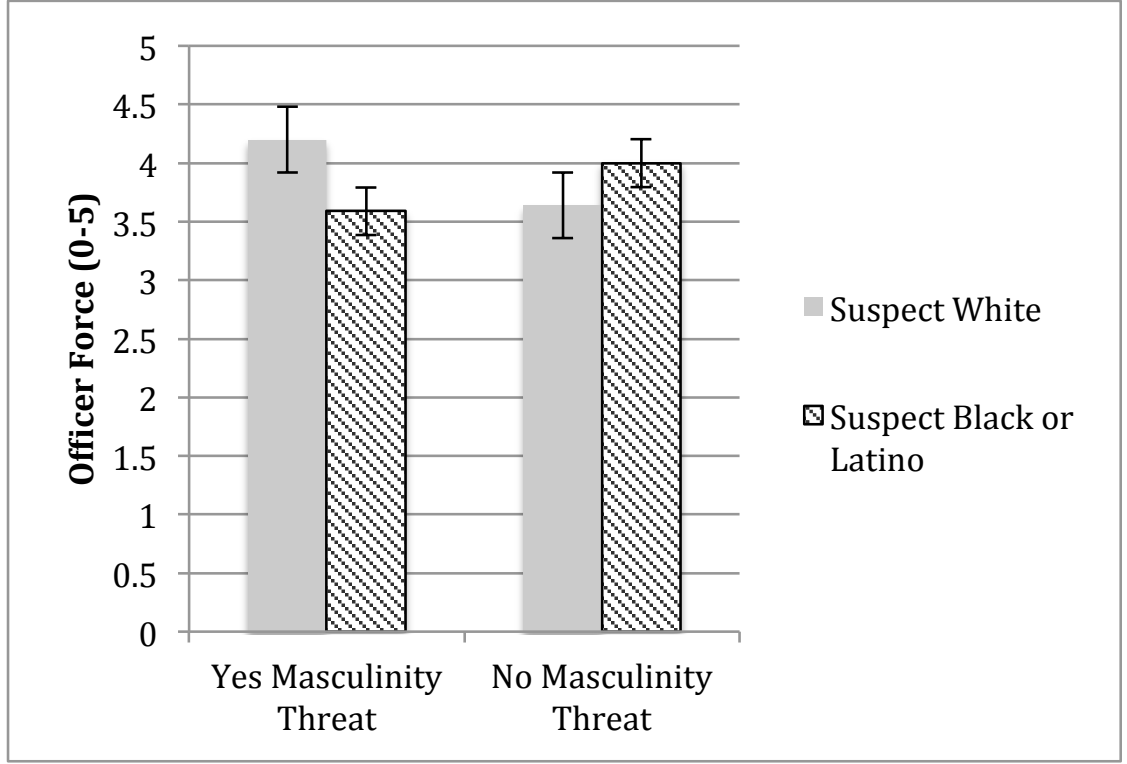

Figure 9. Mean differences in the maximum amount of officer force between officersuspect interactions that involve White suspects that do or do not threaten officer masculinity and Minority suspects that either do or do not threaten officer masculinity (Hypothesis 3c). 


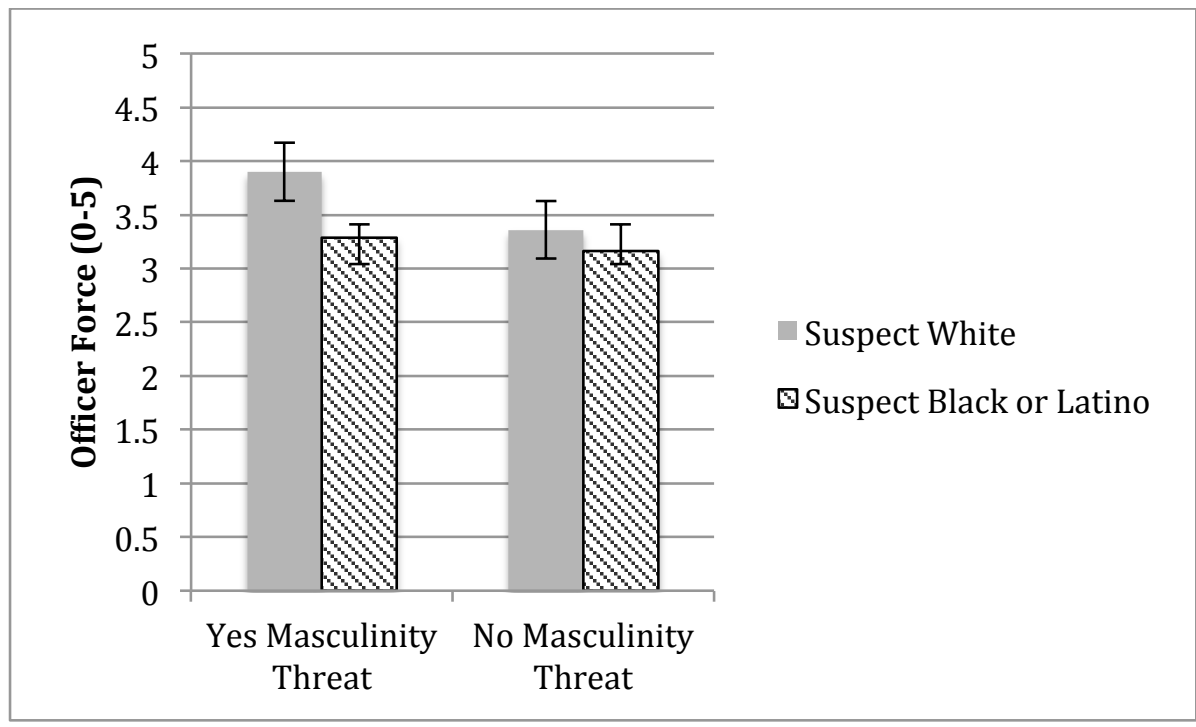

Figure 10. Mean differences in last officer force between officer-suspect interactions that involve White suspects that do or do not threaten officer masculinity and minority suspects that either do or do not threaten officer masculinity (Hypothesis 3d). 


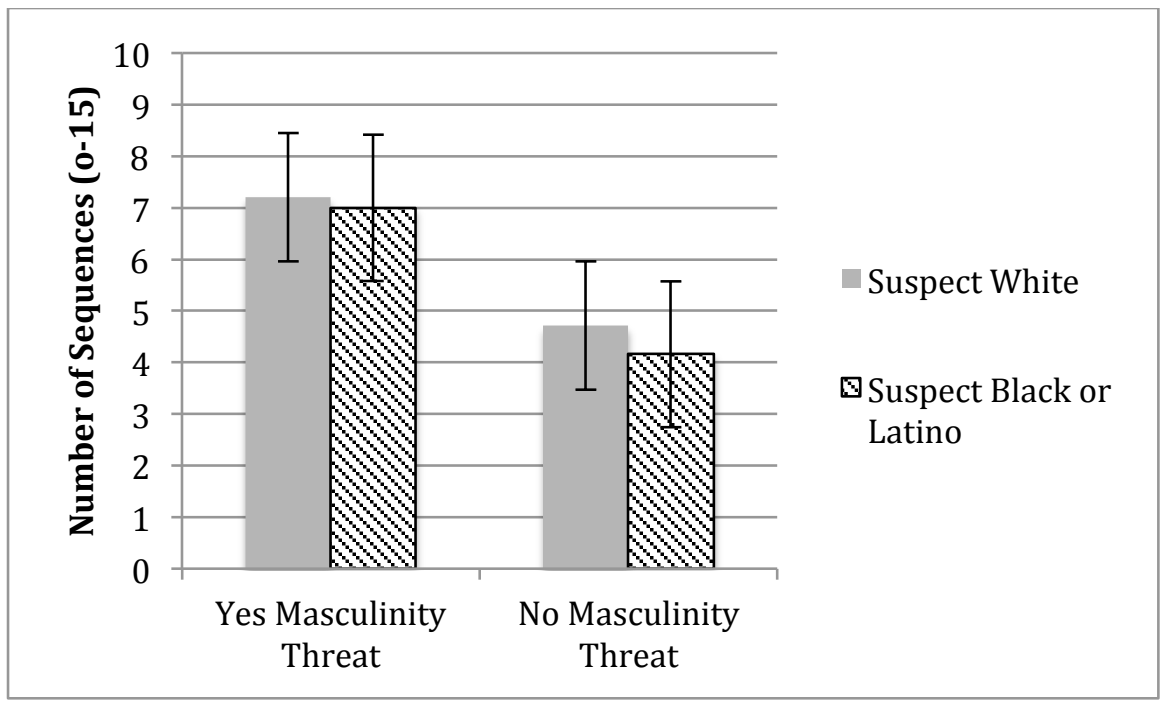

Figure 11. Mean differences in number of sequences between officer-suspect interactions that involve White suspects that do or do not threaten officer masculinity and minority suspects that either do or do not threaten officer masculinity (Hypothesis 3e). 


\section{References}

Amadi, E. N. (2014). A qualitative analysis of community policing in the United States, American International Journal of Contemporary Research, 4, 19-26. http://dx.doi.org/10.1007/978-1-137-07200-9_8

American Psychological Association (2011). Definition of terms: Sex, gender, gender identity, sexual orientation. Retrieved from http://www.apa.org/pi/lgbt/resources/sexuality-definitions.pdf

Aronson, J., Lustina, M. J., Good, C., Keough, K., Steele, C. M., \& Brown, J. (1999). When white men can't do math: Necessary and sufficient factors in stereotype threat. Journal of Experimental Social Psychology, 35, 29-46. http://dx.doi.org/10.1006/jesp.1998.1371

Bem, S. L. (1981). Gender schema theory: A cognitive account of sex typing. Psychological Review, 88, 354-364. http://dx.doi.org/10.1037/0033$295 \times .88 .4 .354$

Biernat, M., \& Manis, M. (1994). Shifting standards and stereotype-based judgments. Journal of Personality and Social Psychology, 66, 5-20. http://dx.doi.org/10.1037/0022-3514.66.1.5

Blazina, C., \& Watkins, C. E. (1996). Masculine gender role conflict: Effects on college men's psychological well-being, chemical substance usage, and attitudes toward help-seeking. Journal of Counseling Psychology, 43, 461-465. http://dx.doi.org/10.1037//0022-0167.43.4.461 
Bosson, J. K., \& Michniewicz, K. S. (2013). Gender dichotomization at the level of ingroup identity: What it is, and why men use it more than women. Journal of Personality and Social Psychology, 105, 425-442. http://dx.doi.org/10.1037/a0033126

Bosson, J. K., Prewitt-Freilino, J. L., \& Taylor, J. N. (2005). Role rigidity: A problem of identity misclassification? Journal of Personality and Social Psychology, 89, 552-65. http://dx.doi.org/10.1037/0022-3514.89.4.552

Bosson, J. K., Taylor, J. N., \& Prewitt-Freilino, J. L. (2006). Gender role violations and identity misclassification: The Roles of Audience and Actor Variables. Sex Roles, 55, 13-24. http://dx.doi.org/10.1007/s11199-006-9056-5

Bosson, J. K., \& Vandello, J. A. (2011). Precarious manhood and its links to action and aggression. Current Directions in Psychological Science, 20, 82-86. http://dx.doi.org/10.1177/0963721411402669

Bosson, J. K., Vandello, J. A, Burnaford, R. M., Weaver, J. R., \& Arzu Wasti, S. (2009). Precarious manhood and displays of physical aggression. Personality and Social Psychology Bulletin, 35, 623-634. http://dx.doi.org/10.1177/0146167208331161

Buchanan, L. (2014). What happened in Ferguson? The New York Times. Retrieved from http://www.nytimes.com/interactive/2014/08/13/us/ferguson-missouri-townunder-siege-after-police-shooting.html?_r=0

Bulman (2011). What is use of force, and what is a use-of-force continuum? National Institute of Justice. Retrieved from http://nij.gov/journals/267/pages/use-of-forcewhat-is.aspx 
Bunting, A. B., \& Reeves, J. B. (2010). Perceived male sex orientation and beliefs about rape. Deviant Behavior, 4, 281-295. http://dx.doi.org/10.1080/01639625.1983.9967618

Bureau of Justice Statistics. (2001). Use of force. BJS. Retrieved from http://www.bjs.gov/index.cfm?ty=tp\&tid=84

Bureau of Justice Statistics. (2008). Use of force. BJS. Retrieved from http://www.bjs.gov/content/pub/pdf/cpp08.pdf

Bureau of Justice Statistics. (2011). Arrest-related deaths. BJS. Retrieved from http://www.bjs.gov/content/pub/pdf/ard0309st.pdf

Buss, D. M., \& Schmitt, D. P. (1993). Sexual strategies theory: An evolutionary perspective on human mating. Psychological review, 100, 204-232. http://dx.doi.org/10.1037/0033-295x.100.2.204

Butler, J. (1988). Acts and gender performative: An essay in phenomenology constitution and feminist theory. Threatre Journal, 40, 519-531. http://dx.doi.org/10.2307/3207893

Butler, J. (1999). Gender trouble. New York: Routledge.

Caswell, T. A., Bosson, J. K., Vandello, J. A., \& Sellers, J. G. (2014). Testosterone and men's stress responses to gender threats. Psychology of Men and Masculinity, 15, 4-11. http://dx.doi.org/10.1037/a0031394

Cohen, J., Cohen, P., \& Stephen, G., West, and Leona S. Aiken (2003). Applied multiple regression/correlation analysis for the behavioral sciences, Mahweh, NJ: Routledge. 
Cohn, A., \& Zeichner, A. (2006). Effects of masculine identity and gender role stress on aggression in men. Psychology of Men \& Masculinity, 7, 179-190. http://dx.doi.org/10.1037/1524-9220.7.4.179

Cook, W. L., \& Kenny, D. A. (2005). The actor-partner interdependence model: A model of bidirectional effects in developmental studies. International Journal of Behavioral Development, 29, 101-109. http://dx.doi.org/10.1080/01650250444000405

Correll, J., Urland, G. R., \& Ito, T. A. (2006). Event-related potentials and the decision to shoot: The role of threat perception and cognitive control. Journal of Experimental Social Psychology, 42, 120-128. http://dx.doi.org/10.1016/j.jesp.2005.02.006

Correll, J., Park, B., Judd, C. M., Wittenbrink, B., Sadler, M. S., \& Keesee, T. (2007). Across the thin blue line: Police officers and racial bias in the decision to shoot. Journal of Personality and Social Psychology, 92, 1006-1023. http://dx.doi.org/10.1037/0022-3514.92.6.1006

Courtenay, W. H. (2000). Constructions of masculinity and their influence on men's well-being: A theory of gender and health. Social Science and Medicine, 50, 1385-401. http://dx.doi.org/10.1016/s0277-9536(99)00390-1

Deaux, K., \& Major, B. (1987). Putting gender into context: An interactive model of gender-related behavior. Psychological Review, 94, 369-389. http://dx.doi.org/10.1037/0033-295x.94.3.369 
de Hoog, N. (2013). Processing of social identity threats. Social Psychology, 44, 361372. http://dx.doi.org/10.1027/1864-9335/a000133

Devine, P. G. (1989). Stereotypes and prejudice : Their automatic and controlled components. Journal of Personality and Social Psychology, 56, 5-18. http://dx.doi.org/10.1037/0022-3514.56.1.5

Devine, P. G., \& Elliott, A. J. (1995). Are racial stereotypes really fading? The Princeton trilogy revisited. Personality and Social Psychology Bulletin, 21, 1139-1150. http://dx.doi.org/10.1177/01461672952111002

Discover Policing. (n.d.). Training/academy life. Discoverpolicing.org. Retrieved from http://discoverpolicing.org/what_does_take/?fa=training_academy_life

Dovidio, J. F., Kawakami, K., \& Gaertner, S. L. (2002). Implicit and explicit prejudice and interracial interaction. Journal of Personality and Social Psychology, 82, 6268. http://dx.doi.org/10.1037/0022-3514.82.1.62

Eagly, A. H., \& Wood, W. (1991). Explaining sex differences in social behavior: A metaanalytic perspective. Personality and Social Psychology Bulletin, 17, 306-315. http://dx.doi.org/10.1177/0146167291173011

Eberhardt, J. L., Goff, P. A., Purdie, V. J., \& Davies, P. G. (2004). Seeing black: race, crime, and visual processing. Journal of Personality and Social Psychology, 87, 876-93. http://dx.doi.org/10.1037/0022-3514.87.6.876

Eisler, R. M., Skidmore, J. R., \& Ward C. H. (1988). Masculine gender-role stress: Predictor of anger, anxiety and health-risk behaviors. Journal of Personality Assessment, 52, 133-141. http://dx.doi.org/10.1207/s15327752jpa5201_12 
Fachner, G., \& Carter, S. (2015). An assessment of deadly force in the Philadelphia police department. Collaborative Reform Initiative. Washington, DC: Office of Community Oriented Policing Services.

Faul, F., \& Erdfelder, E. (1992). GPOWER: A priori, post-hoc, and compromise power analyses for MS-DOS [Computer program]. Bonn, FRG: Bonn University, Dept. of Psychology.

Federal Bureau of Investigation (FBI). (2013). Full-time law enforcement employees. http://www.fbi.gov/about-us/cjis/ucr/crime-in-the-u.s/2013/crime-in-the-u.s.2013/tables/table-74

Feingold, A. (1994). Gender differences in personality: A meta-analysis. Psychological Bulletin, 116, 429-56. http://dx.doi.org/10.1037/0033-2909.116.3.429

Ferber, A. L. (2007). The construction of black masculinity: White supremacy now and then. Journal of Sport \& Social Issues, 31, 11-24. https://doi.org/10.1177/0193723506296829

$B B C$. (2015). Ferguson unrest: From shooting to nationwide protest. Retrieved from http://www.bbc.com/news/world-us-canada-30193354

Funk, L. C., \& Werhun, C. D. (2011). "You're such a girl!” The psychological drain of the gender-role harassment of men. Sex Roles, 65, 13-22. http://dx.doi.org/10.1007/s11199-011-9948-x

Ganster, D. C., \& Rosen, C. C. (2013). Work stress and employee health: A multidisciplinary review. Journal of Management, 39, 1085-1122. http://dx.doi.org/10.1177/0149206313475815 
Garner, J. H., Schade, T., Hepburn, J., \& Buchanan, J. (1995). Measuring the continuum of force used by and against the police. Criminal Justice Review, 20, 146-168. http://dx.doi.org/10.1177/073401689502000204

Glick, P., Fiske, S. T., Mladinic, A., Saiz, J. L., Abrams, D., Masser, B., \& López, W. L. (2000). Beyond prejudice as simple antipathy: Hostile and benevolent sexism across cultures. Journal of Personality and Social Psychology, 79, 763-775. http://dx.doi.org/10.1037//0022-3514.79.5.763

Glick, P., Gangl, C., Gibb, S., Klumpner, S., \& Weinberg, E. (2007). Defensive reactions to masculinity threat: More negative affect toward effeminate (but not masculine) gay men. Sex Roles, 57, 55-59. http://dx.doi.org/10.1007/s11199-007-9195-3

Goffman, E. (1976) Gender advertisements. Studies in the Anthropology of Visual Communication, 3, 65-154. http://dx.doi.org/10.2307/2577822

Goff, P. A., Di Leone, B. A. L., \& Kahn, K. B. (2012). Racism leads to pushups: How racial discrimination threatens subordinate men's masculinity. Journal of Experimental Social Psychology, 48, 1111-1116. http://dx.doi.org/10.1016/j.jesp.2012.03.015

Goff, P. A., Eberhardt, J. L., Williams, M. J., \& Jackson, M. C. (2008). Not yet human: Implicit knowledge, historical dehumanization, and contemporary consequences. Journal of Personality and Social Psychology, 94, 292-306. http://dx.doi.org/10.1037/0022-3514.94.2.292

Goff, P. A., Jackson, M.C., \& Kahn, K.B. (2016). Base in your voice: The effects of masculinity threat on police behavior. Manuscript in preparation. 
Goff, P. A., \& Kahn, K. B. (2013). How psychological science impedes intersectional thinking. Du Bois Review: Social Science Research on Race, 10, 365-384. http://dx.doi.org/10.1017/s1742058x13000313

Goff, P. A., \& Kahn, K.B. (2012). Racial bias in policing: Why we know less than we should, Social Issues and Policy Review, 6, 177-210. http://dx.doi.org/10.1111/j.1751-2409.2011.01039.x

Goff, P. A., Martin, K. D., \& Gamson-Smiedt, M. G. (2012). Protecting equity: The consortium for police leadership in equity report on the San Jose Police Department. Los Angeles, CA: Consortium for Police Leadership in Equity.

Goff, P. A., Thomas, M. A., \& Jackson, M. C. (2008). “Ain’t I a woman?”: Towards an intersectional approach to person perception and group-based harms. Sex Roles, 59, 392-403. http://dx.doi.org/10.1007/s11199-008-9505-4

Good, G. E., Robertson, J. M., Neil, J. M. O., Stevens, M., Fitzgerald, L. F., Debord, K. A., \& Brayerman, D. G. (1995). Male gender role conflict: Psychometric issues and relations to psychological distress, Journal of Counseling Psychology, 42, 310. http://dx.doi.org/10.1037/0022-0167.44.4.432

Greenwald, A., \& Banaji, M. R. (1995). Implicit social cognition: attitudes, self-esteem, and stereotypes. Psychological Review, 102, 4-27. http://dx.doi.org/10.1037/0033-295x.102.1.4

Greenwood, L. (2010). A dot probe study investigating attentional bias in males with regard to drive for muscularity and internalisation of media images. (Unpublished Dissertation). University of Leeds, Leeds. 
Hall, R. E. (1995). Dark skin and the cultural ideal of masculinity. Journal of African American Men, 1, 37-62. http://dx.doi.org/10.1007/bf02692070

Hare-Mustin, R. T., \& Marecek, J. (1988). The meaning of difference: Gender theory, postmodernism, and psychology. American Psychologist, 43, 455. http://dx.doi.org/10.1037/0003-066x.43.6.455

Hernandez, T. K. (2001). Sexual harassment and racial disparity : The mutual construction of gender and race, Gender, Race and Justice, 4, 183-224. http://dx.doi.org/10.12987/yale/9780300098006.003.0029

Herbert, S. (2001). "Hard charger" or "station queen"? Policing and the masculinist state. Gender, Place and Culture, 8, 55-71. http://dx.doi.org/10.1080/09663690120026325

Hickman, M. J., \& Atherley, L. T. (2012). Police use of force in Seattle, January 2009 March 2011. Northwest Justice Solutions.

Hickman, M. J., Atherley, L. T., Lowery, P. G., \& Alpert, G. P. (2015). Reliability of the force factor method in police use-of-force research. Police Quarterly, 18, 368396. http://dx/doi.org/10.1177/1098611115586175

Ho, A. K., Sidanius, J., Pratto, F., Levin, S., Thomsen, L., Kteily, N., \& SheehySkeffington, J. (2012). Social dominance orientation: Revisiting the structure and function of a variable predicting social and political attitudes. Personality and Social Psychology Bulletin, 38, 583-606. http://dx.doi.org/10.1037/e514892012001 
Howell, D. C. (2010). Statistical methods for psychology. Belmont, CA: Thomson Wadsworth.

Hox, J. (2010). Multilevel analysis: Techniques and applications, second edition. New York: Routledge

Huq, A. Z., Tyler, T. R., \& Schulhofer, S. J. (2011). Why does the public cooperate with law enforcement? The influence of the purposes and targets of policing. Psychology, Public Policy, and Law, 17, 419-450. http://dx.doi.org/10.1037/a0023367

Hyde, J. S., \& Plant, E. A. (1995). Magnitude of psychological gender differences: Another side to the story. The American Psychologist, 50, 159-161. http://dx.doi.org/10.1037//0003-066x.50.3.159

IACP. (2012). Emerging issues in use of force: Report from the international association of chiefs of police. COPS. Retrieved from http://www.theiacp.org/portals/0/pdfs/emerginguseofforceissues041612.pdf

Jackson, M. C. (2014). Male pattern blindness: The consequences of defending manhood (Unpublished dissertation; Order No. AAI3564275). Available from PsycINFO. (1523811961; 2014-99081-133). Retrieved from http://stats.lib.pdx.edu/proxy.php?url=http://search.proquest.com.proxy.lib.pdx.ed $\mathrm{u} /$ docview/1523811961?accountid=13265

Jones, S. (2015). PPB force demographics summary report. Professional Standards Division. Retrieved from: https://www.portlandoregon.gov/police/article/524620 
Kahn, K. B., \& Davies, P. G. (2010). Differentially dangerous? Phenotypic racial stereotypicality increases implicit bias among ingroup and outgroup members. Group Processes and Intergroup Relations, 14, 569-580. doi:10.1177/1368430210374609

Kahn, K.B., Goff, P.A., \& Glaser, J. (2016). Research and training to mitigate the effects of implicit stereotypes and masculinity threat on authority figures' interactions with adolescents and minorities. Disparate Opportunity: Understanding and Addressing Inequality in School Discipline. Palgrave-MacMillan.

Kahn, K. B., Goff, P. A., Lee, J. K., \& Motamed, D. (2016). Protecting whiteness: White phenotypic racial stereotypicality reduces police use of force. Social Psychological and Personality Science, 7, 403-411. https://doi.org/10.1177/1948550616633505

Kahn., K.B., Lee, J.K., Renauer, B., Henning, K., \& Stewart, G. (2016). The effects of phenotypic racial stereotypicality and identity threats on racial minorities' attitudes about police. Journal of Social Psychology. Advanced publication online. doi: 10.1080/00224545.2016.1215967

Kahn, K. B., \& Martin, K. D. (2016). Policing and race: Disparate treatment, perceptions, and policy responses. Social Issues and Policy Review, 10, 82-121. http://dx.doi.org/10.1111/sipr.12019

Kahn, K.B., McMahon, J.M., \& Stewart, G. (2016). Misinterpreting danger? Stereotype threat, danger indicators, and police-suspect interactions. Manuscript submitted for publication. 
Kahn, K. B., Steele. J., McMahon, J.M., \& Stewart, G. (2016). How suspect race affects police use of force in an interaction over time. Law and Human Behavior. https://doi.org/10.1037/lhb0000218

Keller, E.F. (1995). Reflections of gender and science. New Haven, CT: Yale University Press.

Kimmel, M.S. (2012). Manhood in America. Oxford University Press.

Kimmel, M. S., \& Mahler, M. (2003). Adolescent masculinity, homophobia, and violence. American Behavioral Scientist, 46, 1439-1458. http://dx.doi.org/10.1177/0002764203046010010

Kimmel, M.S., \& Messner, M.A. (2004). Men's lives. New York, NY: Pearson.

Klahm, C. F., Frank, J., \& Brown, R. a. (2011). Police use of force: tales from another city. Journal of Crime and Justice, 34, 205-220.

http://dx.doi.org/10.1080/0735648X.2011.609735

Lick, D.J., Johnson, K.L., \& Riskind, R.G. (2014). Haven’t I seen you before? Straight men who are insecure of their masculinity remember gender-atypical faces. Group Processes and Intergroup Relations, 18, 131-152. http://dx.doi.org/10.1177/1368430214538324

Lind, E. A., Tyler, T. R., \& Huo, Y. J. (1997). Procedural context and culture : Variation in the antecedents of procedural justice judgments. Journal of Personality and Social Psychology, 73, 767-780. http://dx.doi.org/10.1037//0022-3514.73.4.767 
Luhtanen, R., \& Crocker, J. (1992). A collective self-esteem scale: Self- evaluation of one's social identity. Personality and Social Psychology Bulletin, 18, 302-318. http://dx.doi.org/10.1177/0146167292183006

Maccoby, E. E., \& Jacklin, C. N. (1974). The psychology of sex differences. Stanford, CA: Stanford University Press.

Major, B., \& O’Brien, L. T. (2005). The social psychology of stigma. Annual Review of Psychology, 56, 393-421. http://dx.doi.org/10.1146/annurev.psych.56.091103.070137

Mccreary, D. R., Newcomb, M. D., \& Sadava, S. W. (1999). The male role, alcohol use, and alcohol problems: A structural modeling examination in adult women and men, Journal of Counseling Psychology, 46, 109-124. http://dx.doi.org/10.1037/0022-0167.46.1.109

Moore, T. M., \& Stuart, G. L. (2005). A review of the literature on masculinity and partner violence. Psychology of Men \& Masculinity, 6, 46-61. http://dx.doi.org/10.1037/1524-9220.6.1.46

Najdowski, C. (2011). Stereotype threat in criminal interrogations: Why innocent Black suspects are at risk for confessing falsely. Psychology, Public Policy, and Law, 17, 562-591. http://dx.doi.org/10.1037/a0023741

Najdowski, C. J., Bottoms, B. L., \& Goff, P. A. (2015). Stereotype threat and racial differences in citizens' experiences of police encounters. Law and Human Behavior, 39, 463-477. http://dx.doi.org/10.1037/lhb0000140 
National Institute of Justice. (2015). Police use-of-force. National Institute of Justice. Retrieved from http://www.nij.gov/topics/law-enforcement/officer-safety/use-offorce/pages/welcome.aspx

National Institute of Justice. (2009). The use-of-force continuum. National Institute of Justice. Retrieved from http://www.nij.gov/topics/law-enforcement/officersafety/use-of-force/Pages/continuum.aspx

O'Neil, J. M. (2008). Summarizing 25 years of research on men's gender role conflict using the gender role conflict scale: New research paradigms and clinical implications. The Counseling Psychologist, 36, 358-445. http://dx.doi.org/10.1177/0011000008317057

O’Neil, J. M., Helm, B., Gable, R., David, L., \& Wrightsman, L. (1986). Gender role conflict scale (GRCS): College men's fears of femininity. Sex Roles, 14, 335-350. http://dx.doi.org/10.1007/bf00287583

Parrott, D. J. (2009). Aggression toward gay men as gender role enforcement: Effects of male role norms, sexual prejudice, and masculine gender role stress. Journal of Personality, 77, 1137-1166. http://dx.doi.org/10.1111/j.1467-6494.2009.00577.x

Parrott, D. J., \& Zeichner, A. (2003). Effects of hypermasculinity on physical aggression against women. Psychology of Men and Masculinity, 4, 70-78. http://dx.doi.org/10.1037//1524-9220.4.1.70

Peruche, B., \& Plant, E. (2006). The correlates of law enforcement officers' automatic and con- trolled race-based responses to criminal suspects. Basic and Applied Social Psychology, 28, 193-199. http://dx.doi.org/10.1207/s15324834basp2802_9 
Pleck, J. H. (1993). Masculinity ideology: Its impact on adolescent males 'heterosexual relationships. Journal of Social Issues, 49, 11-29. http://dx.doi.org/10.1111/j.1540-4560.1993.tb01166.x

Pleck, J. H. (1995). The gender role strain paradigm: An update. In R. F.Levant \& W. S. Pollack (Eds.), A new psychology of men (pp. 11-32). New York: Basic Books.

Pleck, J.H., Sonenstein, F.L., \& Ku, L.C. (1994). Attitude toward male roles among adolescent males, Sex Roles, 30, 481-50. http://dx.doi.org/10.1007/bf01420798

Prokos, A., \& Padavic, I. (2002). 'There oughtta be a law against bitches': Masculinity lessons in police academy training. Gender, Work, and Organization, 9, 439-459. http://dx.doi.org/10.1111/1468-0432.00168

ProPublica. (2014). Deadly force, in black and white. Journalism in the public interest. Retrieved from http://www.propublica.org/article/deadly-force-in-black-andwhite

Purdie-Vaughns, V., \& Eibach, R. P. (2008). Intersectional invisibility: The distinctive advantages and disadvantages of multiple subordinate-group identities. Sex Roles, 59, 377-39. http://dx.doi.org/10.1007/s11199-008-9424-4

Purdie-Vaughns, V., Steele, C. M., Davies, P. G., \& Ditlmann, R. (2008). Social identity contingencies: How diversity cues signal threat or safety for African Americans in mainstream institutions. Journal of Personality and Social Psychology, 94, 615630. http://dx.doi.org/10.1037/0022-3514.94.4.615 
Reidy, D. E., Berke, D. S., Gentile, B., \& Zeichner, A. (2014). Man enough? Masculine discrepancy stress and intimate partner violence. Personality and Individual Differences, 68, 160-164. http://dx.doi.org/10.1016/j.paid.2014.04.021

Reidy, D. E., Shirk, S. D., Sloan, C. A., \& Zeichner, A. (2009). Men who aggress against women: Effects of feminine gender role violation on physical aggression in hypermasculine men. Psychology of Men and Masculinity, 10, 1-12. http://dx.doi.org/10.1037/a0014794

Reilly, R. (2014, November 24). Ferguson officer Darren Wilson not indicted in Michael Brown shooting. Huffington Post. Retrieved from http://www.huffingtonpost.com/2014/11/24/michael-brown-grandjury_n_6159070.html

Richardson, L. S. (2015). Police racial violence: Lessons from social psychology. Fordham Law Review, 83, 2961-2976.

Richardson, L. S., \& Goff, P. A. (2015). Interrogating racial violence. Ohio State Journal of Criminal Law, 12, 115-152.

Rios, V. M. (2009). The consequences of the criminal justice pipeline on black and Latino masculinity. The ANNALS of the American Academy of Political and Social Science, 623, 150-162. http://dx/doi.org/doi10.1177/0002716208330489

Robles, F., \& Bosman, J. (2014). Autopsy shows Michael Brown was struck at least 6 times. The New York Times. Retrieved from http://www.nytimes.com/2014/08/18/us/michael-brown-autopsy-shows-he-wasshot-at-least-6-times.html?_r=1 
Rudman, L. A. (2004). Social justice in our minds, homes, and society: The nature, causes, and consequences of implicit bias. Social Justice Research, 17, 129-142. http://dx.doi.org/10.1023/b:sore.0000027406.32604.f6

Sabo, D., \& Gordon, D. F. (1995). Rethinking men's health and illness. In D. Sabo \& D. F. Gordon (Eds.), Men's health and illness: Gender, power, and the body. Thousand Oaks, CA: Sage.

Salter, M. (2013). Toys for the boys? Drones, pleasure and popular culture in the militarization of policing. Critical Criminology, 22, 163-177. http://dx.doi.org/10.1007/s10612-013-9213-4

Schaffer, E. B. (1980). Community policing. London: Croom Helm.

Schmader, T. (2002). Gender identification moderates stereotype threat effects on women's math performance. Journal of Experimental Social Psychology, 38, 194-201. http://dx.doi.org/10.1006/jesp.2001.1500

Sibley, C. G., \& Wilson, M. S. (2004). Differentiating hostile and benevolent sexist attitudes toward positive and negative sexual female subtypes. Sex Roles, 51, 687-696. http://dx.doi.org/10.1007/s11199-004-0718-x

Sidanius, J., Liu, J. H., Shaw, J. S. and Pratto, F. (1994), Social dominance orientation, hierarchy attenuators and hierarchy enhancers: Social dominance theory and the criminal justice system. Journal of Applied Social Psychology, 24, 338-366. http://dx.doi.org/10.1111/j.1559-1816.1994.tb00586.x

Shibley, J., \& Denison, H. (1981). How large are cognitive gender differences? American Psychologist, 36, 892-901. http://dx.doi.org/10.1037//0003-066x.36.8.892 
Shields, S. A. (2008). Gender: An intersectionality perspective. Sex Roles, 59, 301-311. http://dx.doi.org/10.1007/s11199-008-9501-8

Spencer, S., Steele, C. M., \& Quinn, D. M. (1999). Stereotype threat and women's math performance. Journal of Experimental Social Psychology, 35, 4-28. http://dx.doi.org/10.1006/jesp.1998.1373

Steele, C. M., Spencer, S. J., \& Aronson, J. (2002). Contending with group image: The psychology of stereotype and social identity threat. Advances in Experimental Social Psychology, 34, 379-440. http://dx.doi.org/10.1016/s0065-2601(02)800090

Steensma, T. D., Kreukels, B. P. C., de Vries, A. L. C., \& Cohen-Kettenis, P. T. (2013). Gender identity development in adolescence. Hormones and Behavior, 64, 288297. http://dx.doi.org/10.1016/j.yhbeh.2013.02.020

Stewart, B. G. (2013). A quantitative method for the analysis of constitutional factors in police use of force. (Unpublished master's thesis). Portland State University, Portland.

Stone, J., Lynch, C. I., Sjomeling, M., \& Darley, J. M. (1999). Stereotype threat effects on Black and White athletic performance. Journal of Personality and Social Psychology, 77, 1213-1227. http://dx.doi.org/10.1037//0022-3514.77.6.1213

Sunshine, J., \& Tyler, T. R. (2003). The role of procedural justice and legitimacy in shaping public support for policing, Law and Society Review, 37, 513-548. http://dx.doi.org/10.1111/1540-5893.3703002 
Tajfel, H. \& Turner, J.C. (1986). The social identity theory of intergroup behavior. Psychology of Intergroup Relations, 81, 7-24.

Talley, A. E. and Bettencourt, B. A. (2008). Evaluations and aggression directed at a gay male target: The role of threat and antigay prejudice. Journal of Applied Social Psychology, 38, 647-683. http://dx.doi.org/10.1111/j.1559-1816.2007.00321.x

Terrill, W. (2003). Police use of force and suspect resistance: The micro process of the police-suspect encounter. Police Quarterly, 6, 51-83. http://dx.doi.org/10.1177/1098611102250584

Terrill, W., \& Paoline, E. A. (2013). Less Lethal Force Policy and Police Officer Perceptions A Multisite Examination. Criminal Justice and Behavior, 40, 11091130. http://dx.doi.org/ 10.1177/0093854813485074

Thorne, B. (2013). Children and gender. Toward a new psychology of gender: A reader. Delaware: Psychology Press.

Trawalter, S., Todd, A. R., Baird, A. a, \& Richeson, J. A. (2008). Attending to threat: Race-based patterns of selective attention. Journal of Experimental Social Psychology, 44, 1322-1327. http://dx.doi.org/10.1016/j.jesp.2008.03.006

Tyler, T. R., \& Huo, Y. (2002). Trust in the Law: Encouraging Public Cooperation with the Police and Courts Through. Russell Sage Foundation.

Tyler, T. R. (2006). Restorative justice and procedural justice: Dealing with rule breaking. Journal of Social Issues, 62, 307-326. http://dx.doi.org/10.1111/j.15404560.2006.00452.x 
U.S. Census Bureau (2015). Population demographics for Portland, Oregon in 2014 and 2015. Suburban Stats. Retrieved from https://suburbanstats.org/population/oregon/how-many-people-live-in-portland

Vandello, J. A., \& Bosson, J. K. (2013). Hard won and easily lost: A review and synthesis of theory and research on precarious manhood. Psychology of Men and Masculinity, 14, 101-113. http://dx.doi.org/10.1037/a0029826

Vandello, J. A., \& Cohen, D. (2008). Culture, gender, and men's intimate partner violence, Social and Personality Psychology, 2, 652-667. http://dx.doi.org/10.1111/j.1751-9004.2008.00080.x

Vandello, J. A., \& Cohen, D. (2003). Male honor and female fidelity: implicit cultural scripts that perpetuate domestic violence. Journal of Personality and Social Psychology, 84, 997-1010. http://dx.doi.org/10.1037/0022-3514.84.5.997

Vincent, W., Parrott, D. J., \& Peterson, J. L. (2011). Effects of traditional gender role norms and religious fundamentalism on self-identified heterosexual men's attitudes, anger, and aggression toward gay men and lesbians. Psychology of Men \& Masculinity, 12, 383-400. http://doi.org.proxy.lib.pdx.edu/10.1037/a0023807

Walton, G. M., \& Cohen, G. L. (2007). A question of belonging: Race, social fit, and achievement. Journal of Personality and Social Psychology, 92, 82-96. http://dx.doi.org/10.1037/e633962013-253

Weaver, J. R., Vandello, J. A., \& Bosson, J. K. (2013). Intrepid, imprudent, or impetuous? The effects of gender threats on men's financial decisions. 
Psychology of Men and Masculinity, 14, 184-191.

http://dx.doi.org/10.1037/a0027087

Weaver, J. R., Vandello, J. A., Bosson, J. K., \& Burnaford, R. M. (2009). The proof is in the punch: Gender differences in perceptions of action and aggression as components of manhood. Sex Roles, 62, 241-251.

http://dx.doi.org/10.1007/s11199-009-9713-6

West, C., \& Zimmerman, D. H. (1987). Doing gender. Gender \& Society, 1, 125-151. http://dx.doi.org/10.1177/0891243287001002002

Willer, R., Rogalin, C. L., Conlon, B., \& Wojnowicz, M. T. (2014). Overdoing gender: A test of the masculine overcompensation thesis. American Journal of Sociology, 118, 980-1022. http://dx.doi.org/10.1086/668417 
Appendix A: Use of force Coding Sheet - Masculinity threat Case \#

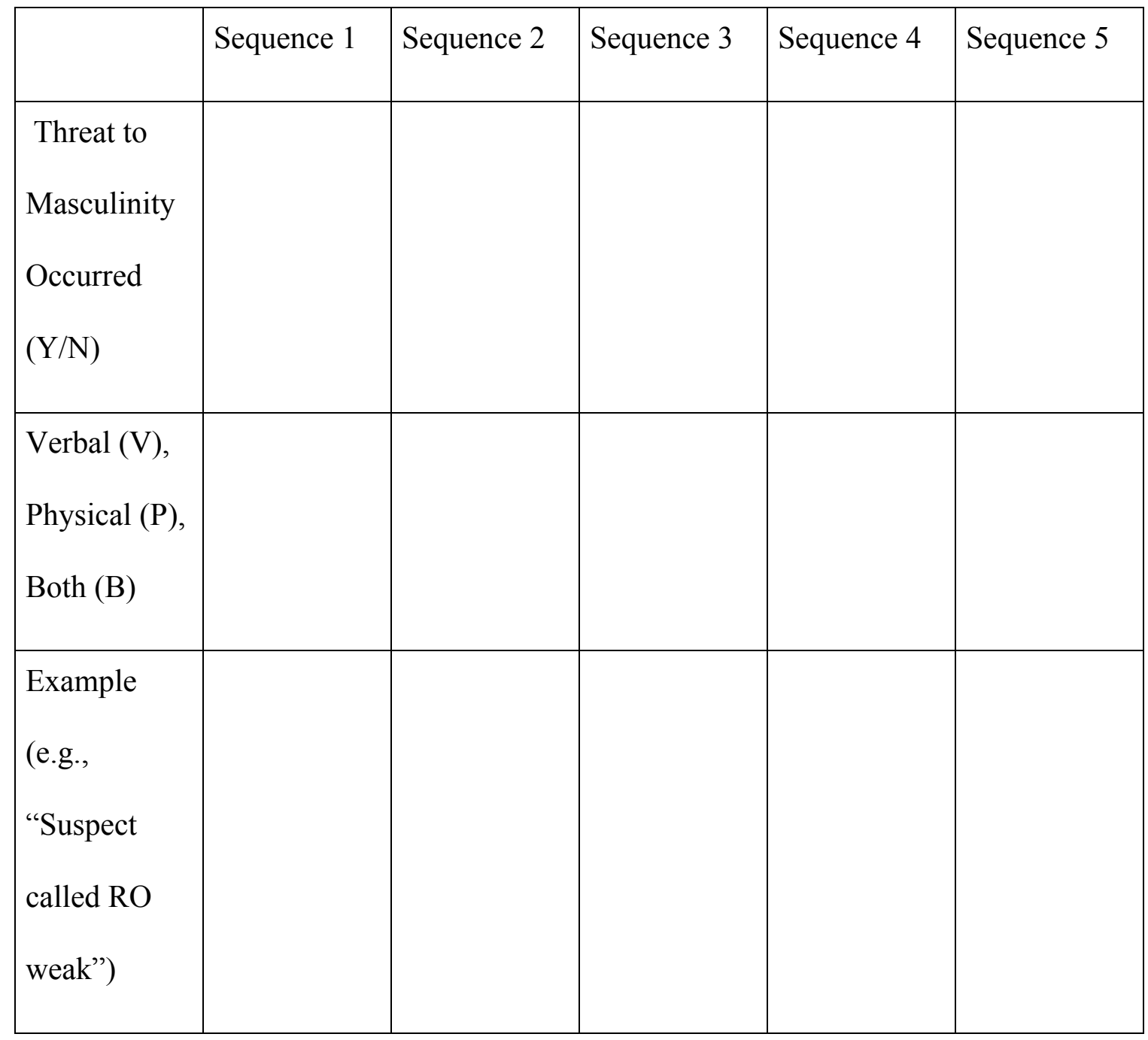




\section{Appendix B: Original use of force coding sheet}

\section{Original use of force coding sheet}

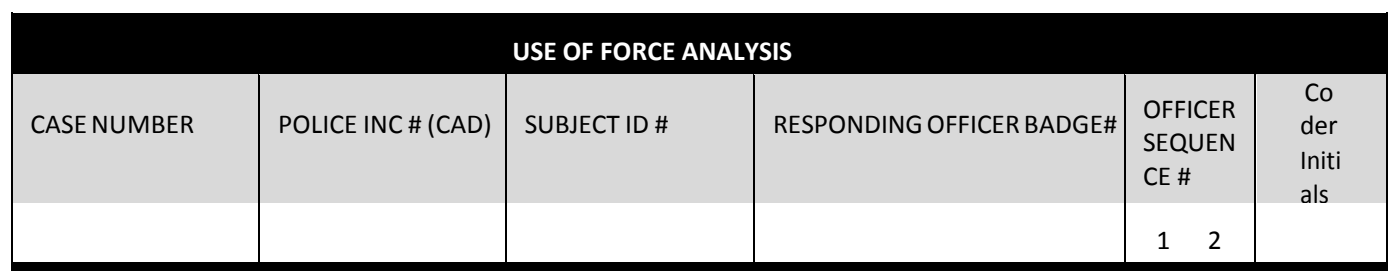

INFORMATION AVAILABLE TO RESPONDING OFFICER PRIOR TO USE OF FORCE

\begin{tabular}{|c|c|c|c|c|}
\hline $\begin{array}{l}\text { INFORMATION KNOWN BY/REPORTED TO RO } \\
\text { PRIOR TO USE OF FORCE } \\
\text { (*excluding current incident) }\end{array}$ & $\begin{array}{c}\text { No Info } \\
\text { Available/N } \\
\text { ot } \\
\text { Documente }\end{array}$ & $\begin{array}{l}\text { Fact } \\
\text { or } \\
\text { Prese } \\
\text { nt }\end{array}$ & $\begin{array}{l}\text { Factor } \\
\text { Absent } \\
\text { (negative) }\end{array}$ & $\begin{array}{l}\text { Conflicti } \\
\text { ng } \\
\text { Informati } \\
\text { on }\end{array}$ \\
\hline Subject ......Age & $\square 2$ & $\square 1$ & $\square 0$ & $\square 8$ \\
\hline Subject .....Gender & $\square 2$ & $\square 1$ & $\square 0$ & $\square 8$ \\
\hline Subject .....Race & $\square 2$ & $\square 1$ & $\square 0$ & $\square 8$ \\
\hline Subject.....Possible Mental Health Problem/Symptom & $\square 2$ & $\square 1$ & $\square 0$ & $\square 8$ \\
\hline Subject.....Possible Drug/Alcohol Involved & $\square 2$ & $\square 1$ & $\square 0$ & $\square 8$ \\
\hline Subject....History of Violence* & $\square 2$ & $\square 1$ & $\square 0$ & $\square 8$ \\
\hline Subject....History of Weapon Access/Use* & $\square 2$ & $\square 1$ & $\square 0$ & $\square 8$ \\
\hline Subject....Possibly Armed Currently & $\square 2$ & $\square 1$ & $\square 0$ & $\square 8$ \\
\hline Gov. Interest....Responding to Violent Crime & & $\square 1$ & $\square 0$ & $\square 8$ \\
\hline Gov. Interest....Responding to Property Offense /DUII & & $\square 1$ & $\square 0$ & $\square 8$ \\
\hline Gov. Interest ....Responding to Public Disorder & & $\square 1$ & $\square 0$ & $\square 8$ \\
\hline Gov. Interest ....Pursuit Call/Subject in Flight & & $\square 1$ & $\square 0$ & $\square 8$ \\
\hline Gov. Interest ....Welfare Check & & $\square 1$ & $\square 0$ & $\square 8$ \\
\hline \multicolumn{5}{|l|}{ TIMING OF EVENTS } \\
\hline FROM............TO & (Yes) & (No) & \multicolumn{2}{|c|}{ UNCLEAR } \\
\hline
\end{tabular}




\begin{tabular}{|l|l|l|l|}
\hline Arrival at Scene ........ Use of Force & $\square$ & $\square$ & $\square$ \\
\hline
\end{tabular}




\section{SEQ 1. DYNAMIC INTERACTION}

BRIEFLY DESCRIBE SUBJECT'S ACTIONS IMMEDIATELY PRIOR TO 1 ST CONTACT WITH RO (optional)

BRIEFLY DESCRIBE OFFICER'S ACTIONS IMMEDIATELY PRIOR TO ${ }^{\text {ST }}$ CONTACT WITH SUBJECT (optional)

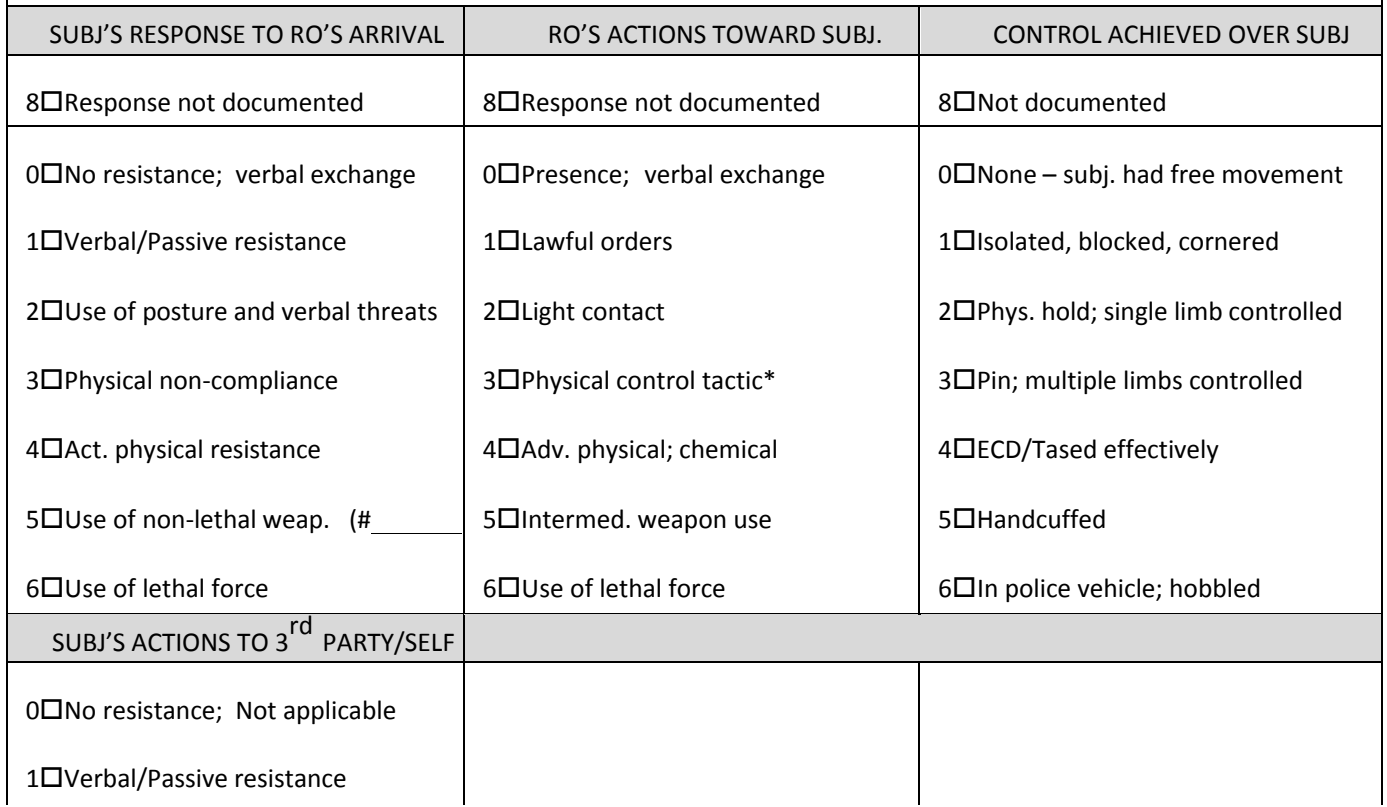


$2 \square$ Postural or verbal threats

3DResisting custody, flight

\begin{tabular}{|l|l|} 
\\
\hline
\end{tabular}




\begin{tabular}{|c|c|c|}
\hline $\begin{array}{l}\text { 4DHitting, kicking, fighting } \\
5 \square \text { Using non-lethal weap. } \\
6 \square \text { Used lethal force/actions (\# }\end{array}$ & & \\
\hline \multicolumn{3}{|l|}{ SEQ 2. DYNAMICINTERACTION } \\
\hline SUBJ'S RESPONSE TO RO & RO'S ACTIONS TOWARD SUBJ. & CONTROL ACHIEVED OVER SUBJ \\
\hline $8 \square$ Response not documented & $8 \square$ Response not documented & $8 \square$ Not documented \\
\hline $\begin{array}{l}\text { 0 } \square \text { No resistance; verbal exchange } \\
1 \square \text { Verbal/Passive resistance }\end{array}$ & $\begin{array}{l}\text { 0 } \square \text { Presence; verbal exchange } \\
1 \square \text { Lawful orders }\end{array}$ & $\begin{array}{l}0 \square \text { None - subj. had free movement } \\
1 \square \text { Isolated, blocked, cornered }\end{array}$ \\
\hline $2 \square$ Use of posture and verbal threats & $2 \square$ Light contact & $2 \square$ Phys. hold; single limb controlled \\
\hline 3ロPhysical non-compliance & $3 \square$ Physical control tactic* & $3 \square$ Pin; multiple limbs controlled \\
\hline 4DAct. physical resistance & $4 \square$ Adv. physical; chemical & $4 \square \mathrm{ECD} /$ Tased effectively \\
\hline $5 \square$ Use of non-lethal weap. (\# & $5 \square$ Intermed. weapon use & $5 \square$ Handcuffed \\
\hline $6 \square$ Use of lethal force & $6 \square$ Use of lethal force & $6 \square$ In police vehicle; hobbled \\
\hline \multicolumn{3}{|l|}{ SUBJ'S ACTIONS TO $3^{\text {rd }}$} \\
\hline \multicolumn{3}{|l|}{$\begin{array}{l}0 \square \text { No resistance; Not applicable } \\
1 \square \text { Verbal/Passive resistance } \\
2 \square \text { Postural or verbal threats }\end{array}$} \\
\hline 3ロResisting custody, flight & & \\
\hline \multicolumn{3}{|l|}{$\begin{array}{l}\text { 4 } \square \text { Hitting, kicking, fighting } \\
5 \square \text { Using non-lethal weap. } \\
6 \square \text { Used lethal force/actions (\# }\end{array}$} \\
\hline \multicolumn{3}{|l|}{ SEQ 3. DYNAMIC INTERACTION } \\
\hline SUBJ'S RESPONSE TO RO & RO'S ACTIONS TOWARD SUBJ. & CONTROL ACHIEVED OVER SUBJ \\
\hline $8 \square$ Response not documented & 8DResponse not documented & $8 \square$ Not documented \\
\hline $0 \square$ No resistance; verbal exchange & 0 $\square$ Presence; verbal exchange & $0 \square$ None - subj. had free movement \\
\hline 1 $\square$ Verbal/Passive resistance & $1 \square$ Lawful orders & $1 \square$ Isolated, blocked, cornered \\
\hline $2 \square$ Use of posture and verbal threats & $2 \square$ Light contact & $2 \square$ Phys. hold; single limb controlled \\
\hline $3 \square$ Physical non-compliance & $3 \square$ Physical control tactic* & $3 \square$ Pin; multiple limbs controlled \\
\hline 4ロAct. physical resistance & $4 \square$ Adv. physical; chemical & $4 \square \mathrm{ECD} /$ Tased effectively \\
\hline $5 \square$ Use of non-lethal weap. (\# & $5 \square$ Intermed. weapon use & $5 \square$ Handcuffed \\
\hline
\end{tabular}




\begin{tabular}{|c|l|l|} 
6DUse of lethal force & $6 \square$ Use of lethal force & $6 \square$ In police vehicle; hobbled \\
\hline SUBJ'S ACTIONS TO 3 $^{\text {rd }}$ & \\
\hline
\end{tabular}




\begin{tabular}{|c|c|c|}
\hline \multirow{3}{*}{$\begin{array}{l}0 \square \text { No resistance; Not applicable } \\
1 \square \text { Verbal/Passive resistance } \\
2 \square \text { Postural or verbal threats } \\
3 \square \text { Resisting custody, flight } \\
4 \square \text { Hitting, kicking, fighting } \\
5 \square \text { Using non-lethal weap. } \\
6 \square \text { Used lethal force/actions (\#_ }\end{array}$} & & \\
\hline & & \\
\hline & & \\
\hline \multicolumn{3}{|l|}{ SEQ 4. DYNAMIC INTERACTION } \\
\hline SUBJ'S RESPONSE TO RO & RO'S ACTIONS TOWARD SUBJ. & CONTROL ACHIEVED OVER SUBJ \\
\hline $8 \square$ Response not documented & $8 \square$ Response not documented & 8DNot documented \\
\hline $\begin{array}{l}0 \square \text { No resistance; verbal exchange } \\
1 \square \text { Verbal/Passive resistance } \\
2 \square \text { Use of posture and verbal threats } \\
3 \square \text { Physical non-compliance } \\
4 \square \text { Act. physical resistance } \\
5 \square \text { Use of non-lethal weap. } \# \\
6 \square \text { Use of lethal force }\end{array}$ & $\begin{array}{l}\text { 0DPresence; verbal exchange } \\
1 \square \text { Lawful orders } \\
2 \square \text { Light contact } \\
3 \square \text { Physical control tactic* } \\
4 \square \text { Adv. physical; chemical } \\
5 \square \text { Intermed. weapon use } \\
6 \square \text { Use of lethal force }\end{array}$ & $\begin{array}{l}0 \square \text { None - subj. had free movement } \\
1 \square \text { lsolated, blocked, cornered } \\
2 \square \text { Phys. hold; single limb controlled } \\
3 \square \text { Pin; multiple limbs controlled } \\
4 \square \text { ECD/Tased effectively } \\
5 \square \text { Handcuffed } \\
6 \square \text { In police vehicle; hobbled }\end{array}$ \\
\hline \multicolumn{3}{|l|}{ SUBJ'S ACTIONS TO $3^{\text {rd }}$} \\
\hline \multicolumn{3}{|l|}{$\begin{array}{l}0 \square \text { No resistance; Not applicable } \\
1 \square \text { Verbal/Passive resistance } \\
2 \square \text { Postural or verbal threats }\end{array}$} \\
\hline $3 \square$ Resisting custody, flight & & \\
\hline $\begin{array}{l}4 \square \text { Hitting, kicking, fighting } \\
5 \square \text { Using non-lethal weap. } \\
6 \square \text { Used lethal force/actions (\#_ }\end{array}$ & & \\
\hline
\end{tabular}

